\title{
A STATISTICAL FORECAST MODEL OF WEATHER-RELATED DAMAGE \\ TO A MAJOR ELECTRIC UTILITY
}

By

\section{BRIAN JOHN CERRUTI}

A thesis submitted to the Graduate School-New Brunswick

Rutgers, The State University of New Jersey

in partial fulfillment of the requirements

for the degree of

Master of Science

Graduate Program in Atmospheric Science

written under the direction of

Dr. Steven G Decker

and approved by

New Brunswick, New Jersey

May 2010 


\begin{abstract}
OF THE THESIS
A statistical forecast model of weather-related damage to a major electrical utility

By: BRIAN JOHN CERRUTI
\end{abstract}

Thesis Director:

Steven G. Decker

A model has been developed to relate meteorological conditions to damages incurred by the outdoor electrical equipment (plant) of Public Service Electric and Gas (PSE\&G), the largest public utility in New Jersey. Utilizing a perfect prognosis approach, the model consists of equations derived from a backwards eliminated multiple linear regression analysis of observed damage (the predictand) and corresponding surface observations from a variety of sources including local storm reports (the predictors). The analysis gives a different equation for each combination of plant damage element (e.g., poles down, transformers blown), the four PSE\&G service territories, and objectively defined storm modes (e.g., Thunderstorm, Heat Wave, None). The predictors used most often were found to be products of maximum wind gust with maximum temperature, daily liquid water equivalent precipitation, and ten day accumulated liquid equivalent precipitation, and were often found to be significant ( $\mathrm{p}$-value less than 0.05). The number of severe weather reports provided significant predictors for the Thunderstorm storm 
mode. The resulting regression equations produced coefficients of determination ranging from 0.032 to 0.697 with the lowest values for the None and Cold storm modes, and the highest values for the Thunderstorm and Mix storm modes. The appropriate model equations were applied to an independent verification dataset and the verification standard deviations were compared to the model derived standard errors which revealed heteroscedasticity (predictand error variance is proportional to the predictand itself) in the model. Both error measurements are calculated assuming independence, and they represent a lower-bound on the error estimation because the training dataset was not transformed into a normal distribution and the use of count data for damaged elements yields a non-independent dataset. Two case studies analyzed to critique model performance yielded insight into model shortcomings where lightning information and wind duration were found to be important missing predictors. The case studies were also used to develop guidelines for applying the model in an operational setting. The development of a damage model for other utility companies in other contexts is discussed. 


\section{ACKNOWLEDGMENT / DEDICATION}

The author would like to acknowledge the support and guidance of Dr. Steven G. Decker through the project. The author would also like to recognize Steven Nicholls for his endless help with preparation of figures and programming difficulties encountered. The author wishes to acknowledge Dr. Lisa Rodenburg for her advice while using Microsoft Excel to calculate multiple linear regression. The author is very grateful for the opportunity to conduct research provided by PSE\&G, in particular, Wayne Wittman. Frank Schwartz, also of PSE\&G, was instrumental in providing the damage data used in this thesis and for answering questions and addressing concerns from the author in a timely and courteous manner.

This thesis is dedicated to my parents for their ability to endure relentless map discussions, stay interested in my mathematically intensive endeavors, and their love and support through my entire life. I also dedicate this thesis to my beautiful fiancé, Kimberlyanne; without her love, respect, and patience, this work would not have been possible. 
Table of Contents

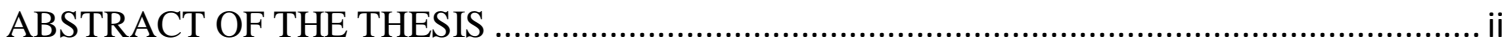

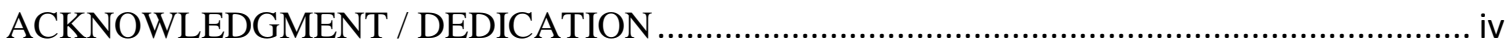

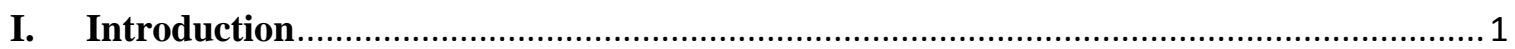

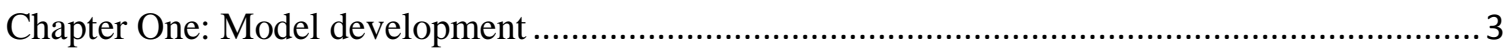

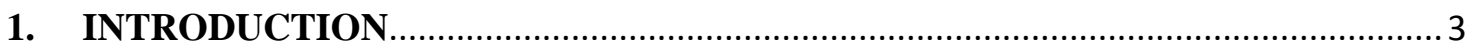

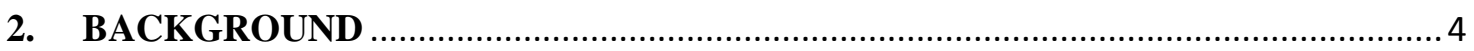

a. Regression methods ......................................................................................... 4

b. $\quad$ Statistical forecasting applications for utilities …...................................................... 5

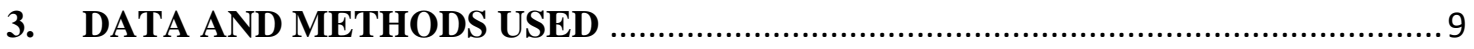

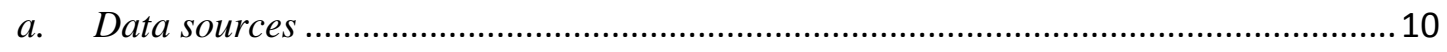

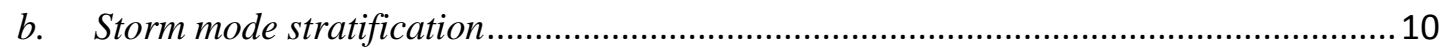

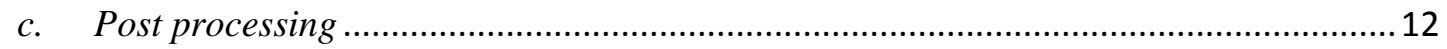

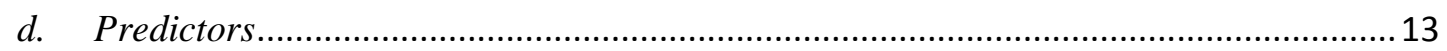

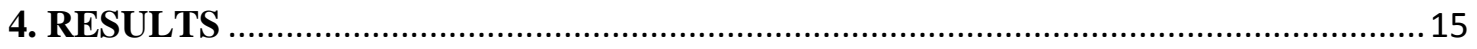

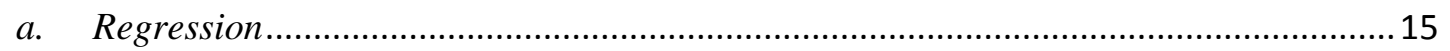

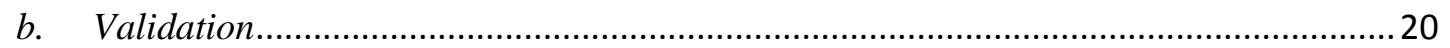

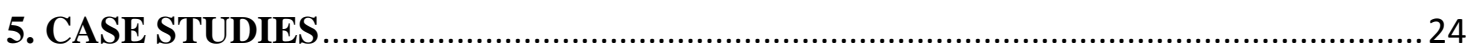

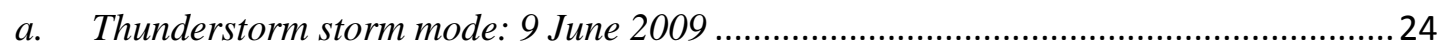

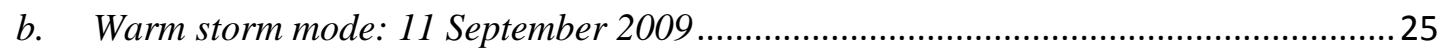

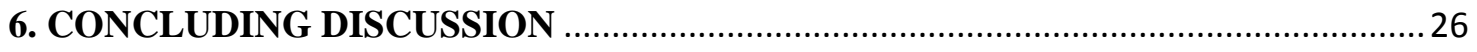

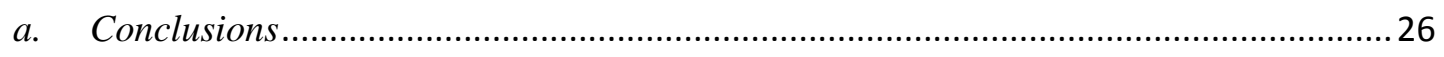

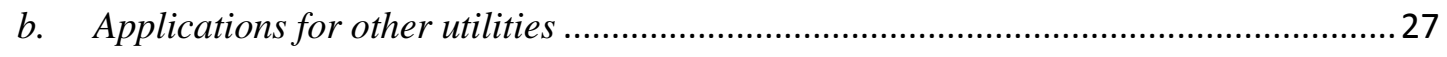

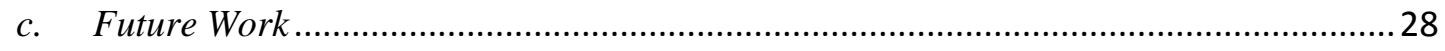


7. TABLES

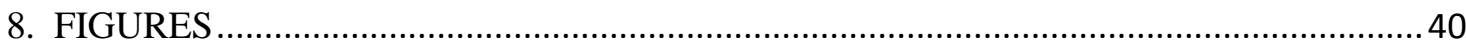

Chapter Two: Model comparison and application .................................................................. 45

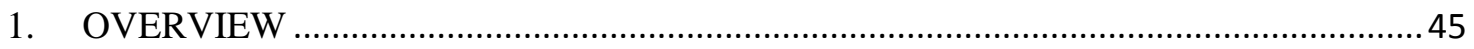

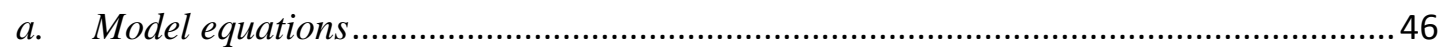

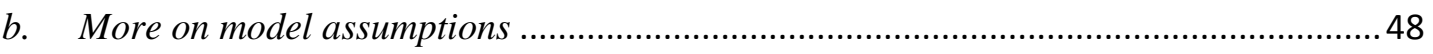

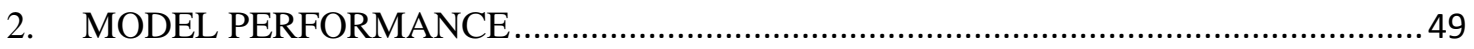

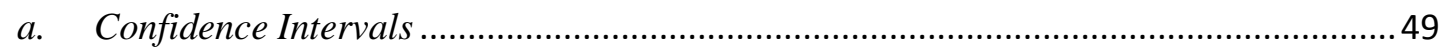

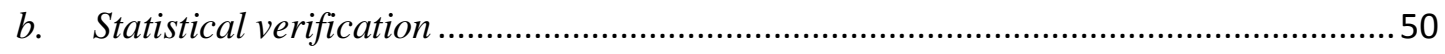

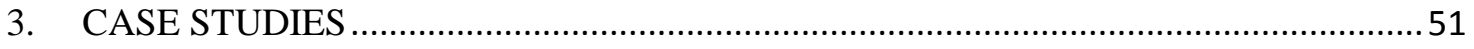

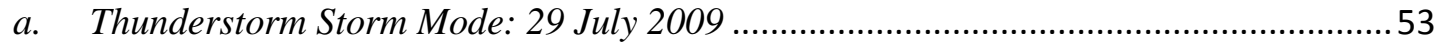

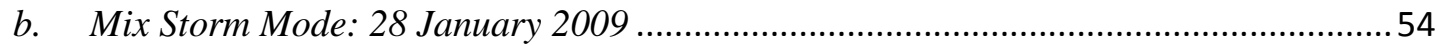

c. $\quad$ None Storm Mode: 12 February 2009 and 4 April 2009 ............................................ 56

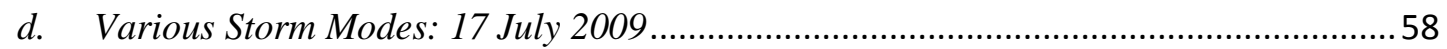

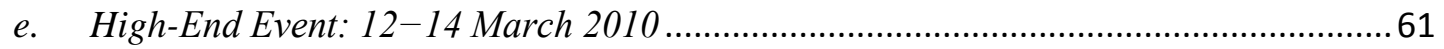

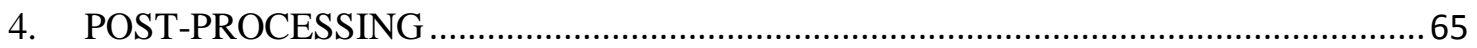

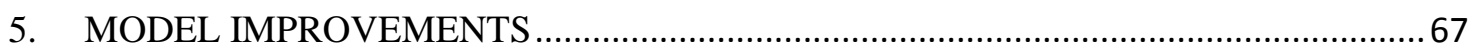

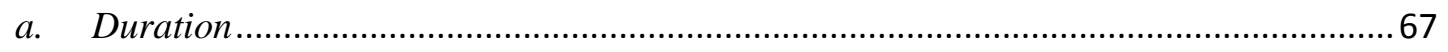

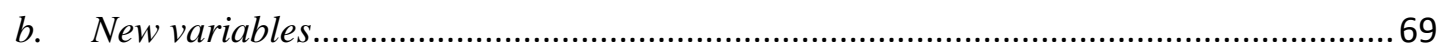

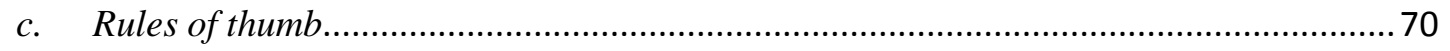

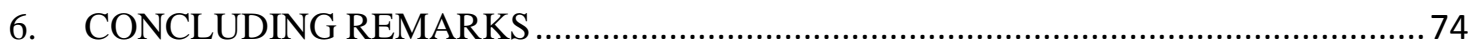

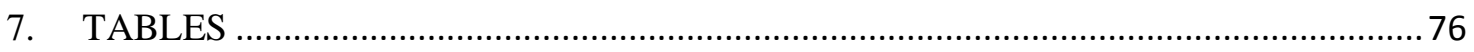

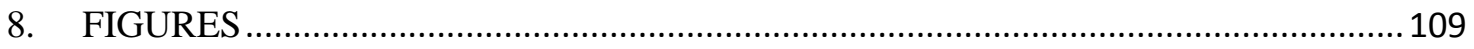




\section{Introduction}

The weather can have a serious impact on electrical equipment (plant), often resulting in financial losses to utility companies. These losses may be the cost of replacing field equipment damaged by a storm or overtime pay for the men and women working to restore power, clear downed trees, and fix damaged elements (i.e., direct losses). Indirect losses, such as revenue loss resulting from unavailable services and fines for unacceptable restoration times, are some possible consequences of a utility company which is unprepared to rapidly mobilize its storm restoration workforce.

Public Service Electric and Gas (PSE\&G) has developed a relationship with Rutgers University where undergraduate students in the University's Undergraduate Meteorology Program provide daily weather forecasts for cooperative credits. Ideally, a method for predicting the plant damage would be incorporated into a forecast issued to PSE\&G so they may adequately prepare for adverse weather As such, a plant damage model is presented in Chapter One to provide a tool by which student participants of the Rutgers University Undergraduate Forecasting Program may provide such forecasts. The plant damage model will consist of utilizing perfect prognosis backwards elimination multiple linear regression to statistically relate observed weather (the predictor) to a database of observed plant damage (the predictand) provided by PSE\&G. The equations will assume the input data is Gaussian, independent, and homoscedastic (i.e., that the variance in the model error will not depend on the magnitude of the predictand). A comparison of various standard error measures will test the underlying assumptions and draw conclusions about the bounds of the error estimates. The model will be applied to an 
independent dataset provided by PSE\&G using surface observations as the input. The model will be verified in Chapter Two according to a statistical reliability analysis (testing whether the observed damage is within the $95 \%$ confidence interval) and statistical forecast verification (assessing the model's ability to predict a given threshold of total plant damage). Case studies will be used in Chapters One and Two to address model shortcomings, investigate new variables, and develop forecasting guidelines to adjust model damage forecasts. 


\section{Chapter One: Model development}

\section{INTRODUCTION}

The weather can have a significant impact on electric utility operations. Hurricanes can cause widespread equipment damage, resulting in power outages which often last for days (Liu et al. 2008; Han et al. 2009). Ice and snow storms have been responsible for significant outages, which typically occur when ice and snow laden trees fall or are blown onto overhead electrical equipment or when ice accrues onto transmission lines (Changnon and Karl 2003; DeGaetano et al. 2008). Thunderstorms can also cause destruction of electrical equipment due to damaging wind gusts, large hail, and cloud to ground lightning (Rakov and Rachidi 2009; Li et al. 2010; Treinish et al. 2010). The impact of a storm is often exacerbated on the electrical grids in densely populated areas because the equipment coverage is dense, allowing an isolated event to cause more damage relative to a rural utility company (Wittman et al. 2006; Cerruti et al. 2009).

Public Service Electric and Gas (PSE\&G) is the largest public utility in New Jersey, the nation's most densely populated state, providing service to several large urban areas such as Trenton, Newark, New Brunswick, and the Philadelphia suburbs. PSE\&G also serves some of the largest waste management facilities, hospitals, and schools in the state. Electrical service to such venues is dependent upon prompt restoration time, typically a function of workforce preparedness. The weather can have a dramatic impact on PSE\&G workforce operations, as a typical overtime crew can cost $\$ 2400$ per hour, and a large cleanup effort may cost over $\$ 1000000$, not counting the costs of materials (Cerruti et al. 2009). 
In an attempt to alleviate the large costs of storm restoration and material replacement, this study presents a statistical damage model, hereafter called a plant damage model, which is a tool forecasters may use to predict the damage to utility equipment (i.e., plant) in advance of adverse weather conditions. In this case, it is a statistical relationship using multiple linear regression with weather observations as the predictors and plant damage as the predictand. The model may be used to create a deterministic forecast of plant damage while allowing for uncertainty in the model to be addressed explicitly via statistical analysis of the model results. A well constructed plant damage model should allow utility companies to be more adequately prepared for impending storms.

\section{BACKGROUND}

\section{a. Regression methods}

Several attempts have been made to use statistical methods for weather prediction, most notably the methods known as Model Output Statistics (MOS) and Regression Estimation of Event Probabilities (REEP), itself an application of MOS. These methods use multiple linear regression to correct deterministic model forecast errors at various lead times (Glahn and Lowry 1972; Glahn 1985). The main advantage to such methods is that systematic errors in the model calculations, including model bias, are statistically corrected, allowing for a more accurate forecast.

The MOS and REEP methods have several shortcomings, however. The first is the need for a large dataset of model forecasted variables as input for the regression. The 
second is that the model should remain constant, which implies that either new equations should be derived for every version of the model or improvements not be implemented to preserve the integrity of the statistical forecasts. An additional drawback is that at longer lead times, the MOS and REEP methods approach the local climatological mean (Vannitsem and Nicolis 2007).

The perfect prognosis (PP) approach avoids these drawbacks. Perfect prognosis forecasts can be similar to REEP and MOS in terms of using a form of linear regression to make a statistical forecast, but the PP method uses observed fields, not model predicted fields, to create the statistical forecast, eliminating the need for a model dataset. Thus, unlike MOS and REEP, the PP method has an advantage because the numerical weather prediction model may be upgraded as needed without affecting the statistical model. In fact, whereas model upgrades may degrade the reliability and accuracy of REEP or MOSbased forecasts, the PP method will likely yield a better forecast, assuming that the model upgrades improve the accuracy of the output (Wilks 2006). The exclusion of model input data during the regression development also makes the PP approach more computationally efficient. In order to remain consistent with MOS, multiple linear regression was the selected statistical method.

\section{b. Statistical forecasting applications for utilities}

In general, statistical models in the utility industry deal with predicting peak electrical loads at various lead times for varying windows of time. These models often depend on economic indicators along with meteorological input while utilizing analogue forecasting 
methods to make predictions. Hippert et al. (2001) provided an in-depth review of load forecasting via neural networks and concluded that, although the issue of overfitting is not well understood with respect to neural networks, the models perform well when used operationally. Saini (2007) was able to produce seven day peak load forecasts using Bayesian regularization and the incorporation of weather variables through backpropagation learning methods. The data were stratified by weekday versus weekend and normal day versus holiday to classify the daily load profiles for input into the backpropagation method. Ružić et al. (2003) related temperature and average daily wind speed to observations of total daily energy and hourly load with stratification for the day of the week and holidays. Fan et al. (2009a) used support vector regression to forecast spatial electric load based on weather diversity throughout a utility's service territory. Fan et al. (2009b) coupled a meteorological ensemble forecast with an ensemble neural network for more accurate load forecasting while incorporating stratification by day.

Several studies have attempted to enhance utility response to significant events. Brown et al. (1997) studied the reliability of distribution systems during high wind events using Monte Carlo simulations and found wind speed and wind duration to be essential for assessing system reliability. Han et al. (2009) used a general additive model to predict power outage risk based on measured characteristics of hurricanes and were able to outperform regression based approaches. The potential for ice storms and hurricanes to produce power outages is addressed in Liu et al. (2008) via a generalized linear mixed model approach which found maximum wind gust and maximum ice thickness to be important predictors for hurricanes and ice storms, respectively. DeGaetano et al. (2008) 
used a precipitation-type algorithm adjustment to 6-12 hr Weather Research and Forecasting (WRF) model forecasts to predict ice accretion to utility equipment in terms of outages. While limited outage data was available for model verification, the model results generally matched the observations. The intended use of these models is to aid distribution managers in deciding how much extra material and how many crews may be needed in advance of a weather event.

Some attempts at explicitly predicting plant damage have recently been made. Takata et al. (2005) used a cross validation method to produce forecasts of damaged poles and transmission lines from typhoons based on 29 typhoon cases. Using the typhoon forward speed, maximum wind speed, central pressure and wind radii as input, they combined the use of neural networks and group methods of data banding. These two methods combined outperform each method individually with an error decreased of up to $40 \%$. Treinish et al. (2010) used weather observations from the New York, NY metropolitan area and power outage information from a local utility company to create a model to predict the outage related infrastructure damage caused by weather events. The statistical damage forecast model was coupled to a numerical weather prediction model, Deep Thunder (DT, a version of the WRF model with three domains at 18, 6, and $2 \mathrm{~km}$ grid spacing), to operationally predict infrastructure damage. Li et al. (2010) expanded on this work by creating a statistical model to predict the spatial extent, duration, and severity (measured by number of customers without power) of power outages. The statistical outage model is stratified according to season and the magnitude of certain weather variables such as precipitation. 
The DT-based models attempted to account for uncertainty exhaustively in several areas, such as the DT initial conditions, the local weather variables used to calibrate the statistical model coupled to DT, the possible input variable errors in the training dataset used for the regression equations, and DT model errors. These numerous and often substantial sources of uncertainty may be to blame for the model's modest performance and large uncertainty in their forecasts presented in the case studies. Additionally, DT's inability to directly produce wind gust forecasts may be a substantial shortcoming for attempting to forecast damage (which will be shown in this work to be an important predictor).

Wittman et al. (2006) describes an early attempt at producing a plant damage model applicable to PSE\&G, which was based on three years of customer phone call data (18 September 2003-7 September 2006). With temperature, wind gust, and precipitation as the primary predictors, the weather observations were stratified and mainly single variable PP regression was used. Multiple linear regression was used when possible, but with a maximum of two variables and only for isolated cases. Here, the principal cause for the observed customer calls was subjectively identified by investigating daily surface observations for each of the four service territories. The resulting model, an excerpt of which is shown in Table 1.1, was presented in tabular form for quick reference forecasting. A forecaster could use the tables by applying their forecast of the weather to obtain a value of expected phone calls, which were then used as a proxy for damage. If multiple events were forecast, the tabular data was summed across all relevant storm 
modes. The forecast could then be subjectively adjusted according to storm coverage and duration.

The first damage model includes several shortcomings that the current study addresses. These shortcomings include the following:

1) The use of call data as a proxy for damage, as one downed pole in a heavily populated area can yield numerous phone calls; this is also an issue for the models documented in Treinish et al. (2010) and Li et al. (2010).

2) The use of single variable regression, which yields low coefficients of determination $\left(\mathrm{R}^{2}\right)$, a measure of how well the predictand is explained by the predictor, and

3) The use of subjectivity in the application of the model, which leads to low confidence forecasts (Wilks 2006).

\section{DATA AND METHODS USED}

The method used in this study is to determine a regression equation for each of the four PSE\&G service territories, six plant elements, and six storm modes, yielding 144 equations. The storm modes [Thunderstorm, Warm Precipitation (Warm), Cold Precipitation (Cold), Mixed Precipitation (Mix), Heat Wave (Heat), and No Weather (None)] are defined later. A multiple linear regression analysis relating various surface weather observations to plant damage observations will result in a PP statistical model, which will be used to predict plant damage. 


\section{a. Data sources}

This study employs several improvements to both the data and methods used in Wittman et al. (2006). Rather than phone call counts, the input data for this study comes from a unified damage database compiled by PSE\&G covering the period 1 January 2003 to 31 October 2008. Typical MOS equations use a dataset of five years to calculate the regression equations, so the training damage dataset used in this study is of sufficient length for statistical analysis (Wilks 2006). Counts of damage to transformers; poles; trees; and service, secondary, and primary wires were selected from the database as the six predictands. To simplify the process, only one weather station per PSE\&G service territory is used, similar to original MOS methods of using the closest model grid point to represent a weather station (Glahn and Lowery 1972). The stations chosen to represent the four service territories were Newark Liberty International Airport (EWR), Teterboro Airport (TEB), Somerset Airport (SMQ), and Trenton Mercer County Airport (TTN) for the PSE\&G service territories of Metropolitan, Palisades, Central, and Southern, respectively (Fig. 1.1). Surface data was obtained from the National Climate Data Center. To identify the occurrence of severe thunderstorms, local storm reports were obtained from the Storm Prediction Center (SPC 2009).

\section{b. Storm mode stratification}

The weather observations for the selected stations in each territory were objectively analyzed to identify each day as a particular storm mode (Thunderstorm, Warm, Cold, Mix, Heat, and None). The stratification method will provide a more straight forward 
forecasting approach relative to stratifying the predictors as in Li et al. (2010). Each storm mode is defined below.

The Thunderstorm storm mode was diagnosed when thunderstorms were observed at the station, in the vicinity of the station, or if severe weather occurred within the territory according to local storm reports. The inclusion of data from local storm reports account for events where thunderstorms hit the territory but not the station. As a result, Thunderstorm days can occur without reports of thunder at the designated station. In particular, there were 15, 7, 7, and 16 such days in Central, Metropolitan, Palisades, and Southern, respectively.

The Warm storm mode was diagnosed if the only form of precipitation observed was rain and precipitation accumulated greater than $0.01 "(0.254 \mathrm{~mm})$. The Cold storm mode was diagnosed if only wintry precipitation was observed (such as snow, freezing rain, or sleet) with precipitation of at least $0.01^{\prime \prime}(0.254 \mathrm{~mm})$. The Mix storm mode was diagnosed if a combination of Warm and Cold storm modes occur (rain and at least one of snow, sleet, or freezing rain) with precipitation of at least $0.01 "$. Precipitation of exactly $0.01 "$ (0.254 mm) was included for Cold and Mix storm modes and excluded for the Warm storm mode to account for possible undercatch of precipitation gauges during times of freezing or frozen precipitation (Yang et al. 1998).

The Heat storm mode was diagnosed if maximum temperatures exceeded $90^{\circ} \mathrm{F}\left(32^{\circ} \mathrm{C}\right)$ and measured precipitation was no more than $0.01^{\prime \prime}(0.254 \mathrm{~mm})$. A no-weather (None) storm mode was diagnosed if none of the previous criteria were met. A seventh storm mode (Questionable) emerged as a result of missing or suspect data or if precipitation 
was measured to be greater than $0.01^{\prime \prime}(0.254 \mathrm{~mm})$ while no report of falling precipitation was observed. The Questionable storm mode days were omitted from the regression procedure. Table 1.2 presents a summary of the occurrence of each storm mode, within this training dataset.

\section{c. Post processing}

The damage database is a collection of field reports compiled on a daily basis with a day defined as midnight to midnight LST. The data is collected as it is reported, which means a significant late-day thunderstorm's damage reports are likely to spill into the next day. For particularly extensive severe weather events, it may take several days for all of the damage from that event to be reported and logged. Thus, the plant element damage data were post-processed to account for any potential lag in reporting during extreme weather. Table 1.2 includes counts of the days and events for which post processing was performed. Days may be post processed if the surface observations indicate a strong storm occurred but damage is higher on the following day(s) and these following day(s) are classified as None storm mode. If the None storm mode is not diagnosed following a strong storm, the damage observations may not be adjusted.

10 June 2008 presents an example of a high end severe weather day that required post processing. On that day, the Thunderstorm mode was diagnosed for Central, Metropolitan, and Palisades territories followed by three consecutive None days; however the damage was spread out over multiple days. In Central, 69 elements were reported as damaged on 10 June compared to 62,21 , and 10 on 11,12 , and 13 June, 
respectively. In Palisades, a total of 287 elements were reported as damaged on 10 June, with 517,237 , and 78 damaged elements reported for 11,12 , and 13 June, respectively. For Metropolitan, damage reports of 190, 598, 282, and 90 total elements for 10, 11, 12, and 13 June, respectively, were observed. As a result of the post-processing, the damage from 11 June to 13 June was set to zero and the sum of the damage from 10 June to 13 June replaced the original damage observed for 10 June. A total of 106 days over the four territories were adjusted according to this method, with Thunderstorm days representing $91.5 \%$ of the adjustments. The post-processed data represents only $1.25 \%(106 / 8516)$ of the days in the dataset.

\section{d. Predictors}

In contrast to Wittman et al. (2006), the regression analysis performed here used multiple predictors as a starting point in each case. Three predictors were included at times in the Wittman et al. (2006) analysis: maximum wind gust $\left(\mathrm{V}_{\max }\right)$, maximum temperature $\left(\mathrm{T}_{\max }\right)$, and liquid water equivalent precipitation $\left(\mathrm{LWE}_{\mathrm{d}}\right)$. Additional parameters were added in an attempt to improve the $\mathrm{R}^{2}$ values in the past model attempt: ten-day accumulated liquid water equivalent precipitation $\left(\mathrm{LWE}_{10}\right)$, three-day maximum temperature sum $\left(\mathrm{T}_{3}\right)$, the number of severe weather reports in a given territory, and various Storm Factors $(\mathrm{SF})$. The $\mathrm{LWE}_{10}$ is the sum of the precipitation amounts from one to ten days prior to the forecast day and was intended to serve as a proxy for the amount of moisture in the top layer of the soil, which is thought to be a contributor to downed trees and poles (Wittman et al. 2006; Han et al. 2009). The $\mathrm{T}_{3}$ was considered as a proxy 
for the cumulative heat to which equipment has been exposed. It is defined as the sum of the maximum temperature for the previous two days and the forecast day.

An investigation of these variables revealed a stronger relationship if the product of some variables were considered. These products, denoted Storm Factors (SF), include the product of the wind gust and liquid equivalent precipitation $\left(\mathrm{SF}_{1}\right)$, the product of the wind gust and ten day accumulated precipitation $\left(\mathrm{SF}_{2}\right)$, and the product of the wind gust and maximum temperature $\left(\mathrm{SF}_{3}\right)$. Figure 1.2 illustrates the importance of $\mathrm{SF}_{3}$ for the Thunderstorm mode in Palisades territory. In Fig. 1.2a, the observed maximum temperature for KTEB is plotted against the total observed damage for Palisades territory where the storm mode was diagnosed to be Thunderstorm, yielding an $\mathrm{R}^{2}$ value of $\sim 0.08$. Figure $1.2 \mathrm{~b}$ shows the total damage for Palisades plotted with the maximum wind gust, with an $\mathrm{R}^{2}$ of $\sim 0.34$. The product of the maximum temperature and maximum wind gust $\left(\mathrm{SF}_{3}\right)$ is plotted in Fig. 1.2c against the total Palisades damage and the $\mathrm{R}^{2}$ increases dramatically to $\sim 0.80$, demonstrating the potential usefulness of the Storm Factors.

A closer inspection of the training dataset reveals that one of the assumptions underlying multiple linear regression is violated. A visual inspection of Fig. 1.2a and 1.2b show that the higher predictand values also have the largest errors while smaller predictand values generally have the smallest errors. This relationship between the magnitude of the predictand and the predictand error variance (i.e., heteroscedasticity) is typical of count data (Han et al. 2009). Heteroscedasticity will cause the standard error $\left(s_{e}\right)$ to underestimate the true error variance of higher forecasts of plant damage, which results in larger uncertainty when high-end plant damage is forecast by the model. Fig 
1.2c shows that a transformation of the data (multiplying $\mathrm{V}_{\max }$ and $\mathrm{T}_{\max }$ ) can decrease heteroscedasticity so that the largest values of the predictand now have similar error values relative to the lower magnitude predictand values.

\section{RESULTS}

a. Regression

The backwards regression consisted of repeatedly removing the predictor with the highest $\mathrm{p}$-value from the regression until the adjusted $\mathrm{R}^{2}$ value of the regression, a modified $\mathrm{R}^{2}$ value which accounts for the number of predictors, was maximized (Draper and Smith 1998). The general form of the regression equations is:

$$
\hat{y}_{\text {tpmd }}=b_{0}+b_{1} c_{t p m d}+b_{2} d_{\text {tpmd }}+\cdots+b_{n} x_{\text {tpmd }}
$$

Here, $\hat{\mathrm{y}}$ is the model predicted plant damage and $t$ denotes the various territories, $p$ denotes the plant element under consideration, $m$ denotes the storm mode, and $d$ denotes a particular day. The regression coefficients are denoted by $b$ and the predictors are denoted as $c$, $d$, etc. In some cases the adjusted $\mathrm{R}^{2}$ value was maximized with only one variable remaining, leading to a simple linear regression model. Conversely, if the adjusted $\mathrm{R}^{2}$ value decreased as a result of removing the first variable, then all variables were used in the final regression model. Out of the 144 regression models produced, 12 extreme cases occurred with six resorting to single variable regression and six necessitating all eight input variables. All six cases which used all eight original variables were in the Mix storm mode. Table 1.3 shows a summary of the $\mathrm{R}^{2}$ values for each 
territory and storm mode, which vary from 0.032 to 0.697 for the None and Mix storm modes, respectively. Table 1.3 also shows the percentage of p-values which were found to be significant for each storm mode. The regression program automatically calculated the $s_{e}$ values for every equation. However, discussing all $144 s_{e}$ values would be cumbersome, so the following equation is used to summarize the results and redefine $s_{e}$ for convenience:

$$
s_{\theta} \equiv\left(s_{\theta}\right)_{t \bar{p} m}=\sqrt{\sum_{p}\left(s_{\theta}\right)_{t p m}{ }^{2}},
$$

where the overbar denotes not an average, but the $s_{e}$ of the total damage [i.e., summed over all plant damage elements $(p)]$. The $s_{e}$ values for every storm mode and territory are shown in Table 1.4. Strictly speaking, equation (2) is only valid if the individual errors are Gaussian (normally distributed) and independent (i.e., when a pole breaks, wires and trees are not more likely to break as a result). However, transformers are typically attached to poles and wires are usually supported by poles and attached to transformers. This ensures that if a pole fails, the attached transformer and wires will be much more likely to fail. Therefore, under stormy conditions the damage data is likely to become highly dependent. This should ensure that equation (2) produces a lower bound on the true $s_{e}$.

The baseline storm type, None, represents the situations where meteorological conditions are assumed to be unfavorable for causing plant damage. Not surprisingly, this type displays the lowest $\mathrm{R}^{2}$ values. The None storm mode was found to have an 
unexpectedly large percent of significant predictors, however this is likely a side effect of having a large (>1 200) number of data points to train the model, as this would inflate the degrees of freedom and possibly cause the p-values calculated to be a lower bound. When the weather is presumably not having a strong impact on the physical plant (as the None mode would imply), non-weather-related damage factors not included in the model, such as random car accidents, equipment failure due to age alone, or human error factors, should dominate. By comparison, all other storm types have higher $\mathrm{R}^{2}$ values for each territory, validating the assumed hypothesis that the weather has an impact on electrical field equipment. The most important predictors for the None storm mode are $\mathrm{LWE}_{10}$ and $\mathrm{SF}_{2}$, which were each used 22 times, and were often significant. The None storm mode also yielded the lowest average $s_{e}$ value, likely due to less damage resulting from a lack of adverse weather. It should be noted, however, that an exception to this rule exists: when strong mid-latitude cyclones exit the area, the synoptic conditions are typified by strong cold air advection, partly cloudy skies, and strong gusty winds. These dry, gusty days are responsible for the weather-related damage in the None storm mode.

The Warm storm mode also has the highest percentage of significant coefficients, meaning the predictors likely adequately captured the damage variance in the training dataset. The high percentage of significant p-values may also indicate the model is over fit due to large degrees of freedom value due to excessive data points. For the Warm storm mode, $\mathrm{SF}_{1}$ was the most important variable (used for every regression equation) and was often significant. The $\mathrm{LWE}_{\mathrm{d}}$ was also found to be very important for the Warm storm mode as it was used 23 times in the 24 regressions. $\mathrm{SF}_{2}$ was also essential, used 18 
times in the 24 regressions. The $s_{e}$ values for the Warm storm mode are generally higher than most other storm modes due to several high-end events such as the passage of the remnants of Hurricane Ernesto. Possible improvements for the None and Warm storm modes due to the excessive number of data points used in each regression are suggested in section 5.2 of Chapter One.

The Heat storm mode had low $\mathrm{R}^{2}$ values, but it was concluded that only the transformers are expected to incur damage in this instance due to their failure dependence on high temperatures, and most territories display a much higher $\mathrm{R}^{2}$ value for transformers relative to the other plant damage elements. The percent of significant coefficients is the largest among all storm modes when considering transformers alone, compared to $50.6 \%$ when considering all plant elements. This provides evidence to the claim that transformers are the only plant element expected to fail in the Heat storm mode. The transformers had an average $\mathrm{R}^{2}$ value of 0.317 for Central, Palisades, and Southern territories combined, which was found to be $313 \%$ higher than the rest of the $\mathrm{R}^{2}$ values for the other five elements considered in these territories, signifying that the variables used are able to capture some variance of transformer heat-related damage. The transformer $\mathrm{R}^{2}$ value for Metropolitan was 0.129 , which was found to be only $32 \%$ higher than the other five elements. This discrepancy likely exists for Metropolitan because several of the transformers in that territory are underground, providing enhanced insulation from extreme heat (F. Schwartz 2010, personal communication). As expected, $\mathrm{T}_{\max }$ was used most frequently (14 times) for the Heat storm mode, with $\mathrm{SF}_{3}$ used second most (13 times). $\mathrm{V}_{\max }$ and $\mathrm{LWE}_{\mathrm{d}}$ were used 12 and 11 times, respectively. While it may 
seem nonsensical that $\mathrm{LWE}_{\mathrm{d}}$ could be used so frequently, it is mainly used for nontransformer damage and is of little consequence since only transformers are expected to break in the Heat storm mode. The maximum temperature was used in the regression equations for transformers in all territories except Metropolitan, providing further evidence of the insulating effect of placing equipment underground.

The $\mathrm{V}_{\max }$ was the most commonly used predictor for the Cold storm mode, used 14 times, and, $\mathrm{SF}_{3}, \mathrm{LWE}_{\mathrm{d}}$, and $\mathrm{SF}_{1}$ were used 13 times each. It is not surprising that $\mathrm{V}_{\max }$, $\mathrm{LWE}_{\mathrm{d}}$, and $\mathrm{SF}_{1}$, are often significant and the most frequently used predictors because it has been well documented that precipitation and strong winds are important for producing damage in winter storms (Changnon and Karl 2003; Changnon 2007; Lui et al. 2009). The Cold storm mode also displays the lowest percent of significant predictors, indicating that other predictors may be necessary. Several of the high-end Cold storm mode days in the training dataset were immediately preceded by Mix or Warm storm mode days which produced high $\mathrm{LWE}_{\mathrm{d}}$ and $\mathrm{V}_{\max }$. The damage observed on the second day potentially should have been post-processed and assigned to the preceding day which might have caused the importance of $\mathrm{LWE}_{10}$ and $\mathrm{SF}_{2}$ to be inflated. This lack of postprocessing may be to blame for the lack of significant coefficients.

The Mix storm mode presumably has high $\mathrm{R}^{2}$ values because cyclones bringing multiple precipitation types tended to have higher precipitation totals and stronger winds. The most frequently used variable for the Mix storm type was $\mathrm{SF}_{1}$, used 20 times, followed by $\mathrm{LWE}_{\mathrm{d}}, \mathrm{V}_{\max }$, and $\mathrm{SF}_{3}$, each used 18 times. One would expect these variables to dominate based on previous winter storm studies. The high $\mathrm{R}^{2}$ values for Metropolitan 
are likely a result of all eight variables being included in four out of six of the regressions. The Mix storm mode displayed the largest number of predictors included after the backwards elimination procedure, which may cause most of these equations to be over fit, further evidenced by this storm mode having the lowest percentage of significant predictors.

The Thunderstorm storm mode is unique in that it has an extra predictor, the number of severe thunderstorm reports within the territory. This predictor proved essential as it was used in all 24 regressions, was always significant, and was often the most significant predictor in each equation. The $\mathrm{V}_{\max }$ was also used in all 24 regressions, and $\mathrm{T}_{\max }$ was used in 23 of the regressions. The largest $s_{e}$ values are for the Thunderstorm storm mode, likely due to the inclusion of several large scale and high-end severe weather episodes. Because thunderstorms are a small-scale phenomena, typically smaller in scale than the spacing of the stations used in this study, they are likely not adequately resolved in the model, leading to larger residuals in the regression equations. The inverse problem, when a small storm only strikes the vicinity of a station used in the study, also would contribute to increasing residuals.

\section{b. Validation}

To verify the plant damage model developed in the previous subsection, an independent data set was obtained from PSE\&G for the period 1 November 2008-15 November 2009. The daily weather observations and local storm reports were obtained for the appropriate weather stations and the plant damage data was post-processed 
according to the methods in Section 3.3 of Chapter One. A summary of storm occurrence for the verification dataset can be found in Table 1.5. The training and verification datasets both show similar trends, with the None storm mode occurring most often, Warm storm mode occurring second most often, and the Cold and Heat storm modes occurring less frequently. The plant damage model discussed in the previous section was applied to produce hindcasts of plant damage, which were compared to the observed damage.

Several methods were used to analyze the results of the model validation. First, the model error $\left(e_{\text {tpmd }}\right)$ was calculated for all days and plant elements using the subscripts as in equation (1):

$$
e_{t p m d}=y_{t p m d}-\hat{y}_{t p m d}
$$

Next, the standard deviation $\left(\sigma_{t p m}\right)$ of the model error is calculated for every territory, plant element, and storm mode using (4):

$$
\sigma_{t p m}=\sqrt{\frac{1}{n} \sum_{t=1}^{n}\left(e_{t p m d}-\bar{e}_{t p m}\right)^{2}}
$$

To easily compare standard deviations between storm mode and territories for discussion, a cumulative standard deviation is calculated via (5) making the same assumptions as (2):

$$
\sigma_{\theta} \equiv \sigma_{t \bar{p} m}=\sqrt{\sum_{p} \sigma_{t p m}^{2}}
$$

The subscripts are the same as in (2) to show a representative standard deviation value for each storm mode and territory. The total model error $\left(E_{t \bar{p} m d}\right)$ is calculated according to 
(6), and it will be utilized to construct an additional standard deviation value to analyze the results:

$$
E_{t \bar{p} m d}=\sum_{p} y_{t p m d}-\sum_{p} \hat{y}_{t p m d}
$$

The second method for analyzing standard deviation per territory and mode is:

$$
\sigma_{E} \equiv \sigma_{t \bar{p} m}^{*}=\sqrt{\frac{1}{n} \sum_{t=1}^{n}\left(E_{t \bar{p} m d}-\bar{E}_{t \bar{p} m}\right)^{2}} .
$$

The $\sigma_{E}$ value in (7) represents the standard deviation of the total model error for each storm mode and territory.

In light of many y-intercepts of the regression having a negative value, weak storms often produced damage estimates less than zero. In these instances, to eliminate nonsensical damage estimates, plant elements calculated to have damage less than zero were automatically set equal to zero. However, removing the bias introduced by this model post-processing step does not change the variance. Therefore, the error measures defined here are still acceptable measures of the relative error magnitude for each territory and storm mode.

When using count data, the distribution is by definition not Gaussian, and in many instances, the variance of the data is not constant (Han et al. 2009). Therefore, the $s_{e}$ values should provide a lower bound on the cumulative standard deviations, which are provided in Table 1.6. However, this is not the case. Instead, comparing Tables 1.6 and 1.4 show that the $\sigma_{e}$ values are often smaller then the $s_{e}$ values. Reasons for this will be discussed below. The one case where $s_{e}$ values are higher is the None storm mode, 
probably because damage occurrence is non-weather related and more randomized. In Metropolitan, where the most plant is located underground, the $\sigma_{e}$ value is the lower, indicating the damage is still non-independent and may be due to the insulating effect of locating equipment underground.

Figure 1.3 shows a box and whiskers plot of the damage counts in each of the six storm modes in the training and validation datasets. Notice that the validation dataset has fewer high-end damage events then the training dataset, suggesting that sampling error exists. This may explain why the $s_{e}$ values are larger then the $\sigma_{e}$ values for the Thunderstorm, Mix, Cold, Heat, and Warm storm modes. The only exception is the None storm mode where the validation dataset has more high-end damage events; however, in that case the $\sigma_{e}$ value was larger. It also becomes apparent that neither dataset is Gaussian because the log-transformed box and whisker plots do not resemble a log-transformed normally distributed dataset.

The $\sigma_{E}$ values, shown for every territory and storm mode in Table 1.7, mainly fall between the other two standard error measures. The notable exceptions are for the Thunderstorm storm mode and the None storm mode. The $\sigma_{E}$ values for the Thunderstorm storm mode are the highest of the three because the data is highly nonindependent (i.e., when a pole must be replaced, transformers and wires are more likely to be replaced) and non-Gaussian (normally distributed; i.e., there are many more days with very little damage than days with more appreciable damage). However, the $\sigma_{E}$ value is the smallest for the None storm, indicating that the data is more independent and 
the damage in this mode is more reliant on causes not included in the model, such as agerelated failure, automobile collisions with equipment, or installation errors.

\section{CASE STUDIES}

The following is a series of two case studies intended to show the functionality of the plant damage model on a per-territory basis for two selected storm types. The model results will be compared with observed damage per territory, and a discussion will follow. Please note that the damage in the figure and table may not match due to rounding error as each damage element forecast was rounded to the nearest whole number.

a. Thunderstorm storm mode: 9 June 2009

Thunderstorms affected the PSE\&G service territories in the early morning hours of 9 June 2009 with frequent lightning, wind gusts of 16-31 mph $\left(7-14 \mathrm{~m} \mathrm{~s}^{-1}\right)$, rainfall of 0.2-1.05" $(5-27 \mathrm{~mm})$, and a report of severe hail in the Southern territory. The appropriate regression equations were applied for each territory to the surface observations from each weather station using the Thunderstorm storm mode. The results are summed graphically in Fig. 1.4, and the complete results are in Table 1.8.

The model performed well in Central by correctly predicting a low damage total. The model overestimated the damage to Palisades and underestimated damage to the Southern territory. These errors may be due to the anomalous timing of the convection crossing New Jersey, as temperatures likely would have risen higher had the storms arrived in the 
late afternoon allowing for a higher model damage forecast due to the strong correlation between maximum temperature and predicted damage. The damage in Metropolitan was measured to be zero, but the model predicted four elements to break, indicating further impact of placing plant underground. Another possible source of error is the omission of lightning data in the damage model, as this particular thunderstorm event was observed to have frequent lightning at EWR for several hours. Other surrounding stations such as TEB, TTN, and Philadelphia International Airport (PHL) also observed lightning for several hours. The large underestimation in Southern may be caused by the selection for the input station. TTN is in the northernmost part of the territory and may not fully represent the surface weather conditions experienced during this storm as evidenced by the report of severe hail originating $\sim 40 \mathrm{~km}$ south of the station.

b. Warm storm mode: 11 September 2009

A weak surface cyclone formed late on 10 September and tracked across New Jersey from south to north through the day of 11 September while dissipating. This system was responsible for wind gusts of $31-37 \mathrm{mph}\left(14-17 \mathrm{~m} \mathrm{~s}^{-1}\right)$, rainfall of $0.5-1.5^{\prime \prime}(13-38 \mathrm{~mm})$, and maximum temperatures of $64-68^{\circ} \mathrm{F}\left(18-20^{\circ} \mathrm{C}\right)$ across the area. The damage model's Warm storm mode was applied for each territory (Fig. 1.5; Table 1.9).

The model performed quite well in Central where the total damage estimate error was nine elements with small errors for each element except poles and primary wires. The damage is underestimated again in Metropolitan with the only observed damage assigned 
to trees. The damage for Palisades is overestimated, mainly attributed to an overestimation of service wire and pole damage. The Southern territory's damage is underestimated by the model due to substantial errors in pole, service wire, and tree forecasts. The large underestimation in Southern may again be caused by the selection for the input station, as PHL reported rainfall of 2.00" and a maximum wind gust of $48 \mathrm{mph}$ (21.5 $\mathrm{m} \mathrm{s}^{-1}$ ) with thunderstorms. Using these values for the Thunderstorm storm mode in Southern yields a total damage forecast of 126 plant elements, and substituting the TTN observed weather into the Southern Warm storm mode yields a total damage forecast of 54 plant elements. This illustrates the importance of proper storm mode selection and choosing predictor values which properly represent the territory for operational use.

\section{CONCLUDING DISCUSSION}

\section{a. Conclusions}

Using multiple linear regression to forecast damage to PSE\&G's physical plant yielded encouraging results as measured by relatively high coefficients of determination for most storm modes and territories, with the most variance captured in the Thunderstorm and Mix modes. The verification of the model yielded reasonable standard deviation scores, which encourage future work. The largest standard deviations occurred with the Thunderstorm storm mode, which also has the highest $\mathrm{R}^{2}$ values. An explanation for this contradiction is that the Thunderstorm storm mode incurs most of the damage as shown in Fig. 3. The large range in observed damage explains why the Thunderstorm mode would have the largest errors and the ability for predictors like $\mathrm{SF}_{3}$ and the number 
of severe weather reports to predict high-end damage account for the relatively high $\mathrm{R}^{2}$ values. The high $\mathrm{R}^{2}$ values may also be a byproduct of the post-processing method. This contradiction may also be explained by the use of station observations in the training dataset instead of in-situ storm data for predictors such as $\mathrm{V}_{\mathrm{Max}}$ and $\mathrm{LWE}_{\mathrm{d}}$ during model development and validation, as the model is very sensitive to these variables as demonstrated by the 9 June 2009 case study. Additionally, the lack of lightning activity in the model may be a substantial shortcoming as lightning can have a destructive impact on utility equipment (Bothwell 2002).

Unlike some previous work, the data was not stratified by season. For example, stratifying the None storm mode by season will likely allow for the occurrence of windy but fair weather, which was found to mainly occur in the cold season, to be emphasized in the colder months and for borderline Heat storm mode days found in the data to be emphasized in the warmer months. Due to the lack of seasonal stratification, $\mathrm{LWE}_{10}$ was not corrected for precipitation type. This would likely yield an overestimate of soil moisture after snow events because the precipitation is in solid form and would not seep into the soil until the snowpack melts. This may cause some overestimations in damage forecasts following heavy snow events for equations where the coefficients for $\mathrm{LWE}_{10}$ or $\mathrm{SF}_{2}$ are positive.

\section{b. Applications for other utilities}

This study was performed with the New Jersey climate in mind; therefore, it is recommended other utility companies use different data stratification methods. For 
example, New Jersey experiences an infrequent number of tropical cyclones relative to the Gulf coast and southeast United States. Thus, it may be prudent in such areas to include a Tropical Cyclone mode to allow for damage calculations of tropical cyclones explicitly (whereas for the model presented in this paper, the Warm storm mode would be used for forecasting damage incurred by tropical systems). Locations which more frequently experience high-end severe convection may include a Severe storm mode to address tornado and high wind thunderstorm outbreaks. In locations where wintry precipitation is uncommon, combining stratification from the Cold and Mix modes into a single storm mode may prove beneficial. In locations where destructive ice storms are more frequent an Ice Storm mode may be a more appropriate stratification. Finally, in areas prone to wildfires such as California and the southwest United States, a Fire Weather storm mode may be necessary.

\section{c. Future Work}

Future plans include implementing the plant damage model via a web interface wherein a forecaster may enter a forecast of the necessary variables and obtain a statistical damage forecast for each territory. The idea is to utilize the damage model output as a forecast guidance tool, similar to MOS. Human interaction with the damage model will hopefully produce more useful forecasts in certain situations, similar to how human forecasters outperform MOS forecasts, and better convey forecast uncertainty by using the most appropriate standard error measure. An example of possible improvements a human forecaster may provide is using a forecast of wind gust and precipitation which 
represent the entire territory as input for the model. In contradiction to using a point forecast approach to only forecast the weather at the stations used, a forecast entered into the damage model which is representative of the impending weather will produce a better damage forecast, as shown in the 9 June 2009 case study. This case study also highlighted the importance of selecting the correct storm mode.

A number of approaches may be taken to improve the current model. For instance, the number of stations used for surface observations may be increased to better account for spatial variability within a service territory. With subterritory-scale damage data, damage observations could be assigned to the closest weather station leading to a damage forecast on a smaller scale than at present, which would provide added insight into the amount and location of materials and man-power needed.

Other improvements to the plant damage model should act to overcome the use of count data and the associated heteroscedasticity within the training data. The count data errors may be corrected by utilizing a generalized linear model with negative binomial regression following the methods of Han et al. (2009). This will correct the false assumption that the input data is Gaussian distributed and homoscedastic. The importance of the SFs in the regression equations suggests transforming the data (such as taking the $\log$ of the predictands) will also act to decrease the variance in the predictand as the predictor magnitude increases.

Finally, incorporating new variables, such as thunderstorm coverage and wind direction, may improve the model performance. Including lightning information could account for cases where weak thunderstorms cause anomalously large damage, as seems 
plausible in the 9 June 2009 case study, and would account for the substantial impact lightning has on electrical distribution operations (Balijepalli et al. 2005). The type of thunderstorm observed (e.g., pulse, supercellular, linear) may also provide beneficial information which was previously subjectively accounted for in Wittman et al. (2006). Analysis of morning atmospheric soundings may provide additional useful variables, such as the strength of the morning capping inversion when thunderstorms are expected (James et al. 2005). Inclusion of additional upper air parameters such as the magnitude and direction of the low level jet may provide useful information into the regression for heavy precipitation and wind events (Gronas 1995; Harnack et al. 2001). Wind duration was found to be an important predictor by Brown et al. (1997) and would likely provide important additional information for long lasting events. To avoid overfitting the regression for the None and Warm storm modes, an additional stratification into seasonal regression equations may be necessary. 


\section{TABLES}

TABLE 1.1. An excerpt from the Wittman et al. (2006) damage model for the PSE\&G service territory. Pole represents the expected number of customer calls about damaged poles, Wire represents the expected number of customer calls for downed wires, Tree represents the number of expected customer calls for trees or branches which must be cleared, and Trans represents the expected number of customer calls for transformers that need to be replaced.

\begin{tabular}{cccccc}
\hline Metropolitan & Pole & Wire & Tree & Trans & Total \\
\hline Wind Gust 25 mph & 2 & 12 & 7 & 0.25 & 21.25 \\
Wind Gust 30 mph & 3 & 15 & 8 & 0.25 & 26.25 \\
Wind Gust 35 mph & 4 & 24 & 12 & 0.25 & 40.25 \\
Wind Gust 40 mph & 6 & 32 & 15 & 0.25 & 53.25 \\
Wind Gust 45 mph & 8 & 43 & 27 & 0.3 & 78.30 \\
Wind Gust 50 mph & 9 & 75 & 45 & 0.3 & 129.30 \\
Wind Gust 55 mph & 12 & 120 & 67 & 1 & 200.00 \\
Wind Gust 60 mph & 20 & 182 & 94 & 2 & 298.00 \\
Cold (Any) & 2 & 12 & 7 & 0.25 & 21.25 \\
Heat Temp > 94 & 2 & 12 & 7 & 0.25 & 21.25 \\
Heat 90 - 94 & 2 & 12 & 7 & 0.25 & 21.25 \\
Ice (Any) & 12 & 35 & 20 & 0.5 & 67.50 \\
Snow > 8" & 7 & 30 & 17 & 0.5 & 54.50 \\
Snow < 8" & 5 & 17 & 6 & 0.3 & 28.30 \\
Rainfall < 1" & 4 & 17 & 9 & 0.3 & 30.30 \\
Rainfall 1 - 1.5" & 6 & 25 & 14 & 0.7 & 45.70 \\
Rainfall < 1.5" & 7 & 29 & 16 & 1 & 53.00 \\
Lightning & 7 & 30 & 25 & 1 & 63.00 \\
Severe (Average) & 8 & 42 & 28 & 1 & 79.00 \\
Severe (Extreme) & 14 & 77 & 85 & 1.5 & 177.50 \\
Severe (Isolated) & 6 & 14 & 10 & 0.5 & 30.50 \\
\hline
\end{tabular}


Table 1.2. A summary of storm mode occurrence (number of days) for the training dataset. The bottom row depicts the number of total days in which data was modified and the corresponding number of events necessitating the lagged damage corrections, separated by a slash. Territories are abbreviated so that CEN, MET, PAL, and SOU represent Central, Metropolitan, Palisades, and Southern, respectively.

\section{STORM MODE OCCURRENCE}

\section{...Training Dataset...}

\begin{tabular}{ccccc}
\hline MODE & CEN & MET & PAL & SOU \\
THUNDER & 163 & 131 & 133 & 158 \\
WARM & 426 & 560 & 546 & 461 \\
COLD & 91 & 91 & 98 & 100 \\
MIX & 39 & 43 & 56 & 46 \\
HEAT & 78 & 106 & 101 & 55 \\
NONE & 1160 & 1167 & 1143 & 1151 \\
?? & 331 & 163 & 182 & 316 \\
\hline Modified & $22 / 9$ & $17 / 6$ & $30 / 10$ & $37 / 13$ \\
\hline
\end{tabular}

Thunder is Thunderstorm mode

?? are Questionable days 
TABLE 1.3. Summary of regression models for each storm type and division. The $\mathrm{R}^{2}$ value shown is an average of the $\mathrm{R}^{2}$ values from each of the six plant element regressions. Also shown is the percent of coefficients measured to be significant.

\begin{tabular}{ccccccc}
\hline MODE & CEN & MET & PAL & SOU & Avg. & p-values $<0.05^{\star \star}$ \\
\hline THUNDER & 0.310 & 0.456 & 0.569 & 0.223 & 0.389 & 0.632 \\
WARM & 0.121 & 0.186 & 0.189 & 0.182 & 0.169 & 0.640 \\
COLD & 0.177 & 0.138 & 0.092 & 0.124 & 0.131 & 0.549 \\
MIX & 0.452 & 0.697 & 0.187 & 0.309 & 0.411 & 0.508 \\
HEAT* & 0.355 & 0.103 & 0.318 & 0.278 & 0.263 & 0.643 \\
NONE & 0.045 & 0.064 & 0.032 & 0.072 & 0.053 & 0.579 \\
\hline
\end{tabular}

*Only $\mathrm{R}^{2}$ values for Transformers are shown; see text for details. $* *$ Percent of coefficients having significant $\mathrm{p}$-values $(<0.05)$. 
TABLE 1.4. Model derived $s_{e}$ values for each territory and storm mode. Bold-faced (italicized and underlined) values denote the maximum (minimum) of the three error scores analyzed, here and in Tables 1.6 and 1.7.

\begin{tabular}{cccccc}
\hline MODE & CEN & MET & PAL & SOU & Average \\
\hline THUNDER & $\underline{15.586}$ & 46.610 & 36.318 & 28.617 & 31.783 \\
WARM & $\mathbf{1 2 . 1 1 8}$ & $\mathbf{1 1 . 7 8 1}$ & $\mathbf{2 2 . 1 7 9}$ & $\mathbf{1 0 . 3 7 6}$ & $\mathbf{1 4 . 1 1 4}$ \\
COLD & $\mathbf{5 . 7 2 0}$ & 10.766 & 2.102 & $\mathbf{1 0 . 6 1 3}$ & $\mathbf{7 . 3 0 0}$ \\
MIX & $\underline{6.863}$ & $\mathbf{1 6 . 3 0 8}$ & $\mathbf{2 . 1 0 0}$ & $\mathbf{7 . 7 3 7}$ & $\mathbf{8 . 2 5 2}$ \\
HEAT & $\mathbf{5 . 6 1 4}$ & $\mathbf{2 . 4 4 6}$ & $\mathbf{5 . 6 6 3}$ & $\underline{3.812}$ & $\mathbf{4 . 3 8 4}$ \\
NONE & 3.676 & $\mathbf{5 . 3 7 1}$ & 3.183 & 3.546 & 3.944 \\
\hline Average & $\underline{8.263}$ & $\mathbf{1 5 . 5 4 7}$ & $\mathbf{1 1 . 9 2 4}$ & 10.783 & 11.629 \\
\hline
\end{tabular}


TABLE 1.5. Same as Table 1.2, except for the verification dataset.

\begin{tabular}{ccccc}
\hline \multicolumn{5}{c}{ STORM MODE OCCURRENCE } \\
... Verification Dataset... \\
\hline MODE & CEN & MET & PAL & SOU \\
THUNDER & 23 & 21 & 13 & 25 \\
WARM & 93 & 112 & 121 & 111 \\
COLD & 20 & 20 & 18 & 19 \\
MIX & 8 & 9 & 14 & 5 \\
HEAT & 4 & 7 & 5 & 3 \\
NONE & 174 & 199 & 173 & 190 \\
?? & 79 & 31 & 47 & 50 \\
\hline Modified & $12 / 5$ & $2 / 1$ & $2 / 1$ & $11 / 5$ \\
\hline
\end{tabular}

Thunder is Thunderstorm mode

?? are Questionable days 
TABLE 1.6. Standard deviations $\left(\sigma_{e}\right)$ from the verification dataset, see text for calculation. Bold-faced (italicized and underlined) values denote the maximum (minimum) of the three error scores analyzed, here and in Tables 1.4 and 1.7.

\begin{tabular}{cccccc}
\hline MODE & CEN & MET & PAL & SOU & Average \\
\hline THUNDER & $\underline{15.586}$ & 46.610 & 36.318 & 28.617 & 31.783 \\
WARM & $\mathbf{1 2 . 1 1 8}$ & 11.781 & $\mathbf{2 2 . 1 7 9}$ & $\mathbf{1 0 . 3 7 6}$ & $\mathbf{1 4 . 1 1 4}$ \\
COLD & $\mathbf{5 . 7 2 0}$ & 10.766 & $\underline{2.102}$ & $\mathbf{1 0 . 6 1 3}$ & $\mathbf{7 . 3 0 0}$ \\
MIX & $\underline{6.863}$ & $\mathbf{1 6 . 3 0 8}$ & $\mathbf{2 . 1 0 0}$ & $\mathbf{7 . 7 3 7}$ & $\mathbf{8 . 2 5 2}$ \\
HEAT & $\mathbf{5 . 6 1 4}$ & $\mathbf{2 . 4 4 6}$ & $\mathbf{5 . 6 6 3}$ & $\underline{3.812}$ & $\mathbf{4 . 3 8 4}$ \\
NONE & 3.676 & $\mathbf{5 . 3 7 1}$ & 3.183 & 3.546 & 3.944 \\
\hline Average & $\underline{8.263}$ & 15.547 & $\mathbf{1 1 . 9 2 4}$ & 10.783 & 11.629 \\
\hline
\end{tabular}


TABLE 1.7. Total model damage standard deviation $\left(\sigma_{E}\right)$ from the verification dataset, see text for calculation. Bold-faced (italicized and underlined) values denote the maximum (minimum) of the three error scores analyzed, here and in Tables 1.4 and 1.6.

\begin{tabular}{cccccc}
\hline MODE & CEN & MET & PAL & SOU & Average \\
\hline THUNDER & $\mathbf{3 5 . 9 3 0}$ & $\mathbf{5 3 . 6 1 3}$ & 34.827 & $\mathbf{6 4 . 0 8 0}$ & $\mathbf{4 7 . 1 1 2}$ \\
WARM & $\underline{6.108}$ & $\mathbf{4 . 0 5 1}$ & 8.266 & 7.425 & 6.463 \\
COLD & $\underline{3.871}$ & 1.753 & $\mathbf{3 . 3 2 7}$ & 3.335 & 3.072 \\
MIX & $\mathbf{1 1 . 0 9 6}$ & 4.391 & 1.840 & 5.450 & 5.694 \\
HEAT & 4.796 & 0.787 & 1.581 & 6.110 & 3.318 \\
NONE & $\underline{\mathbf{1 4 . 5 5 5}}$ & 4.495 & $\underline{5.962}$ & $\underline{9.063}$ & $\underline{8.519}$ \\
\hline Average & $\mathbf{1 2 . 7 2 6}$ & $\mathbf{1 1 . 5 1 5}$ & 9.301 & $\mathbf{1 5 . 9 1 1}$ & $\mathbf{1 2 . 3 6 3}$ \\
\hline
\end{tabular}


TABLE 1.8. Complete damage count data for 9 June 2009 Case Study. Model $=$ Modeled data (according to Thunderstorm storm type); Obs = Observed data. The plant damage elements are labeled on the left side as TRANS is the number of transformers transformers damaged, POLE is the number of poles damaged, SVC is the number of service wires replaced, SEC is the number of secondary wires replaced, PRI is the number of primary wires replaced, and TREE is the number tree related damages. The bold-faced values indicate where the model error is two or less (and the observed damage is nonzero).

\begin{tabular}{ccc|cc|cc|cc}
\hline \multicolumn{4}{c}{ CASE STUDY: 9 June 2009 (Thunderstorm Storm Mode) } \\
& \multicolumn{2}{c}{ CEN } & \multicolumn{2}{c}{ MET } & \multicolumn{2}{c}{ PAL } & \multicolumn{2}{c}{ SOU } \\
& Obs & Model & Obs & Model & Obs & Model & Obs & Model \\
\hline TRAN & 9 & 2 & 0 & 1 & 2 & 5 & 18 & 0 \\
POLE & 0 & 1 & $\mathbf{1}$ & $\mathbf{0}$ & 2 & 5 & $\mathbf{1}$ & $\mathbf{3}$ \\
SVC & $\mathbf{0}$ & $\mathbf{0}$ & 0 & 1 & 0 & 11 & $\mathbf{6}$ & $\mathbf{8}$ \\
SEC & 0 & 2 & $\mathbf{0}$ & $\mathbf{0}$ & 0 & 2 & 12 & 2 \\
PRI & $\mathbf{2}$ & $\mathbf{0}$ & $\mathbf{0}$ & $\mathbf{0}$ & 0 & 3 & 27 & 6 \\
TREE & $\mathbf{2}$ & $\mathbf{1}$ & 0 & 1 & 0 & 2 & 25 & 4 \\
\hline
\end{tabular}


TABLE 1.9. Same as Table 8, except for 11 September 2009 and using the Warm storm mode.

\begin{tabular}{ccc|cc|cc|cc}
\hline & \multicolumn{2}{c}{ CEN } & \multicolumn{2}{c}{ MET } & \multicolumn{2}{c}{ PAL } & \multicolumn{2}{c}{ SOU } \\
& Obs & Model & Obs & Model & Obs & Model & Obs & Model \\
\hline TRAN & $\mathbf{3}$ & $\mathbf{4}$ & 0 & 1 & $\mathbf{4}$ & $\mathbf{2}$ & $\mathbf{4}$ & $\mathbf{4}$ \\
POLE & 10 & 4 & 0 & 1 & 3 & 12 & 8 & 4 \\
SVC & $\mathbf{1 3}$ & $\mathbf{1 2}$ & 0 & 6 & 7 & 11 & 14 & 8 \\
SEC & $\mathbf{1}$ & $\mathbf{2}$ & 0 & 1 & 0 & 1 & 4 & 3 \\
PRI & 6 & 2 & 0 & 2 & $\mathbf{1}$ & $\mathbf{3}$ & 14 & 5 \\
TREE & $\mathbf{1 3}$ & $\mathbf{1 3}$ & $\mathbf{3}$ & $\mathbf{5}$ & 0 & 3 & 9 & 5 \\
\hline
\end{tabular}




\section{FIGURES}

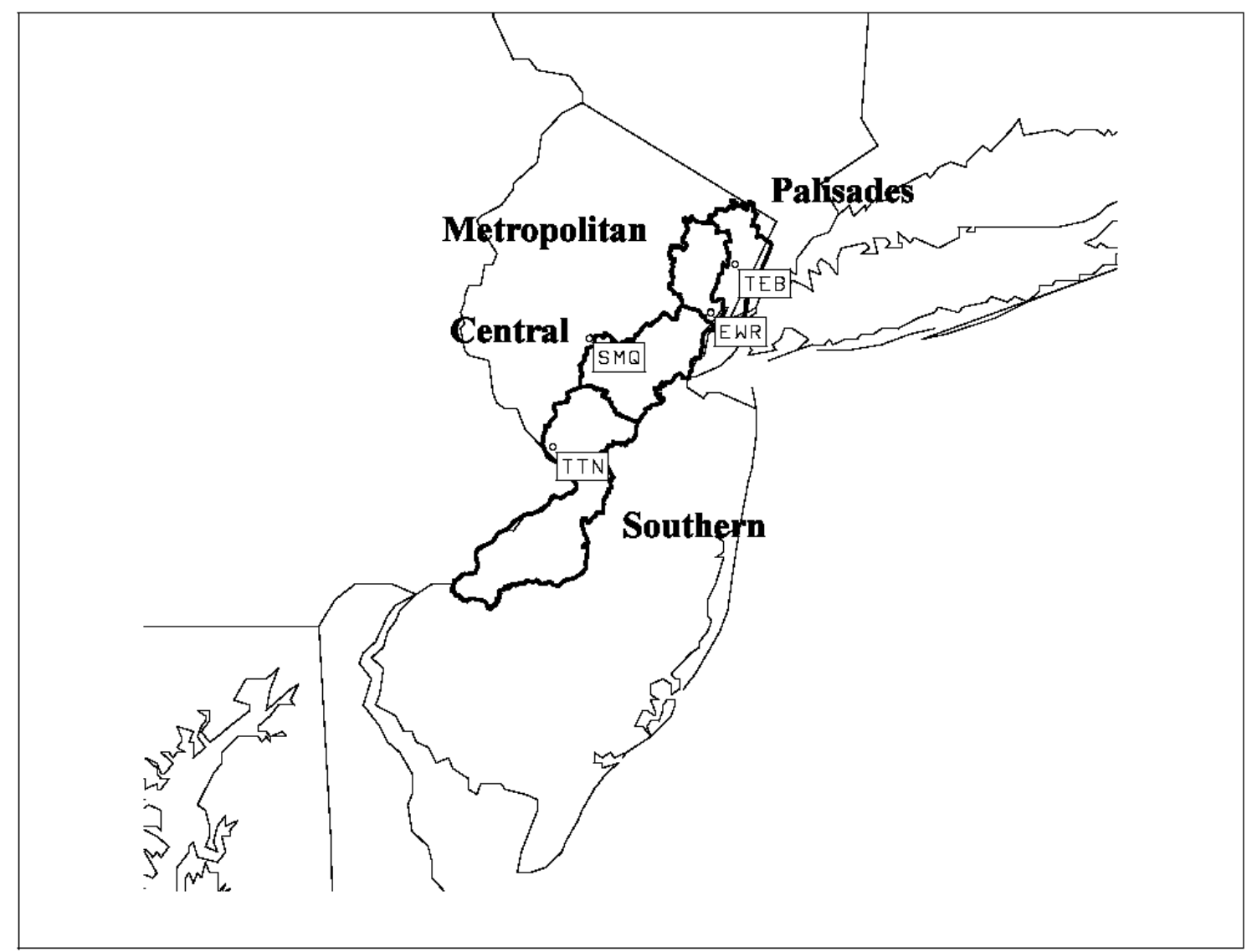

FIG 1.1. A map showing the location of the PSE\&G service territories and the weather stations used to construct the plant damage model. 


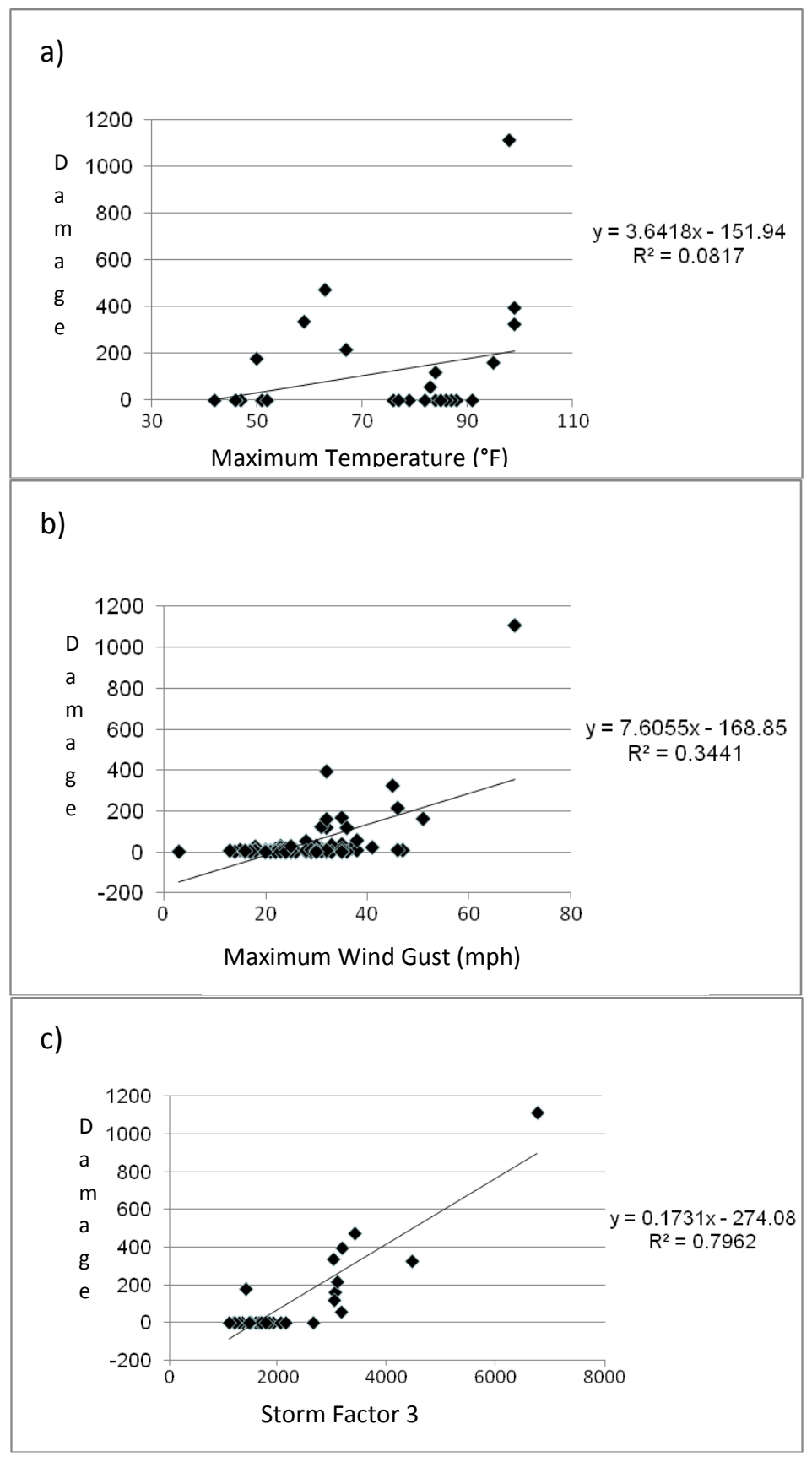

FIG 1.2. Plots for (a) $\mathrm{T}_{\max }$ versus total damage, (b) $\mathrm{V}_{\max }$ versus total damage, and (c) $\mathrm{SF}_{3}$ versus total damage used to investigate new potential predictors for the Thunderstorm storm mode in Palisades. 

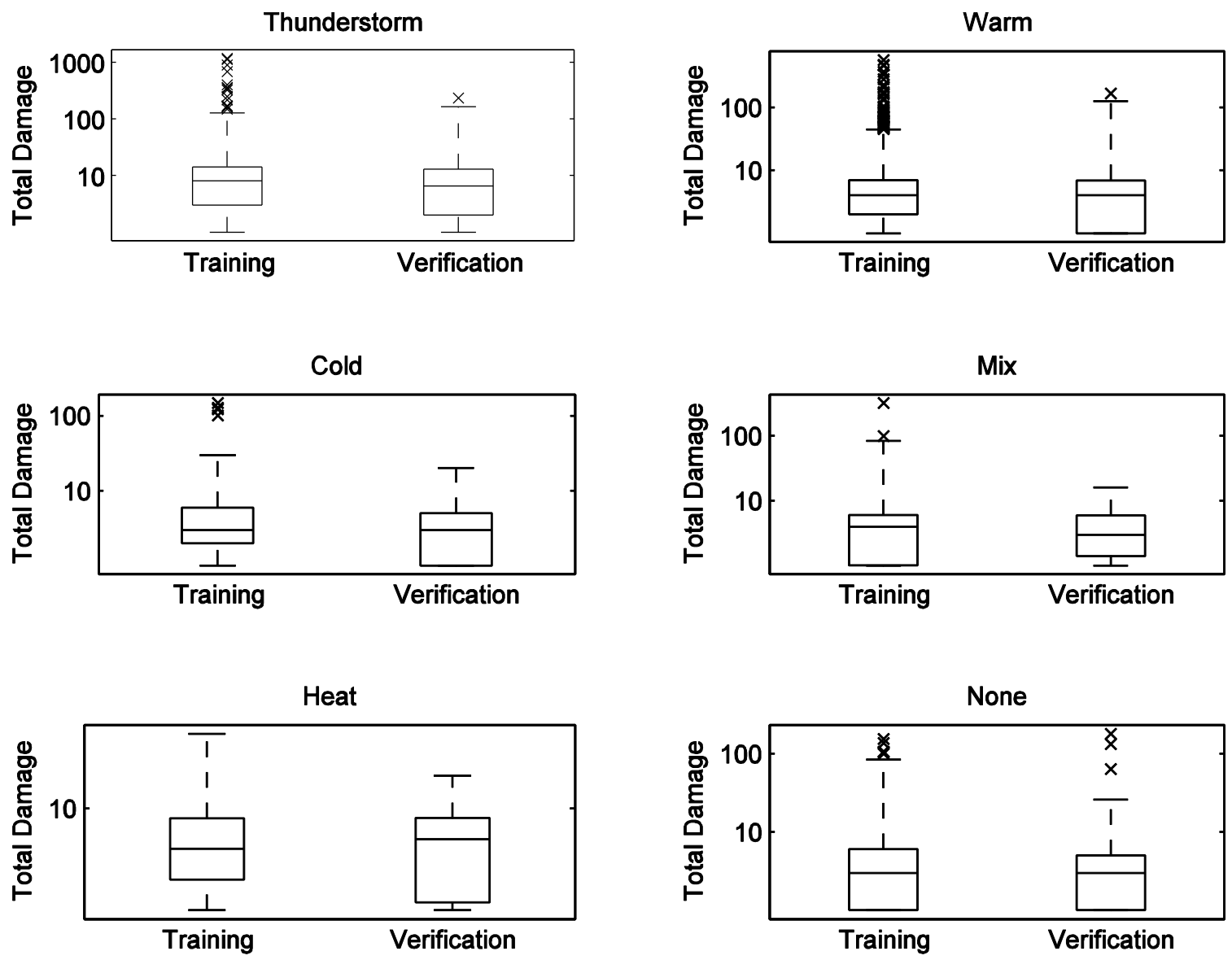

FIG 1.3. Box and whiskers plot showing the total observed damage for all territories in each storm mode for all territories for the Test dataset and Verification dataset in log-10 scale. The top and bottom of the box represents the first and third quartiles, respectively, and the middle line represents the median. The upper and lower whiskers extend to the $90^{\text {th }}$ and $10^{\text {th }}$ percentile, respectively. The values denoted by ' $x$ ' are outside the $90^{\text {th }}$ and $10^{\text {th }}$ percentile, which represent extreme values. 

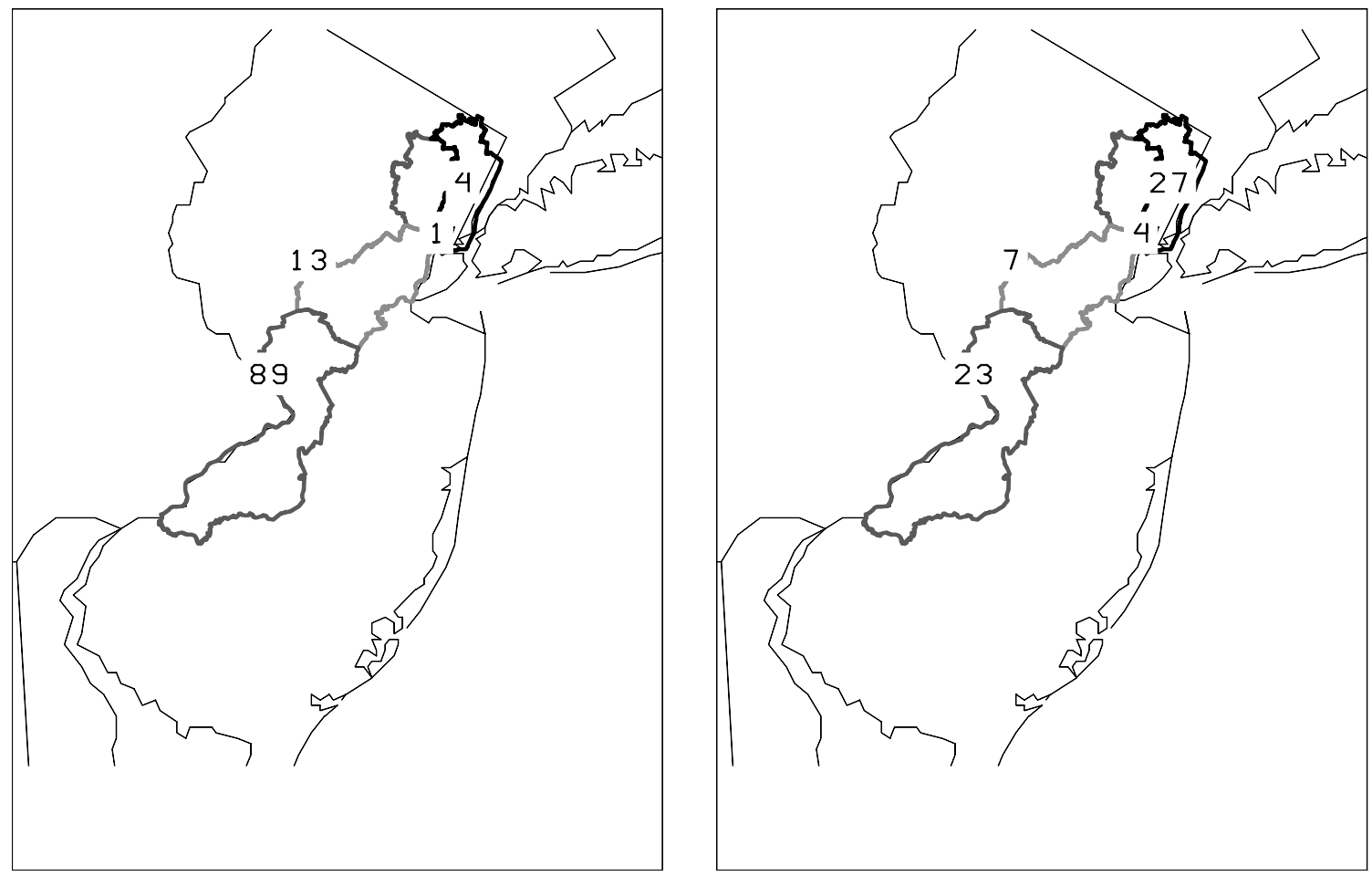

FIG 1.4. PSE\&G total plant damage observations (left) and corresponding Thunderstorm model prediction (right) for 9 June 2009. 

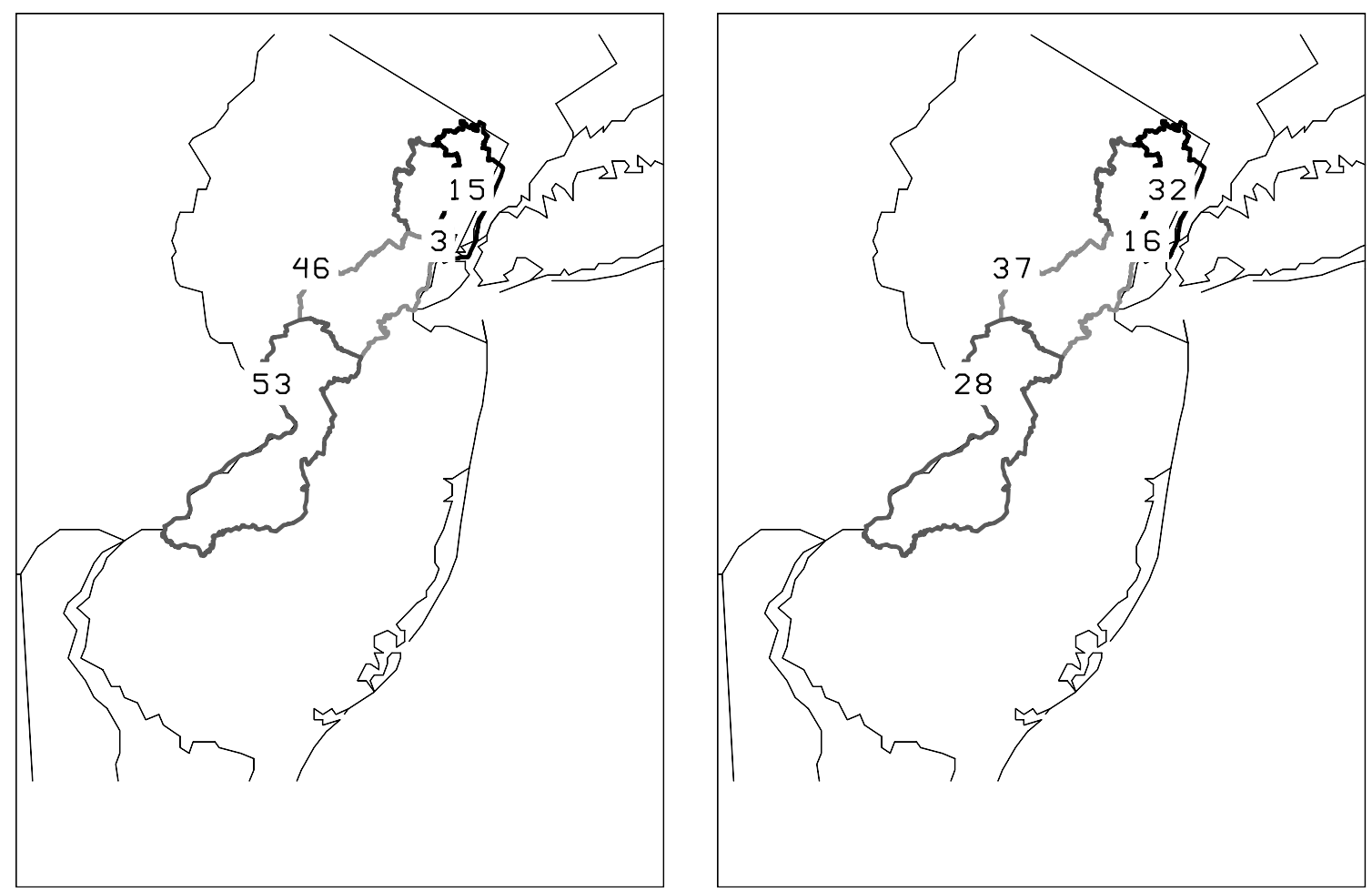

FIG 1.5. Same as Fig 4, but for 11 September 2009 using the 'Warm’ model. 


\section{Chapter Two: Model comparison and application}

\section{OVERVIEW}

The model presented in Chapter One resulted from a backwards elimination of the initial model. This first model attempt contained some insignificant predictors which act to artificially increase the $\mathrm{R}^{2}$ values. It follows that this original model may suffer from overfitting. Thus, the first model containing all available predictors will be referred to as the overfitted model and the model studied in Chapter One which was developed using backwards elimination will be referred to as the backwards eliminated model throughout chapter Two. This chapter will provide deeper insight via several methods into some questions raised in Chapter One and a few issues which were omitted. The first method will be comparing the equations from the overfitted model, and the backwards eliminated model to investigate changes in the coefficients and to explain the behavior of the model. Next, the assumptions for a linear model are investigated, and conclusions are drawn based on violations of these assumptions. This will be followed by a comparison of model reliability and skill by applying forecast verification techniques to the model derived forecasts for the verification dataset. Next, additional case studies will be presented to seek potential predictors for any future work and to develop guidelines for utilizing plant damage guidance in an operational forecast setting. Post-processing of storms that occur over the course of multiple days and when the post-processing methods presented in Chapter One fail will then be discussed. Finally, model improvements will be suggested based on the content of the investigation. 


\section{a. Model equations}

Some interesting aspects of the predictor coefficients must be addressed, including negative $b_{1}-b_{8}$ values, large and positive $b_{0}$ values, and situations when the sign of the coefficient differs from the overfitted model to the backwards eliminated model. No significant $(\mathrm{p}$-values $<0.05)$ predictors were removed from the overfitted model as a result of the objective backwards elimination procedure, however in some isolated instances significant predictors were omitted from the overfitted models, described in more detail shortly. A summary of the predictors and corresponding coefficients is presented in Table 2.1. The coefficients for every equation in the overfitted model and backwards eliminated model are presented in Table (2.2) and (2.3), respectively.

Plant element damage was found to be positively correlated with predictor magnitude, which suggests that the y-intercepts $\left(b_{0}\right)$ should be negative or near zero, but several equations display large and positive $b_{0}$ values. This may intuitively imply the slope of these equations is negative, but these equations mainly contain large positive coefficients which quickly act to overcome the effect of a large positive $b_{0}$. For instance, the service wire equations for the Thunderstorm storm mode in Metropolitan have $b_{0}$ values $>200$ for both model versions. However, these equations also possess $b_{7}$ coefficients on the order of 0.16215 and 0.108894 for the overfitted and backwards eliminated models, respectively. When multiplied with the associated predictor (SF3) they produce a product on the order of $10^{2}$. Even if moderate conditions for thunderstorms to produce damage 
exist $\left[\mathrm{T}_{\max }=75^{\circ} \mathrm{F}\left(10^{\circ} \mathrm{C}\right), \mathrm{V}_{\max }=30 \mathrm{mph}\left(4.5 \mathrm{~m} \mathrm{~s}^{-1}\right), \mathrm{SF}_{3}=1870\right]$. Substituting these values for the predictors and applying the appropriate coefficients for service wires in Metropolitan using the Thunderstorm storm mode that the $b_{0}$ values are overcome easily $\left[b_{7} * \mathrm{SF}_{3}(0.108894 * 1875)=204.177\right]$

The nuance discussed above leads into an understanding of why negative $b_{1}-b_{8}$ coefficients exist. Under the special circumstance of a large and positive $b_{0}$ value, negative coefficients will act to decrease the damage forecast and negative coefficients exist widespread in the model equations. While this seems counterintuitive, when large positive predictor coefficients exist, other predictors act to constrain the model predictions to match the training dataset observations, herein referred to as restrictor coefficients. Knowledge of restrictor coefficients may allow for constraints to be removed during high-end events, such as hurricanes and severe weather outbreaks, which are not common or may not exist in the training dataset. An example of this scenario will be provided in the case studies.

The third scenario, coefficient signs differing between the overfitted model and backwards eliminated model, exists merely because some restricting predictors are removed. For example, the Heat Storm mode in Central has negative $b_{8}$ coefficients $\left(T_{3}\right)$ in the overfitted model but positive coefficients in the backwards eliminated model for transformers and primary wires. In each equation, restrictor coefficients $b_{5}$ and $b_{3}$ were objectively eliminated from the transformer and primary wire equations, respectively. Conversely, for the None storm mode in Central, coefficients with positive slopes $\left(b_{4}\right.$ and $b_{5}$ ) were objectively eliminated, resulting in the restrictor variable $b_{8}$ becoming positive. 


\section{b. More on model assumptions}

The plant damage model presented in the previous chapter utilized a multiple linear regression approach, but some clear assumption violations exist in the training and validation dataset. The three main violated assumptions are:

1) The data is independent

2) The data is Gaussian distributed

3) The data is homoscedastic.

Intuition suggests that the damage data is dependent. The box and whiskers plot demonstrate that the data is non-Gaussian. The heteroscedasticity of the data is demonstrated via plots of the residuals (Fig. 2.1). This plot clearly shows an increasing variance with increasing magnitude of the predictand. This property introduces error during attempts to measure the error of the model (e.g., standard error, standard deviation), which has important implications for conveying uncertainty when using guidance generated by the model in question. For example, a linear model will assume the $s_{e}$ is a constant and can be applied to measure uncertainty at any range of predictand provided it is within the bounds of the training dataset (i.e., calibration issues can be ignored). However, the $s_{e}$ values are not constant, and they depend on the magnitude of the predictand. Given the inadequate power of the tool used to formulate the regression coefficients for such a situation, the calculated $s_{e}$ values are incorrect for high and low damage estimates alike. Despite this lack of an explicit method to convey uncertainty when the model is used for forecasting, it follows that uncertainty will likely be larger for 
more intense storms (i.e., larger predictions of damage) and smaller for weaker storms (i.e., lower predictions of damage) assuming the magnitude of the storm is relatively well known. Explicit methods for overcoming this issue will be developed later.

\section{MODEL PERFORMANCE}

Two methods were used to investigate the performance of the model using the verification dataset. The first was applying the 95\% confidence interval (CI95) bounds, calculated to be $1.96\left(s_{e}\right)$, to all model forecasts and testing whether the observed damage fell between the bounds. This analysis will provide a discussion on the error bounds, previously presented, and will allow for an assessment of model reliability. The second was carried out using well known forecasting verification scores [e.g., probability of detection (POD), false alarm ratio (FAR), critical success index (CSI), and Heidke skill score (HSS)] to verify the model's ability to predict a predetermined amount of total damage. For more information on the calculations associated with these indices, the reader is referred to Roebber (2009). This analysis will allow for an assessment of deterministic model skill.

\section{a. Confidence Intervals}

Tables 2.4 and 2.5 show the CI95 results for the overfitted model and the backwards eliminated model, respectively. It would be expected that the overfitted model would have more observations within its CI95 because it has extraneous predictors. This will 
increase the $s_{e}$ values, allowing a larger possible range for which the observations may lie, resulting in more then $95 \%$ of the observations falling within the CI95 bounds. If the model were very reliable, all values in the tables would be 0.95 . However, given the assumption violations and sample error presented in Chapter One, the error estimates used seem to be an upper bound for the validation dataset, so several values greater than 0.95 can be expected in both tables. This is indeed the outcome with over half of the values in both tables scoring greater than 0.95 .

This analysis found the backwards eliminated model to be more reliable via 17 values closer to 0.95 compared to 12 for the overfitted model. This indicates that the error bounds calculated by the backwards eliminated model outperform those of the overfitted model in terms of reliability. When using the error bounds to convey forecast uncertainty, ideally the CI95 would verify $95 \%$ of the time, however these findings showed that the error range may be artificially large due to sample error and assumption violations.

\section{b. Statistical verification}

Statistical forecasting parameters were used to analyze the model predictions. Here, both models' ability to predict greater than 10, 20, and 30 total damaged plant elements is critiqued using the POD, FAR, CSI, and HSS values. While the analysis would ideally be carried out for all storm modes individually, the lack of damage greater than 30 total elements per division on a daily basis in the verification dataset precludes such a study. 
The results of the analysis for predictions of greater than 10, 20, and 30 total damaged plant elements are presented in Table 2.6, Table 2.7, and Table 2.8, respectively.

Tables 2.6-8 show that both models suffer from high (>0.50) FARs, however skill (HSS > 0) does exist across most storm modes and territories for both versions of the model (except in Metropolitan for greater than 30 damaged elements). The skill appears to be increasing as the prediction threshold increases as displayed by the total HSS values increasing with increasing threshold value. This is further evidenced by decreasing FARs and increasing POD and SCI values as the damage threshold increases. This would likely benefit a utility company receiving the model output, as detecting damaging events is essential to planning workforce operations and material needs. It is interesting to note that while the backwards eliminated model has less predictors, it consistently has a similar HSS value compared to the overfitted model and actually shows more skill at predicting higher values of damage. This is unexpected because the loss of predictors decreases the $\mathrm{R}^{2}$ value of the backwards eliminated model, meaning it should explain less of the variance and show less skill. However, the backwards eliminated model likely outperforms the overfitted model because extraneous predictors were removed during the backwards elimination process.

\section{CASE STUDIES}

The following is a series of case studies used to investigate new predictors and potential forecasting guidelines for operational use of the plant damage model in PSE\&G 
operations. The cases are selected to intentionally highlight shortcomings or to display working examples of how forecasting guidelines may be utilized. The first case study, 29 July 2009, investigates the performance of the model for severe thunderstorms and sensitivity to the number of severe thunderstorm reports in a territory. The second analyzes a Mix storm mode case, 28 January 2009, in which freezing rain occurred widespread across the PSE\&G service territories. This case will be investigated to determine model performance with the Mix storm mode and to analyze hourly observations to suggest improvements to the application of the model in instances when the strongest winds do not correlate with the times of precipitation. Next, two None storm mode days typified by dry, windy conditions, 12 February 2009 (a high-end damage day), and 4 April 2009 (a typical damage day) are investigated to elucidate the model shortcoming responsible for vastly underestimating observed damage in the 12 February 2009 case. An example of when multiple storm modes are anticipated for the PSE\&G area is then analyzed using 17 December 2008 and operational forecasting guidelines are suggested. Finally, an in depth study of the 12-14 March 2010 Nor'easter is conducted to investigate the possible causes for underestimation of damage for this multi-day event and to suggest model improvements and forecasting guidelines which may be utilized to reduce large errors during high-end events. The findings of these case studies will be discussed fully in Section 5 of Chapter One.

Within the case studies, the role of forecaster will be investigated by using alternate predictor values to explore the model's sensitivity. In this sense, the damage model will be used as a guidance tool, similar to MOS forecasts, except the damage model will have 
the flexibility to calculate alternate scenarios at the forecaster's discretion. Some examples of alternate model calculations analyzed include using alternate storm modes and adjusting $\mathrm{V}_{\max }$ to match observations not sampled by the selected stations. The findings will provide a basis for damage model guidelines, which will be used to aid the forecaster when utilizing the damage model output.

\section{a. Thunderstorm Storm Mode: 29 July 2009}

A line of thunderstorms crossed the northern half of the PSE\&G service territories in the early afternoon of 29 July 2009. These storms contained heavy downpours, frequent lightning, wind gusts up to $70 \mathrm{mph}\left(31 \mathrm{~m} \mathrm{~s}^{-1}\right)$, and severe $\left[>0.75^{\prime \prime}\right.$ in diameter or larger (19 mm)] hail. Maximum temperatures ranged between $85-87^{\circ} \mathrm{F}\left(29.4-30.5^{\circ} \mathrm{C}\right)$ and daily rainfall totals ranged from 0.47-2.97" (11.9-75.4 $\mathrm{mm})$. The storms were responsible for 11 total severe weather reports within the PSE\&G service territories with four, three, three, and one severe reports for Central, Metropolitan, Palisades, and Southern, respectively. On this date, SMQ was diagnosed as a Questionable weather day due to a suspect wind gust of $87 \mathrm{mph}\left(39.9 \mathrm{~m} \mathrm{~s}^{-1}\right)$. However a gust of $70 \mathrm{mph}$ was measured within Central territory at Edison, $\mathrm{NJ}$ and this value is substituted into the surface observations in place of the suspect measurement from SMQ. The appropriate regression equations were applied to the surface observations using the Thunderstorm storm mode for all territories and the results are discussed below. A summary of the results is presented in Table 2.9 and graphically in Fig. 2.2. 
The model did not perform well in all territories for this particular event, overestimating the damage for Central, Metropolitan, and Palisades, but underestimating the damage for Southern. The errors in Central, Metropolitan, and Palisades may be due to the convection arriving before peak heating and the hail reports causing inflated damage estimates as hail was found to have less destructive potential relative to wind of the data in this study. Decreasing the number of severe reports to ignore severe hail results in the number of severe reports decreasing from three to two in Central and two to one in Metropolitan, respectively. This yields a total plant damage forecast of 124 and 13 for Central and Metropolitan, respectively, which is closer to the observations. For forecasting applications, this case study suggests not forecasting a high number of severe weather reports when hail is the main threat, as wind-related severe weather reports appear to be the important predictor. The damage may be underestimated in Southern because this area experienced two waves of thunderstorms, both containing wind gusts to $30 \mathrm{mph}\left(13.4 \mathrm{~m} \mathrm{~s}^{-1}\right)$ and frequent cloud-to-ground lightning. The lack of lightning information in the model is again exposed as an important weakness.

\section{b. Mix Storm Mode: 28 January 2009}

A weak storm system emerged from the Rocky Mountains and crossed the southern plains 27 January 2009 bringing light snow and rain to the central United States. Taking an inland track, the storm began to intensify the afternoon of 28 January before tracking into eastern Canada. Across the PSE\&G service territories, light snow began to fall 
widespread late on 27 January. This light snow continued into 28 January resulting in 0.5-4.0" (13-101 mm) of snow by $\sim 12$ UTC. Warmer air aloft began to intrude into the area after $8 \mathrm{UTC}$, causing light freezing rain to fall across western portions of the area from around 9 UTC to 15 UTC. With profiles continuing to warm through the morning and early afternoon, light rain took over and was widespread by 18 UTC lasting until 00 UTC on 29 January. As the storm departed, wind gusts quickly rose to 31-39 mph (13.9-17.4 $\mathrm{m} \mathrm{s}^{-1}$ ) after 21 UTC. Maximum temperatures for the event were $40-41{ }^{\circ} \mathrm{F}$ $\left(\sim 4.5^{\circ} \mathrm{C}\right)$ and liquid equivalent precipitation was measured to be $0.76-1.00^{\prime \prime}(19.3-25.4$ $\mathrm{mm}$ ) across the service territories. The Mix storm mode was applied to the appropriate surface observations and the model results are compared with plant damage observations below. The Mix storm mode was applied for all territories and a summary of the results is presented in Table 2.10 and graphically in Fig. 2.3.

The Mix storm mode produced accurate damage forecasts for Metropolitan and Palisades by correctly predicting no damage for all wire types and tree-related damage in Metropolitan and secondary wires and tree-related damage in Palisades. The model performed adequately in Central and Southern, exactly predicting the number of secondary wires and transformers in Central and Southern, respectively. The model also accurately predicted primary wire damage and damaged poles in Central and Southern, respectively. However, the model performed poorly for predicting the other damage elements in Central and service and primary wires in Southern. The damage may be overestimated in these areas because the wind gusts did not occur during the precipitation, which is more common in the Training dataset. Here, the gusty winds 
occurred well after the light ice accretion produced by the period of light freezing rain had melted. Substituting in the maximum wind observed during precipitation [7 $\mathrm{mph}$ (3.1 $\left.\mathrm{m} \mathrm{s}^{-1}\right)$ for Central and $12 \mathrm{mph}\left(5.4 \mathrm{~m} \mathrm{~s}^{-1}\right)$ for Southern] yields total plant damage forecasts of 0 and 3 for Central and Southern, respectively. Forecasting a lower wind gust for Palisades [13 mph $\left.\left(5.8 \mathrm{~m} \mathrm{~s}^{-1}\right)\right]$ also decreased the total plant damage forecast to two. While these differences appear non-substantial due to their small magnitude, a few elements may mean the difference between holding an overtime crew and releasing one, which over time will save PSE\&G money if the forecast is adjusted properly.

\section{c. None Storm Mode: 12 February 2009 and 4 April 2009}

A storm system in the lower Mississippi River valley on 11 February 2009 tracked north northeast and intensified through the day on 12 February, deepening from a $997 \mathrm{mb}$ surface low over Missouri at 12 UTC on 11 February to a $985 \mathrm{mb}$ surface low over Lake Champlain at 12 UTC on 12 February. The storm would move slightly northeast and continue to intensify, reaching $973 \mathrm{mb}$ over Nova Scotia at 00 UTC on 13 February. The storm brought little in the way of precipitation to the PSE\&G area, but winds gusted 51-60 mph (22.7-27.3 $\left.\mathrm{m} \mathrm{s}^{-1}\right)$ on 12 February as the storm intensified.

The None storm mode was generally applied to the appropriate surface observations, with a few exceptions. In Metropolitan, 0.06" $(1.5 \mathrm{~mm})$ of rain fell from a few scattered showers, so the Warm storm mode was used for the model results. In Palisades, 0.08 " (2 $\mathrm{mm}$ ) of liquid equivalent precipitation was reported at TEB, but an observation of rainfall 
was not reported for 12 February, causing this day to be classified as Questionable. However, given that EWR did report light rain, the Warm storm mode was applied for the Palisades data using the observations from TEB. The results are presented in Table 2.11 and graphically in Fig. 2.4.

The model drastically underestimated the observed damage for all elements in all territories. When compared to the Training dataset, the 597 combined total plant elements damaged on 12 February 2009 is by far the largest for the None storm. While the model seems to be inadequate for this day's damage, the sampling error can likely be blamed for its poor performance.

The None storm mode was also applied to an event that began on 3 April at 12 UTC, as a deep surface cyclone $(988 \mathrm{mb})$ located over Ohio tracking northeastward. This storm then became occluded while deepening slightly to $982 \mathrm{mb}$ over southern Ontario by 00 UTC on 4 April. By 4 April 12 UTC, the cyclone had filled slightly (996 mb) while drifting slowly northeast and continuing to occlude, after which it slightly deepened to $989 \mathrm{mb}$ while reforming over Maine by 5 April 00 UTC. This system brought wind gusts of 37-49 mph $\left(16.5-21.9 \mathrm{~m} \mathrm{~s}^{-1}\right)$ to the area on 4 April. A light shower produced rainfall near TEB, so the Warm storm mode was diagnosed and applied to the surface observations. All other territories used the None storm mode to predict the damage. A summary of the results is presented in Table 2.12 and graphically in Fig. 2.5.

The model performed adequately for this wind event and showed a vast improvement over the 12 February case. The model correctly forecast no damage for most of 
Metropolitan, tree-related damage in Southern, and secondary wire damage in Palisades. The model also exactly forecast the number of transformers and primary wires in Central and damaged poles in Southern.

This discrepancy in model performance for similar high-end westerly wind events was further investigated by examining hourly observations of wind gusts. It was concluded that the magnitude of the wind in the 12 February case combined with eight consecutive hours of sustained winds near or above $35 \mathrm{mph}\left(15.6 \mathrm{~m} \mathrm{~s}^{-1}\right)$ likely caused the enhanced damage. In the 4 April case, the winds were not greater than $35 \mathrm{mph}$ more for more than three consecutive hours. This indicates a predictor to account for wind duration should be included in any future work.

\section{d. Various Storm Modes: 17 July 2009}

An upper level trough centered near Lake Superior allowed a southerly flow of warm, moist air from the northern Gulf of Mexico to spread into the Mid Atlantic and New England through the morning of 17 July 2009. The trough deepened and amplified through the afternoon allowing a cold front to advance toward the U.S. East Coast. This front interacted with the lake breeze off Lake Ontario to produce numerous showers and a few severe thunderstorms across New England, responsible for wind damage and large hail (SPC 2010). As the front crossed the Mid Atlantic, a surface low developed along the front near Washington, D.C., at approximately 00 UTC on 18 July. This feature enhanced 
low level convergence in south New Jersey, resulting in scattered thunderstorms which produced three severe weather reports (one hail, two wind) in Southern territory.

In terms of sensible weather for the PSE\&G area, high temperatures ranged from 88-91 ${ }^{\circ} \mathrm{F}\left(31.6-32.8^{\circ} \mathrm{C}\right)$, with the warmest temperatures in Metropolitan and Palisades. Central and Metropolitan did not report precipitation for this day, which resulted in the None and Heat storm modes being diagnosed, respectively. In Palisades, showers did occur with the frontal passage, resulting in a diagnosis of Warm storm mode. In Southern, TTN reported rain and only $0.01^{\prime \prime}(0.25 \mathrm{~mm})$ of precipitation, however, the severe weather reports necessitate the Thunderstorm storm mode be diagnosed. Wind gusts from the frontal passage were measured to be 16-29 mph $\left(7.1-12.9 \mathrm{~m} \mathrm{~s}^{-1}\right)$, however higher gusts occurred within the thunderstorms in Southern but the exact magnitude was not observed. The appropriate storm modes were applied for the surface observations and the results are summarized in Table 2.13 and Fig. 2.7.

The model performed quite well for all territories with low errors indicated for many of the plant elements, and often correctly forecast the exact damage count. While the model performance for this particular case is very encouraging, correctly forecasting the storm mode for each territory may prove difficult. Often, situations may become favorable for several storm modes to occur, such as during a heat wave when thunderstorms are possible or an event when the precipitation type is not forecast with sufficient confidence, which often happens for the PSE\&G service territories in the winter months. When multiple storm modes may be possible for a territory, it follows that a forecaster would consider each mode when creating a plant damage forecast. Tables 
2.14-17 present the possible combinations of damage forecasts for Central, Metropolitan, Palisades, and Southern, respectively, when various storm modes are applied to the observations assuming perfect prognosis was attainable (i.e., the same predictor values are used regardless of storm type).

Table 2.14 presents the model results for Central which suggest the Heat storm mode, while not the diagnosed storm mode, would have produced a more accurate forecast. In Metropolitan, Table 2.15 shows that the None and Warm storm modes would have also produced an excellent damage forecast. For Palisades, all applied models would have produced an excellent forecast, with the Heat and None storm modes providing more insight (Table 2.16). For Southern, the other applied storm modes would have performed quite poorly because they do not account for the thunderstorms which produced severe weather (Table 2.17).

It is interesting that the observations for KTTN were able to adequately describe the plant damage for storms which were not observed at the station. This may be because most damaging thunderstorms for Southern in the Training dataset occurred south of the station in a similar fashion to the day under consideration. Also, the timing of the convection was very close to what is typical in the training dataset, allowing the predictors used to reach a value representative of the conditions when the thunderstorms arrived.

While the data presented in the case study verified for most storm modes, it is unlikely the assumptions made to construct Tables $2.14-17$ would hold in a real world 
forecasting scenario. For example, assuming precipitation of $0.25^{\prime \prime}(6.4 \mathrm{~mm})$ and a wind gust of $30 \mathrm{mph}\left(13.4 \mathrm{~m} \mathrm{~s}^{-1}\right)$ for Palisades, the plant damage model forecast becomes 18 total elements, and if severe thunderstorms are anticipated [assuming a wind gust of 55 mph $\left(24.6 \mathrm{~m} \mathrm{~s}^{-1}\right)$ and the number of severe reports is one] the plant damage model forecast becomes 48 total elements. An ensemble forecast, where ensemble in this sense refers to a weighted average of the possible predictor values given the range of possible storm modes, may be used as the predictors in the damage model. This method will likely produce more reliable forecasts in conditions when the storm mode is highly uncertain.

\section{e. High-End Event: 12-14 March 2010}

The following is a case study of a strong nor'easter which affected the PSE\&G service territories from 12-14 March 2010 with strong easterly winds and heavy rain. This storm caused near record crests on several rivers in northern New Jersey and several million dollars of flood related damage in New Jersey alone (NWS 2010). A discussion of the synoptic evolution of the storm (Fig. 2.7) will be followed by a discussion of damage data and modeling efforts using the plant damage model presented herein.

On 11 March 201012 UTC, a deep upper level trough was positioned over the central United States with a surface low pressure located over northern Missouri and an attendant occluded front stretching south to a triple point in Louisiana. The triple point was associated with a warm front extending from Louisiana into northern Florida and a cold front draped from Louisiana westward into Texas. A strong $300 \mathrm{mb}$ jet streak was located 
over the northern Gulf of Mexico, providing upper level divergence for scattered thunderstorm activity along the southeast United States coast. A weak high pressure system to the north of the upper trough was located over the southern Hudson Bay.

By 12 March 00 UTC the convective activity in the southeast U.S. had moved off the Georgia coast. The upper level support for these storms rounded the base of the mean trough and resulted in a surface low pressure forming along the warm front approximately $150 \mathrm{~km}$ east of Savannah, GA. By this time, a deep, moist fetch had developed from the southern Mid-Atlantic southeastward into the western Atlantic Ocean in response to a strengthening of the high pressure system in eastern Canada and slight eastward movement of the upper trough. By 12 March 12 UTC the trough had deepened slightly and the jet streak in the northern Gulf of Mexico strengthened, likely due to a phasing of the polar and subtropical jet streams. The high pressure system in eastern Canada also strengthened, increasing the temperature and pressure gradient across the Mid-Atlantic as the low pressure system, now off the South Carolina coast, deepened slightly (Fig. 2.7a).

On 13 March 00 UTC, the coastal low had deepened further and tracked north to the Outer Banks while the Canadian high strengthened, resulting in a strong $\left(30 \mathrm{~m} \mathrm{~s}^{-1}\right)$ easterly low level jet over the Mid-Atlantic. The upper level trough also continued to strengthen and had tilted more negatively, allowing the attendant upper level jet to provide strong diffluence across much of the Mid-Atlantic and causing the moisture flux off the northwest Atlantic to increase (Fig 2.7b). By 12 UTC 13 March, the easterly low level jet over the Middle Atlantic area strengthened to approximately $40 \mathrm{~m} \mathrm{~s}^{-1}$ in response 
to a tightening of the pressure gradient between the coastal low, now over eastern Virginia, and the Canadian high. At this time, the upper level trough became oriented west-to-east from the Ohio River Valley to the Mid-Atlantic Coast. The low level jet maintained intensity, shifting slightly north to the northern Mid-Atlantic and southern New England in response to the coastal low tracking into central Virginia and Canadian high drifting slightly northeastward (Fig 2.7c).

By 14 March 00 UTC, the upper-level and lower-level storms became stacked, indicating a weakening trend would begin, but the strong low level jet was still maintaining its intensity over New England (Fig 2.7d). On 14 March 12 UTC, the Canadian high had moved further northeastward, allowing the upper-level trough and attendant surface low to track slowly northeast across the Mid-Atlantic into the northwest Atlantic by 16 March 00 UTC.

In terms of sensible weather, light rain began to fall the evening of 12 March and increased in intensity into 13 March as a result of the strong easterly low level jet moving into the area. In response, winds at the surface became easterly and sustained at 20-30 mph (8.9-13.4 $\left.\mathrm{m} \mathrm{s}^{-1}\right)$ with gusts to $45-70 \mathrm{mph}\left(20.1-31.3 \mathrm{~m} \mathrm{~s}^{-1}\right)$ into the evening of 13 March. The heavy rain and strong easterly winds subsided in the early morning of 14 March, but thunderstorms formed across the area bringing heavy downpours and lightning strikes to all territories. This storm resulted in major river flooding, coastal flooding and beach erosion, and substantial power outages. PSE\&G incurred approximately 459000 customers without power on 13 March, making this nor'easter the worst storm in PSE\&G's 107 year history (NOAA 2010). 
Surface observations were collected and the appropriate model equations were applied for each day and territory for 12-15 March 2010. The model results and corresponding PSE\&G damage observations are presented in Table 2.18. The damage only included tree-related damage, service and secondary wires, and poles replaced because the transformer damage and primary wire damage data was not available at the time of publication. The model vastly underpredicted the amount of damage, tying into the heteroscedasticity of the count data used, as an event of this magnitude would be expected to have a large residual. The damage model was re-calculated using the Warm storm mode for all days, as the cooler conditions provide more favorable predictor values for higher damage in this mode, however the model total plant damage forecast does not increase very much (Table 2.19). Due to the extreme magnitude of this event, a special model circumstance was considered; removing restrictor coefficients from the equations to allow an extreme upper bound value to be calculated. The results of this procedure are presented in Table 20, and the total model damage forecast increases but still does not adequately forecast the amount of damage.

A comparative study where the maximum observed wind gust and maximum observed precipitation (according to local NWS storm summaries) were used as the model predictor values for each territory represent a perfect prognosis forecast to account for the selected stations failing to capture the strongest wind or heaviest precipitation (Table 2.21). These values are substituted for the predictors and the model equations are carried out with and without restrictor coefficients (Table 2.22). This study revealed that using the maximum value for precipitation and wind gust allowed for the highest model 
predictions when the restrictor coefficients were eliminated, but the model errors are still quite high.

This case study demonstrates the importance of wind duration and direction for subjectively adjusting forecasts. Despite the large model error and relatively poor performance, it is hoped that the damage data (once received in complete form) will provide an analogue forecast for any future tropical system or nor'easter expected to bring strong easterly winds to the area. This analogue technique will provide forecasters some objectivity when subjectively adjusting damage forecasts for high-end easterly wind events.

\section{POST-PROCESSING}

While the plant damage model presented in the previous chapter displays characteristics which encourage future work, such as an increasing skill (increasing and positive HSS values) with predicting higher damage totals, some flaws in model developmental stages exist. One main factor which could not adequately be accounted for using the post-processing methods presented in Chapter One is post-processing multi-day storm-related damage. The methods of Chapter One state that damage may only be postprocessed if the day in question is followed by None storm mode days. However, several examples of significant multi-day events which were un-processed in the training dataset exist. 
The remnants of Hurricane Eduardo, which tracked up the eastern United States Coast 31 August 2006 to 2 September 2006 provide an example of a multi-day event which presented post processing issues. The gusty winds and heavy rainfall, which occurred in the PSE\&G service territories for several days, resulted in substantial damage (Table 2.23). The cumulative plant damage totals of 1257 elements for 2 September is the $3^{\text {rd }}$ highest daily total observed in the training dataset. The corresponding cumulative plant damage total observed on 3 September represented the $7^{\text {th }}$ highest total in the training dataset. A None storm mode was diagnosed widespread for 4 September, but reassigning this damage to 3 September (as per the method presented in Chapter One) did not seem to be rational given that the damage and meteorological observations from 3 September do not warrant such methods. The relatively high total observed damage for 5 September seems to indicate the associated observed damage is anomalously large and perhaps is left-over cleanup from the remnants of Ernesto due to the observed weak wind gusts and low precipitation totals.

While the remnants of Ernesto provide an extreme example of how multiple-day events are poorly post-processed using the current technique, several more examples can be found in the training dataset. A similar problem is present in the verification dataset from 26 July to 2 August 2009 when several severe thunderstorms impacted the PSE\&G territories with 22 reports of severe weather resulting in 948 cumulative plant elements damaged. While None storm mode days do exist between these Thunderstorm storm mode days, it is unlikely the current post-processing method fully accounts for such periods. To adequately describe storms which encompass multiple days, perhaps a future 
damage model attempt would redefine the post-processing to stratify the damage data not by day when adverse weather is present, but by event.

\section{MODEL IMPROVEMENTS}

Several improvements to the model were suggested in Chapter One and will be expanded in this section. Also, further improvements utilizing lessons learned from the additional case studies will be examined. Improvements will also be suggested to address the additional shortcomings of the model addressed previously in this chapter.

\section{a. Duration}

The case study of the 12-14 March 2010 Nor'easter and the investigation of the remnants of Hurricane Ernesto which impacted the PSE\&G territories from 1-2 September 2006 strongly suggest incorporating the duration of the wind and wind direction to account for strong, long duration easterly winds which appear to be quite destructive, especially in Palisades. The duration of the wind may be accounted for in several ways, but the two easiest seem to be either defining a binary predictor or creating a count predictor. The binary predictor for duration would act like switches, operating on the basis of 'on' if the winds are expected to be above a certain magnitude for a certain amount of time or 'off' if they will be below it (Wilks 2006). However a count predictor is suggested in order to follow the count data theme already existing. A count predictor for wind duration could be developed based on the number of hours the wind will be 
above a certain magnitude, as suggested by the None storm mode case studies. While the potential for such a variable seems promising based on previous case studies, obtaining accurate values for this predictor in a practical sense may prove difficult. However, ensemble forecasts, such as the Short Range Ensemble Forecast (SREF), or any other combination of NWP output can easily be processed to create probabilities of wind duration and magnitude, given the model output has sufficient timesteps, to aid in the decision making process for creating forecasts of a duration variable.

The Thunderstorm storm mode also has practical use for a duration predictor. The 29 July 2009 and 9 June 2009 case studies highlight the importance of the duration of frequent lightning events. While severe winds from thunderstorms are often discrete events, frequent lightning may last for several hours after the strongest winds and heaviest downpours have passed. In order to incorporate lightning data adequately into the model, cloud-to-ground strikes must first be segregated from any lightning dataset and these strikes must be sorted by geographical area using a mapping interface such as GIS to obtain strike density values for the PSE\&G service territories. As a substitute for the process of including lightning data, a duration element for the Thunderstorm storm mode may be developed. Conditions favorable for thunderstorm formation and sustenance have been known to exist in a post-thunderstorm environment. Forecasters routinely are able to predict the occurrence of multiple thunderstorms in a single day; therefore, the number of thunderstorms may be used as a predictor. More directly, hourly observations may be examined for the Thunderstorm storm mode to define the number of hours a station reported lightning. 


\section{b. New variables}

Through a discussion with PSE\&G officials familiar with plant damage data, it became apparent that non-meteorological predictors should be incorporated into the prediction of transformer failures (F. Schwartz 2010, personal communication). Transformers process the electrical load travelling through the wires and are subject to large stresses during times of large demand. For instance, during times of extreme heat or cold most homes and businesses continuously run their air conditioning unit or furnace, respectively, to moderate the indoor air on a large scale which produces a substantial demand for electricity. This demand stress can act alone to cause transformer failure, and when combined with adverse weather, transformer failure becomes more likely. Therefore, combining daily load profiles, which have been well researched, would result in more accurate forecasts of transformer damage. While most techniques used to predict load profiles involve neural networks, a simpler approach could be made to account for load profiles through stratification. Electricity demand is higher on weekdays than weekends, and is typically lower on most national holidays when most businesses are closed. Stratification to account for the day of the week and holiday versus non-holiday may act to improve model forecasts as in Ružić (2003) and Saini (2007).

Several of the new variables introduced in Chapter One provide necessary insight into the variance between the observed damage and surface observations. However, the tenday accumulated liquid equivalent precipitation $\left(\mathrm{LWE}_{10}\right)$ does not fully account for soil 
moisture. Thusly, it is suggested that future work with soil moisture variables utilize additional predictors such as fractional soil moisture at varying depths or recent precipitation anomalies presented in Han et al. (2009) and Liu et al. (2008). While these methods generally deal with modeling soil moisture in advance of landfalling hurricanes, this work could be extended and applied to soil-moisture related plant damage as a predictor of plant damage. Specifically, utilizing actual measurements of water content at various depths for use as potential predictors may add to the accuracy of the model, especially for the None, Warm, and Cold storm modes which rely heavily on $\mathrm{LWE}_{10}$ and $\mathrm{SF}_{2}$. Because such data would not need a correction for precipitation type, seasonal stratification for the None storm mode is made simpler.

\section{c. Rules of thumb}

The 16 July 2009 case study provided some insight into how a human forecaster may input data into the plant damage model and how utilizing multiple storm modes may elucidate the uncertainty for a particular day. Applying the lessons learned from the various case studies to create some general rules of thumb for forecasting will hopefully provide a useful guide for future users of the plant damage model developed above. The following is an overview of forecast application guidelines.

In general, a deterministic forecast must be accompanied by a standard error measure to effectively communicate uncertainty. However, using a range of expected values as predictors will naturally create an effective range of plant damage which accounts for 
uncertainty in the forecast. When entering the predictors into the model, one must closely examine the predictor coefficients to ensure an upper-bound and lower-bound are produced [i.e., the values which will maximize (minimize) the damage forecast are entered simultaneously to create a maximum (minimum) damage forecast]. For example, ranges of maximum temperature, maximum wind gust, and maximum precipitation should be entered as the predictors to produce a range of plant damage forecasts.

Since duration has been shown to be an important predictor omitted by the plant damage model, it is recommended that damage forecasts be adjusted to compensate using the following method. If a long-lasting storm is expected, the forecaster should reference the training dataset for clues about the potential damage outcome and make adjustments in an objective manner. The training dataset analogue should be thoroughly searched to find an event which most closely resembles the expected conditions in terms of $\mathrm{T}_{\max }$, $\mathrm{V}_{\max }, \mathrm{LWE}_{\mathrm{d}}$, and season. If a sufficient analogue cannot be found, then removing restrictors is recommended for high-end events. When considering the None storm mode, if maximum temperatures are expected to be greater than $86^{\circ} \mathrm{F}$, it is recommended the Heat storm mode be applied in addition to the None storm mode to investigate potential transformer damage trends. If the storm mode is anticipated to be None but a slight chance of showers or flurries exists, entering $0.01^{\prime \prime}$ as the value for $\mathrm{LWE}_{\mathrm{d}}$ may prove useful. This method may be extended to account for situations when maximum temperatures are expected to be well in excess of $90^{\circ} \mathrm{F}$ (high confidence Heat storm mode day) but isolated showers or weak thunderstorms are possible. 
For the Thunderstorm storm mode, several rules of thumb must be developed to handle the relatively large uncertainty inherent in prediction of such events. An upward adjustment of the plant damage forecast should be applied in the following circumstances:

1) When multiple storms are anticipated to strike the same territory.

2) When thunderstorms are expected to be contained in a large squall line.

3) When frequent lightning is expected to occur .

4) When lightning activity is anticipated to linger in the area.

While the upward adjustment will be subjective, an investigation of the training dataset may provide clues for the adjustment magnitude. In circumstances when conditions for thunderstorms are favorable but aerial coverage of thunderstorms is expected to be isolated, it is recommended that the maximum wind gust of the nonconvective wind be entered as $\mathrm{V}_{\max }$. This will simulate the conditions when a storm affects the area but is not directly observed at the station, which often occurred in the training dataset.

When severe thunderstorms are anticipated, the number of severe weather reports should be representative of both the confidence in severe weather occurring and potential magnitude of the event. The following values are recommended based on experience forecasting for severe thunderstorms in the PSE\&G area and intimate knowledge of the damage dataset: 
1) For low confidence of severe weather occurring and isolated storm coverage, a value of one severe thunderstorm report and a $\mathrm{V}_{\max }$ equal to the non-convective wind gust is recommended.

2) For moderate confidence of severe weather occurring with scattered storm coverage, a value of three severe thunderstorm reports and a Vmax between 35-55 mph (15.6-24.6 $\left.\mathrm{m} \mathrm{s}^{-1}\right)$ is recommended. The value for $\mathrm{V}_{\max }$ in this situation should approximately be the magnitude of the low level jet at the time of storm passage.

3) For high confidence of severe weather occurring and widespread storm coverage, a value of five severe thunderstorm reports is recommended. The value for $V_{\max }$ when confidence is high for widespread severe thunderstorms should be derived from a WINDEX calculation or chosen to be the maximum gust measured in the training dataset in an attempt to produce an upper bound on the damage forecast.

When forecasting an ice storm or an event where nontrivial amounts of freezing rain accretion are expected, the following is recommended:

1) When the maximum wind gust is expected to occur before any accretion takes place, subjectively decrease the plant damage forecast.

2) When ice accretion is expected and trees are not bare (e.g., leaves are present or trees are in bloom) subjectively increase the plant damage forecast. 
3) When greater than 1 " of ice accretion is expected but the maximum wind gust is expected to be relatively low, subjectively increase the plant damage forecast.

4) In situations where freezing rain is expected to change to rain, the timing of the maximum wind gust is thought to play a key role. If the maximum gust is expected to occur after substantial melting of ice, subjectively decrease the plant damage forecast.

Snow is only expected to be a significant contributor to plant damage if snow is permitted to accumulate on equipment. This is most likely to happen when

1) Winds are light while snow is accumulating.

2) The snowfall has a high density (e.g., wet snow).

When both factors combine, a subjective increase to plant damage forecasts is recommended. In situations when both factors exist and strong wind gusts are anticipated after a period of calm winds, removing the restrictor coefficients may produce a better forecast.

\section{CONCLUDING REMARKS}

The plant damage model presented herein provides encouraging results for use in an operational setting and for future research. The model $s_{e}, \sigma_{e}$, and $\sigma_{E}$ values provide an underestimate of the true variance due to a non-Gaussian distribution, non-independence, and heteroscedasticity in the training and verification datasets. Although these 
assumptions are often violated, human forecasters can account for them in order to produce a more accurate range of forecasted damage. Rules of thumb were presented to serve as a guide for operational forecasting applications, which generally act to compensate for model shortcomings such as a lack of lightning information, storm duration and wind direction in the model equations. The model was applied to an independent verification dataset and displayed skill (HSS > 0) in forecasting greater than 10, 20, and 30 total damaged elements for all territories and damage thresholds except 30 total damaged elements in Metropolitan. With the exception of Metropolitan, which has the most subterranean plant out of the four territories, skill seemed to increase as the damage threshold increased, providing very encouraging implications for using the model to identify extreme events. Based on the model skill and the ability of human forecasters to overcome model shortcomings to apply the forecasting guidelines discussed above, an electric utility receiving damage model forecasts presented by this thesis would likely be more adequately prepared for damaging storms. 


\section{TABLES}

TABLE 2.1. Equation coefficients and corresponding predictors. SVR is the number of severe weather reports in a territory.

\begin{tabular}{cc}
\hline \multicolumn{2}{c}{ Coefficients } \\
\hline $\mathrm{b}_{1}$ & $\mathrm{~T}_{\max }$ \\
$\mathrm{b}_{2}$ & $\mathrm{LWE}_{10}$ \\
$\mathrm{~b}_{3}$ & $\mathrm{LWE}_{\mathrm{d}}$ \\
$\mathrm{b}_{4}$ & $\mathrm{~V}_{\max }$ \\
$\mathrm{b}_{5}$ & $\mathrm{SF}_{1}$ \\
$\mathrm{~b}_{6}$ & $\mathrm{SF}_{2}$ \\
$\mathrm{~b}_{7}$ & $\mathrm{SF}_{3}$ \\
$\mathrm{~b}_{8}$ & $\mathrm{~T}_{3}$ \\
$\mathrm{~b}_{9}$ & $\mathrm{SVR}$ \\
\hline
\end{tabular}


TABLE 2.2. Overfitted Model coefficients. Values have been truncated to four decimal places for display purposes. The '- ' indicates the coefficient is not used in the equation.

\begin{tabular}{|c|c|c|c|c|c|c|c|c|c|c|}
\hline \multicolumn{11}{|c|}{ CENTRAL Thunderstorm Storm Mode } \\
\hline & $\mathrm{b}_{0}$ & $b_{1}$ & $\mathrm{~b}_{2}$ & $b_{3}$ & $b_{4}$ & $b_{5}$ & $b_{6}$ & $b_{7}$ & $\mathrm{~b}_{8}$ & $b_{9}$ \\
\hline TRAN & 6.6058 & -0.0938 & 0.1895 & -0.6512 & -0.4279 & 0.0553 & -0.0251 & 0.0064 & 0.0102 & 1.6365 \\
\hline POLE & -2.5723 & 0.0296 & 0.1992 & -1.5311 & 0.3375 & 0.0729 & -0.0138 & -0.0036 & 0.0036 & 0.9679 \\
\hline SVC & -6.9635 & 0.0786 & 0.2144 & -2.6055 & 0.3888 & 0.1369 & -0.0174 & -0.0037 & 0.0012 & 2.6513 \\
\hline SEC & -2.2103 & 0.0364 & -0.1631 & -1.0810 & 0.1122 & 0.0506 & 0.0095 & -0.0014 & -0.0020 & 0.5570 \\
\hline PRI & -6.5235 & 0.0881 & -0.2362 & -1.8126 & 0.2352 & 0.1242 & 0.0037 & -0.0030 & 0.0031 & 2.0719 \\
\hline TREE & -5.2021 & 0.0384 & 0.2786 & -2.2112 & 0.2507 & 0.1304 & -0.0158 & -0.0016 & 0.0078 & 2.3167 \\
\hline \multicolumn{11}{|c|}{ METROPOLITAN Thunderstorm Storm Mode } \\
\hline & $b_{0}$ & $b_{1}$ & $b_{2}$ & $\mathrm{~b}_{3}$ & $\mathrm{~b}_{4}$ & $b_{5}$ & $b_{6}$ & $\mathrm{~b}_{7}$ & $b_{8}$ & $b_{9}$ \\
\hline TRAN & 53.1119 & -0.9062 & -0.6649 & 6.5925 & -2.0786 & -0.2244 & 0.0308 & 0.0294 & 0.0484 & 2.4700 \\
\hline POLE & 57.8779 & -0.9101 & -0.6871 & 4.8453 & -2.1054 & -0.1743 & 0.0364 & 0.0293 & 0.0321 & 1.9761 \\
\hline svc & 202.2051 & -3.1137 & -3.4123 & 20.2920 & -7.7444 & -0.6762 & 0.1625 & 0.1078 & 0.0864 & 10.9683 \\
\hline SEC & 86.5930 & -1.3658 & -0.7343 & 7.0621 & -3.1571 & -0.2587 & 0.0415 & 0.0443 & 0.0471 & 2.5399 \\
\hline PRI & 93.3291 & -1.4935 & -1.8787 & 9.3095 & -3.5024 & -0.3374 & 0.0858 & 0.0480 & 0.0649 & 6.1476 \\
\hline TREE & 20.1907 & -0.4637 & 1.0629 & 1.4355 & -0.9809 & -0.0044 & -0.0443 & 0.0164 & 0.0356 & 1.6201 \\
\hline
\end{tabular}

\begin{tabular}{|c|c|c|c|c|c|c|c|c|c|c|}
\hline \multicolumn{11}{|c|}{ PALISADES Thunderstorm Storm Mode } \\
\hline & $b_{0}$ & $b_{1}$ & $b_{2}$ & $\mathrm{~b}_{3}$ & $\mathrm{~b}_{4}$ & $b_{5}$ & $b_{6}$ & $b_{7}$ & $b_{8}$ & $b_{9}$ \\
\hline TRAN & 60.5595 & -1.0625 & 1.5784 & -3.8303 & -2.8023 & 0.1756 & -0.0471 & 0.0404 & 0.0641 & 3.3418 \\
\hline POLE & 38.0359 & -0.5708 & 1.5681 & -2.9684 & -1.4545 & 0.1170 & -0.0606 & 0.0213 & 0.0063 & 1.6830 \\
\hline SVC & 279.1048 & -4.6125 & 8.3994 & -27.1499 & -11.5697 & 1.0913 & -0.3256 & 0.1664 & 0.1919 & 11.7752 \\
\hline SEC & 118.0548 & -1.7273 & 1.9006 & -8.7737 & -4.5401 & 0.3075 & -0.0591 & 0.0629 & 0.0285 & 2.6265 \\
\hline PRI & 61.3107 & -0.9901 & 2.3578 & -6.6071 & -2.6567 & 0.3025 & -0.0948 & 0.0376 & 0.0373 & 4.2526 \\
\hline TREE & 139.8248 & -2.1369 & 3.8382 & -4.2218 & -5.8054 & 0.1533 & -0.1393 & 0.0835 & 0.0364 & 4.7043 \\
\hline \multicolumn{11}{|c|}{ SOUTHERN Thunderstorm Storm Mode } \\
\hline & $b_{0}$ & $b_{1}$ & $b_{2}$ & $\mathrm{~b}_{3}$ & $\mathrm{~b}_{4}$ & $b_{5}$ & $b_{6}$ & $b_{7}$ & $b_{8}$ & $b_{9}$ \\
\hline TRAN & -4.6555 & 0.1712 & 1.2079 & -0.3195 & 0.1904 & 0.0624 & -0.0611 & 0.0011 & -0.0529 & 1.4722 \\
\hline POLE & -19.3629 & 0.3827 & 0.8376 & -6.0100 & 1.1249 & 0.2352 & -0.0366 & -0.0123 & -0.0522 & 1.1975 \\
\hline SVC & -28.3333 & 0.4737 & 3.3077 & -13.1934 & 1.5164 & 0.5269 & -0.1684 & -0.0106 & -0.0844 & 3.2080 \\
\hline SEC & -9.6063 & 0.1702 & 0.1416 & -2.6620 & 0.4656 & 0.1040 & 0.0091 & -0.0052 & -0.0213 & 0.6000 \\
\hline PRI & -29.8867 & 0.4680 & 0.5101 & -3.2011 & 1.4829 & 0.1792 & -0.0299 & -0.0164 & -0.0400 & 2.7905 \\
\hline TREE & -38.8775 & 0.6815 & 1.2534 & -9.5638 & 1.9449 & 0.4301 & -0.0625 & -0.0204 & -0.0870 & 2.4637 \\
\hline
\end{tabular}




\begin{tabular}{|c|c|c|c|c|c|c|c|c|c|c|}
\hline \multicolumn{11}{|c|}{ CENTRAL Warm Storm Mode } \\
\hline & $\mathrm{b}_{0}$ & $b_{1}$ & $\mathrm{~b}_{2}$ & $b_{3}$ & $\mathrm{~b}_{4}$ & $b_{5}$ & $b_{6}$ & $\mathrm{~b}_{7}$ & $\mathrm{~b}_{8}$ & $b_{9}$ \\
\hline TRAN & -2.5856 & 0.0505 & 0.4165 & -0.6615 & 0.1365 & 0.0593 & -0.0181 & -0.0012 & -0.0013 & -- \\
\hline POLE & -0.5949 & 0.0223 & -0.0750 & -1.7112 & 0.1331 & 0.0782 & 0.0095 & -0.0015 & -0.0003 & -- \\
\hline svc & 0.2834 & 0.0034 & -0.6072 & -8.3476 & 0.0184 & 0.4120 & 0.0435 & 0.0005 & -0.0002 & -- \\
\hline SEC & -0.0911 & -0.0051 & 0.1565 & -0.6685 & 0.0051 & 0.0360 & -0.0051 & 0.0004 & -0.0001 & -- \\
\hline PRI & 0.7034 & -0.0106 & -0.1088 & -1.9580 & -0.0392 & 0.1257 & 0.0062 & 0.0011 & -0.0004 & -- \\
\hline TREE & -1.1218 & 0.0179 & -0.3916 & -6.6978 & 0.0016 & 0.3443 & 0.0360 & 0.0013 & 0.0005 & -- \\
\hline
\end{tabular}

\begin{tabular}{|c|c|c|c|c|c|c|c|c|c|c|}
\hline \multicolumn{11}{|c|}{ METROPOLITAN Warm Storm Mode } \\
\hline & $\mathrm{b}_{0}$ & $b_{1}$ & $\mathrm{~b}_{2}$ & $\mathrm{~b}_{3}$ & $\mathrm{~b}_{4}$ & $\mathrm{~b}_{5}$ & $\mathrm{~b}_{6}$ & $\mathrm{~b}_{7}$ & $\mathrm{~b}_{8}$ & $\mathrm{~b}_{9}$ \\
\hline TRAN & -1.5843 & 0.0332 & -0.3210 & -2.6387 & 0.0752 & 0.0977 & 0.0140 & -0.0011 & -0.0023 & -- \\
\hline POLE & -1.7296 & 0.0379 & -0.2186 & -3.4763 & 0.0940 & 0.1240 & 0.0091 & -0.0010 & -0.0051 & -- \\
\hline SvC & -5.2561 & 0.0934 & -0.2448 & -15.3542 & 0.2343 & 0.5910 & 0.0089 & -0.0015 & -0.0166 & -- \\
\hline SEC & -1.1278 & 0.0104 & -0.2128 & -2.7246 & 0.0518 & 0.1004 & 0.0090 & -0.0003 & -0.0003 & -- \\
\hline PRI & -2.6623 & 0.0405 & -0.4095 & -5.6795 & 0.1240 & 0.2085 & 0.0159 & -0.0013 & -0.0026 & -- \\
\hline TREE & -4.4897 & -0.0006 & -0.4289 & -11.1976 & 0.1918 & 0.4248 & 0.0209 & -0.0008 & 0.0104 & -- \\
\hline
\end{tabular}

\begin{tabular}{|c|c|c|c|c|c|c|c|c|c|c|}
\hline \multicolumn{11}{|c|}{ PALISADES Warm Storm Mode } \\
\hline & $\mathrm{b}_{0}$ & $b_{1}$ & $\mathrm{~b}_{2}$ & $b_{3}$ & $\mathrm{~b}_{4}$ & $b_{5}$ & $b_{6}$ & $b_{7}$ & $b_{8}$ & $b_{9}$ \\
\hline TRAN & 7.1462 & -0.0669 & -0.9508 & -6.0521 & -0.2664 & 0.2678 & 0.0394 & 0.0031 & -0.0003 & -- \\
\hline POLE & 2.0878 & -0.0164 & -0.2782 & -9.2301 & -0.0382 & 0.3764 & 0.0132 & 0.0007 & -0.0008 & -- \\
\hline SVC & 7.4664 & -0.1069 & 0.0065 & -33.6694 & -0.3643 & 1.5904 & 0.0135 & 0.0044 & 0.0012 & -- \\
\hline SEC & 8.8300 & -0.0879 & -1.1184 & -11.4933 & -0.3983 & 0.4787 & 0.0535 & 0.0042 & -0.0007 & -- \\
\hline PRI & 12.5985 & -0.1305 & -1.4528 & -16.7269 & -0.5544 & 0.7009 & 0.0665 & 0.0064 & -0.0012 & -- \\
\hline TREE & 14.9414 & -0.1569 & -1.6331 & -20.3117 & -0.6866 & 0.8456 & 0.0779 & 0.0076 & -0.0008 & -- \\
\hline
\end{tabular}

SOUTHERN Warm Storm Mode

\begin{tabular}{ccccccccccc} 
& $\mathrm{b}_{0}$ & $\mathrm{~b}_{1}$ & $\mathrm{~b}_{2}$ & \multicolumn{1}{c}{$\mathrm{b}_{3}$} & $\mathrm{~b}_{4}$ & $\mathrm{~b}_{5}$ & $\mathrm{~b}_{6}$ & $\mathrm{~b}_{7}$ & $\mathrm{~b}_{8}$ & $\mathrm{~b}_{9}$ \\
\hline TRAN & -0.5970 & 0.0131 & -0.3889 & -2.1065 & 0.0126 & 0.1209 & 0.0185 & -0.0005 & 0.0074 & -- \\
POLE & -1.4211 & 0.0437 & -0.2485 & -1.0667 & 0.1092 & 0.0776 & 0.0099 & -0.0012 & -0.0039 & -- \\
SVC & -4.7643 & 0.0624 & -1.8760 & -11.3060 & 0.1761 & 0.4935 & 0.1124 & -0.0037 & 0.0155 & -- \\
SEC & -1.3732 & 0.0603 & -0.1356 & -3.5766 & 0.0616 & 0.1643 & 0.0122 & -0.0009 & -0.0125 & - \\
PRI & -2.3602 & 0.0496 & -0.9601 & -4.3689 & 0.0622 & 0.2369 & 0.0516 & -0.0013 & 0.0006 & -- \\
TREE & -3.6994 & -0.0331 & -2.1365 & -7.3533 & 0.1201 & 0.3216 & 0.1160 & -0.0029 & 0.0414 & -- \\
\hline
\end{tabular}




\begin{tabular}{cccccccccccc}
\hline \multicolumn{10}{c}{ CENTRAL Cold Storm Mode } \\
& b0 & b1 & b2 & b3 & b4 & b5 & b6 & b7 & b8 & b9 \\
\hline TRAN & -2.1778 & 0.0603 & -0.4939 & -5.0496 & 0.0314 & 0.2424 & 0.0114 & -0.0025 & 0.0245 & -- \\
POLE & -0.3871 & 0.0237 & -0.5767 & -1.7423 & 0.0203 & 0.1441 & 0.0228 & -0.0013 & 0.0153 & -- \\
SVC & -0.1406 & 0.0119 & -0.6240 & 1.9117 & 0.0273 & -0.1856 & 0.0335 & -0.0008 & 0.0055 & -- \\
SEC & 0.1014 & 0.0173 & -0.2509 & -1.3808 & 0.0029 & 0.0751 & 0.0100 & -0.0003 & -0.0030 & -- \\
PRI & 0.6396 & 0.0173 & -0.4511 & 0.3450 & -0.0237 & -0.0513 & 0.0160 & 0.0003 & -0.0040 & -- \\
TREE & 0.8012 & -0.0052 & -0.4861 & 1.5891 & -0.0502 & -0.1834 & 0.0461 & 0.0011 & -0.0009 & -- \\
\hline
\end{tabular}

METROPOLITAN Cold Storm Mode

\begin{tabular}{cccccccccccc} 
& \multicolumn{1}{c}{$\mathrm{b} 0$} & $\mathrm{~b} 1$ & $\mathrm{~b} 2$ & \multicolumn{1}{c}{$\mathrm{b} 3$} & \multicolumn{1}{c}{$\mathrm{b} 4$} & \multicolumn{1}{c}{$\mathrm{b} 5$} & $\mathrm{~b} 6$ & $\mathrm{~b} 7$ & $\mathrm{~b} 8$ & $\mathrm{~b} 9$ \\
\hline TRAN & -0.0171 & 0.0003 & 0.0709 & -0.0979 & -0.0054 & 0.0020 & -0.0029 & 0.0002 & -0.0002 & -- \\
POLE & -5.1750 & 0.1085 & 0.3947 & 8.1386 & 0.1598 & -0.2114 & -0.0079 & -0.0038 & 0.0051 & -- \\
SVC & -43.2423 & 0.7424 & -1.8255 & 65.9832 & 1.4139 & -1.7392 & 0.0534 & -0.0346 & 0.1012 & -- \\
SEC & -2.6947 & 0.0463 & -0.1008 & 4.5952 & 0.0875 & -0.1213 & 0.0030 & -0.0021 & 0.0059 & -- & - \\
PRI & -4.0529 & 0.0679 & -0.0855 & 6.0737 & 0.1321 & -0.1560 & 0.0015 & -0.0031 & 0.0091 & -- \\
TREE & -19.9628 & 0.3390 & 0.0255 & 53.5763 & 0.6230 & -1.4110 & -0.0024 & -0.0136 & 0.0271 & -- \\
\hline
\end{tabular}

PALISADES Cold Storm Mode

\begin{tabular}{ccccccccccc} 
& $\mathrm{b} 0$ & $\mathrm{~b} 1$ & $\mathrm{~b} 2$ & $\mathrm{~b} 3$ & $\mathrm{~b} 4$ & $\mathrm{~b} 5$ & $\mathrm{~b} 6$ & $\mathrm{~b} 7$ & $\mathrm{~b} 8$ & b9 \\
\hline TRAN & -0.2341 & 0.0447 & -1.2624 & 0.4003 & 0.0105 & -0.0250 & 0.0450 & -0.0018 & 0.0053 & -- \\
POLE & 2.7435 & -0.1245 & -0.3400 & 2.8724 & -0.1697 & -0.0830 & 0.0083 & 0.0044 & 0.0269 & -- \\
SVC & -0.5416 & 0.0171 & -0.3908 & 1.0569 & 0.0238 & -0.0465 & 0.0208 & -0.0016 & 0.0080 & -- \\
SEC & 0.4200 & 0.0048 & -0.5896 & 0.1351 & -0.0244 & -0.0102 & 0.0219 & 0.0002 & 0.0002 & -- \\
PRI & 0.8827 & -0.0131 & -0.2108 & 0.2983 & -0.0266 & 0.0029 & 0.0058 & 0.0008 & -0.0015 & -- \\
TREE & -0.0907 & 0.0012 & 0.0190 & -0.0038 & 0.0007 & 0.0008 & -0.0009 & 0.0000 & 0.0004 & -- \\
\hline
\end{tabular}

\section{SOUTHERN Cold Storm Mode}

\begin{tabular}{crrrrrrrrrr} 
& \multicolumn{1}{c}{$\mathrm{b} 0$} & $\mathrm{~b} 1$ & $\mathrm{~b} 2$ & \multicolumn{1}{c}{$\mathrm{b} 3$} & $\mathrm{~b} 4$ & $\mathrm{~b} 5$ & \multicolumn{1}{c}{$\mathrm{b} 6$} & $\mathrm{~b} 7$ & $\mathrm{~b} 8$ & $\mathrm{~b} 9$ \\
\hline TRAN & -1.3718 & 0.0456 & 0.3026 & -0.9630 & 0.1041 & 0.0452 & -0.0150 & -0.0016 & -0.0045 & -- \\
POLE & 2.9842 & -0.0733 & -0.8918 & 1.5502 & -0.0568 & 0.0132 & 0.0304 & 0.0023 & 0.0089 & -- \\
SVC & -18.1689 & 0.2664 & 4.8361 & -25.0184 & 0.7709 & 1.0156 & -0.2385 & -0.0109 & 0.0210 & -- \\
SEC & -12.5603 & 0.2531 & 0.6838 & -9.5508 & 0.5408 & 0.4399 & -0.0350 & -0.0123 & 0.0170 & -- \\
PRI & -6.5073 & 0.0957 & 1.1770 & -2.5427 & 0.2826 & 0.1773 & -0.0567 & -0.0049 & 0.0123 & -- \\
TREE & -6.0042 & 0.0207 & 2.4089 & -6.7800 & 0.2478 & 0.3244 & -0.1253 & -0.0011 & 0.0158 & -- \\
\hline
\end{tabular}




\begin{tabular}{ccccccccccc}
\hline \multicolumn{10}{c}{ CENTRAL Mix Storm Mode } \\
& $\mathrm{b}_{0}$ & $\mathrm{~b}_{1}$ & $\mathrm{~b}_{2}$ & $\mathrm{~b}_{3}$ & $\mathrm{~b}_{4}$ & $\mathrm{~b}_{5}$ & $\mathrm{~b}_{6}$ & $\mathrm{~b}_{7}$ & $\mathrm{~b}_{8}$ & $\mathrm{~b}_{9}$ \\
\hline TRAN & 10.5234 & -0.2319 & 0.0381 & -5.6748 & -0.4995 & 0.2785 & 0.0098 & 0.0114 & 0.0005 & -- \\
POLE & 13.3498 & -0.3276 & 0.4239 & -3.4614 & -0.6595 & 0.1894 & -0.0018 & 0.0166 & 0.0000 & -- \\
SVC & 19.3127 & -0.3276 & -0.3182 & -19.6005 & -0.7863 & 1.0179 & -0.0009 & 0.0140 & -0.0009 & -- \\
SEC & 3.2692 & -0.0814 & 0.1830 & -1.0715 & -0.1187 & 0.0612 & -0.0009 & 0.0032 & -0.0006 & -- \\
PRI & 8.0981 & -0.1576 & 0.0111 & -7.2625 & -0.3984 & 0.4060 & -0.0010 & 0.0078 & -0.0003 & -- \\
TREE & 39.8127 & -0.7841 & 0.7599 & -40.1781 & -1.5476 & 1.9620 & -0.0737 & 0.0313 & -0.0017 & -- \\
\hline
\end{tabular}

\section{METROPOLITAN Mix Storm Mode}

\begin{tabular}{ccccccccccc} 
& $\mathrm{b}_{0}$ & $\mathrm{~b}_{1}$ & $\mathrm{~b}_{2}$ & $\mathrm{~b}_{3}$ & $\mathrm{~b}_{4}$ & $\mathrm{~b}_{5}$ & $\mathrm{~b}_{6}$ & $\mathrm{~b}_{7}$ & $\mathrm{~b}_{8}$ & $\mathrm{~b}_{9}$ \\
\hline TRAN & 34.6388 & -0.8903 & -3.2115 & 6.7080 & -1.2592 & -0.2142 & 0.0920 & 0.0296 & 0.0224 & -- \\
POLE & 207.4523 & -5.3089 & -20.1775 & 38.7585 & -7.5599 & -1.2092 & 0.6003 & 0.1756 & 0.1400 & -- \\
SVC & 38.9995 & -1.0058 & -3.7585 & 8.5435 & -1.4137 & -0.2767 & 0.1106 & 0.0331 & 0.0265 & -- \\
SEC & 51.3696 & -1.3424 & -4.7646 & 12.4561 & -1.8611 & -0.4164 & 0.1384 & 0.0441 & 0.0365 & -- \\
PRI & 119.3226 & -3.0187 & -11.6800 & 17.4597 & -4.3754 & -0.5059 & 0.3516 & 0.1005 & 0.0780 & -- \\
TREE & 476.6769 & -12.2120 & -46.2061 & 88.5964 & -17.3732 & -2.7660 & 1.3716 & 0.4039 & 0.3239 & -- \\
\hline
\end{tabular}

\section{PALISADES Mix Storm Mode}

\begin{tabular}{cccccccccccc} 
& $\mathrm{b}_{0}$ & $\mathrm{~b}_{1}$ & $\mathrm{~b}_{2}$ & $\mathrm{~b}_{3}$ & $\mathrm{~b}_{4}$ & $\mathrm{~b}_{5}$ & $\mathrm{~b}_{6}$ & $\mathrm{~b}_{7}$ & $\mathrm{~b}_{8}$ & $\mathrm{~b}_{9}$ \\
\hline TRAN & 4.2630 & -0.0226 & -1.3318 & -0.8709 & -0.1299 & 0.0154 & 0.0531 & 0.0015 & -0.0008 & -- \\
POLE & 0.4418 & -0.0027 & -0.7536 & 3.0984 & 0.0086 & -0.0988 & 0.0193 & 0.0002 & 0.0005 & -- \\
SVC & 0.3155 & -0.0150 & -0.0281 & 0.4070 & 0.0156 & -0.0179 & 0.0011 & 0.0005 & -0.0002 & -- \\
SEC & 0.6338 & -0.0095 & -0.0289 & -0.2106 & -0.0139 & 0.0018 & 0.0015 & 0.0002 & 0.0001 & -- \\
PRI & 3.5981 & -0.0442 & -1.3626 & 0.1374 & -0.1338 & -0.0065 & 0.0505 & 0.0019 & 0.0003 & -- \\
TREE & 0.1201 & 0.0009 & -0.3890 & 0.0184 & -0.0440 & -0.0008 & 0.0185 & 0.0007 & 0.0004 & -- \\
\hline
\end{tabular}

\section{SOUTHERN Mix Storm Mode}

\begin{tabular}{ccccccccccc} 
& $\mathrm{b}_{0}$ & $\mathrm{~b}_{1}$ & $\mathrm{~b}_{2}$ & $\mathrm{~b}_{3}$ & $\mathrm{~b}_{4}$ & $\mathrm{~b}_{5}$ & $\mathrm{~b}_{6}$ & $\mathrm{~b}_{7}$ & $\mathrm{~b}_{8}$ & $\mathrm{~b}_{9}$ \\
\hline TRAN & -1.0954 & -0.0280 & 1.4963 & 3.9445 & 0.0799 & -0.1167 & -0.0459 & 0.0009 & 0.0009 & -- \\
POLE & -0.7859 & -0.1210 & 1.7197 & 0.7893 & 0.0755 & 0.0251 & -0.0646 & 0.0011 & 0.0335 & -- \\
SVC & -14.0325 & 0.2933 & 1.8204 & -13.5226 & 0.5833 & 0.6499 & -0.0789 & -0.0160 & 0.0337 & -- \\
SEC & -1.1172 & 0.0406 & 0.1847 & -1.0963 & 0.0190 & 0.0574 & -0.0083 & -0.0005 & -0.0038 & -- \\
PRI & -1.9451 & 0.0842 & 0.7177 & -5.3871 & 0.1974 & 0.2460 & -0.0407 & -0.0040 & -0.0100 & -- \\
TREE & -3.6923 & 0.0586 & 1.1609 & -5.4018 & 0.1362 & 0.2659 & -0.0420 & -0.0042 & 0.0181 & -- \\
\hline
\end{tabular}




\begin{tabular}{ccccccccccc}
\hline \multicolumn{10}{c}{ CENTRAL Heat Storm Mode } \\
& \multicolumn{1}{c}{$\mathrm{b}_{0}$} & $\mathrm{~b}_{1}$ & $\mathrm{~b}_{2}$ & \multicolumn{1}{c}{$\mathrm{b}_{3}$} & $\mathrm{~b}_{4}$ & $\mathrm{~b}_{5}$ & $\mathrm{~b}_{6}$ & $\mathrm{~b}_{7}$ & $\mathrm{~b}_{8}$ & $\mathrm{~b}_{9}$ \\
\hline TRAN & -221.2898 & 2.3928 & 3.0945 & 471.0767 & 6.5454 & -28.4287 & -0.0950 & -0.0675 & -0.0068 & -- \\
POLE & -3.0878 & 0.0389 & 1.1356 & -187.4568 & 0.2752 & 14.3130 & -0.0576 & -0.0024 & -0.0024 & -- \\
SVC & -2.3074 & 0.0358 & 0.3790 & -140.9134 & -0.4754 & 11.1294 & -0.0156 & 0.0052 & -0.0008 & -- \\
SEC & -25.8764 & 0.2864 & -0.0114 & 200.4169 & 1.4403 & -10.1709 & 0.0051 & -0.0157 & -0.0009 & -- \\
PRI & -13.6921 & 0.1522 & 0.5503 & -13.1802 & 0.7474 & -0.0807 & -0.0288 & -0.0079 & -0.0007 & -- \\
TREE & 21.3896 & -0.2080 & 1.4454 & -277.3864 & -1.5914 & 17.4455 & -0.0741 & 0.0167 & -0.0014 & -- \\
\hline
\end{tabular}

\begin{tabular}{|c|c|c|c|c|c|c|c|c|c|c|}
\hline \multicolumn{11}{|c|}{ METROPOLITAN Heat Storm Mode } \\
\hline & $b_{0}$ & $b_{1}$ & $b_{2}$ & $b_{3}$ & $\mathrm{~b}_{4}$ & $b_{5}$ & $b_{6}$ & $b_{7}$ & $\mathrm{~b}_{8}$ & $b_{9}$ \\
\hline TRAN & -9.4866 & 0.1131 & 0.2896 & 205.2361 & -0.4119 & -9.9717 & -0.0146 & 0.0047 & -0.0044 & -- \\
\hline POLE & -3.4860 & 0.0420 & -0.0787 & -7.8936 & -0.0699 & -0.0102 & 0.0036 & 0.0006 & 0.0001 & -- \\
\hline svc & 1.2764 & -0.0395 & 0.1411 & -180.8901 & -0.8565 & 8.4190 & -0.0040 & 0.0094 & 0.0086 & -- \\
\hline SEC & -9.2439 & 0.0889 & 0.1597 & 14.9618 & 0.2887 & -0.7498 & -0.0063 & -0.0030 & 0.0033 & -- \\
\hline PRI & -7.4803 & 0.0778 & 0.0415 & 41.1075 & 0.2333 & -1.8748 & -0.0016 & -0.0024 & 0.0000 & -- \\
\hline TREE & 1.8886 & -0.0508 & 0.4671 & 127.2216 & -0.6278 & -5.3042 & -0.0216 & 0.0072 & 0.0076 & -- \\
\hline
\end{tabular}

PALISADES Heat Storm Mode

\begin{tabular}{crccrrrrrrr} 
& \multicolumn{1}{c}{$\mathrm{b}_{0}$} & $\mathrm{~b}_{1}$ & \multicolumn{1}{c}{$\mathrm{b}_{2}$} & \multicolumn{1}{c}{$\mathrm{b}_{3}$} & \multicolumn{1}{c}{$\mathrm{b}_{4}$} & \multicolumn{1}{c}{$\mathrm{b}_{5}$} & \multicolumn{1}{c}{$\mathrm{b}_{6}$} & \multicolumn{1}{c}{$\mathrm{b}_{7}$} & $\mathrm{~b}_{8}$ & $\mathrm{~b}_{9}$ \\
\hline TRAN & -89.3319 & 0.7264 & -0.4591 & -850.1683 & 0.1814 & 31.1590 & 0.0242 & -0.0037 & 0.1070 & -- \\
POLE & 2.8232 & 0.0439 & -0.1272 & -58.1308 & -0.0157 & 1.5531 & 0.0105 & -0.0003 & -0.0197 & -- \\
SVC & -24.2135 & 0.0894 & 0.4374 & -231.8984 & 0.0272 & 7.5826 & -0.0168 & 0.0000 & 0.0604 & -- \\
SEC & -3.3436 & 0.0212 & -0.0404 & 25.2796 & -0.0052 & -0.9920 & 0.0027 & 0.0000 & 0.0055 & -- \\
PRI & -4.2456 & 0.0681 & -0.1626 & -221.8845 & 0.0276 & 9.0169 & 0.0079 & -0.0005 & -0.0043 & -- \\
TREE & -0.3564 & -0.0043 & 0.0085 & -243.6249 & -0.0060 & 11.6026 & -0.0002 & -0.0001 & 0.0046 & -- \\
\hline
\end{tabular}

\section{SOUTHERN Heat Storm Mode}

\begin{tabular}{crccccccccc} 
& \multicolumn{1}{c}{$\mathrm{b}_{0}$} & $\mathrm{~b}_{1}$ & $\mathrm{~b}_{2}$ & $\mathrm{~b}_{3}$ & \multicolumn{1}{c}{$\mathrm{b}_{4}$} & $\mathrm{~b}_{5}$ & $\mathrm{~b}_{6}$ & $\mathrm{~b}_{7}$ & $\mathrm{~b}_{8}$ & $\mathrm{~b}_{9}$ \\
\hline TRAN & -99.8218 & 1.2424 & 1.3074 & 3578.9168 & 1.7773 & -213.5209 & -0.0479 & -0.0207 & -0.0374 & -- \\
POLE & -67.9842 & 0.7269 & 0.3674 & 1016.9446 & 3.6927 & -66.6227 & -0.0095 & -0.0406 & 0.0111 & -- \\
SVC & 4.9353 & 0.0641 & 1.1542 & -6693.4276 & -0.7773 & 409.8694 & -0.0568 & 0.0086 & -0.0382 & -- \\
SEC & -19.1867 & 0.1849 & 0.0513 & 1745.2769 & 1.2328 & -104.6510 & -0.0007 & -0.0133 & 0.0082 & -- \\
PRI & -69.8556 & 0.7810 & -0.3550 & 1928.8379 & 3.1059 & -96.9528 & 0.0231 & -0.0340 & -0.0036 & -- \\
TREE & -51.0976 & 0.5978 & 0.5796 & 1512.3367 & 2.0960 & -80.1960 & -0.0334 & -0.0220 & -0.0155 & -- \\
\hline
\end{tabular}




\begin{tabular}{|c|c|c|c|c|c|c|c|c|c|c|}
\hline \multicolumn{11}{|c|}{ CENTRAL None Storm Mode } \\
\hline & $b_{0}$ & $b_{1}$ & $b_{2}$ & $b_{3}$ & $\mathrm{~b}_{4}$ & $b_{5}$ & $b_{6}$ & $b_{7}$ & $\mathrm{~b}_{8}$ & $b_{9}$ \\
\hline TRAN & -0.1655 & 0.0283 & -0.1558 & -10.8833 & 0.0316 & -0.3288 & 0.0135 & -0.0008 & 0.0000 & -- \\
\hline POLE & 1.5036 & -0.0034 & -0.1240 & 37.9880 & -0.0004 & -0.8820 & 0.0117 & -0.0001 & -0.0003 & -- \\
\hline SVC & -0.8891 & 0.0256 & -0.2961 & 75.7633 & 0.0664 & -3.8690 & 0.0255 & -0.0009 & -0.0008 & -- \\
\hline SEC & -0.1167 & 0.0087 & -0.1856 & 7.3764 & 0.0113 & -0.3891 & 0.0118 & -0.0004 & -0.0001 & -- \\
\hline PRI & -0.3418 & 0.0105 & -0.2624 & 15.8961 & 0.0149 & -0.8066 & 0.0176 & -0.0003 & -0.0001 & -- \\
\hline TREE & -2.4960 & 0.0563 & -0.7448 & 87.0851 & 0.1021 & -5.0431 & 0.0535 & -0.0019 & 0.0010 & -- \\
\hline
\end{tabular}

\begin{tabular}{|c|c|c|c|c|c|c|c|c|c|c|}
\hline \multicolumn{11}{|c|}{ METROPOLITAN None Storm Mode } \\
\hline & $\mathrm{b}_{0}$ & $b_{1}$ & $b_{2}$ & $\mathrm{~b}_{3}$ & $b_{4}$ & $b_{5}$ & $b_{6}$ & $b_{7}$ & $\mathrm{~b}_{8}$ & $b_{9}$ \\
\hline TRAN & -1.2598 & 0.0713 & -0.1873 & 7.6622 & 0.0465 & -0.8981 & 0.0060 & -0.0008 & -0.0150 & -- \\
\hline POLE & -1.3247 & -0.0118 & -0.2028 & 52.8892 & 0.0384 & -2.6821 & 0.0085 & -0.0004 & 0.0106 & -- \\
\hline SVC & -4.5925 & -0.0503 & -1.0461 & 169.4507 & 0.1127 & -8.7875 & 0.0470 & -0.0014 & 0.0410 & -- \\
\hline SEC & -1.4230 & -0.0166 & -0.2378 & 25.3237 & 0.0320 & -1.6316 & 0.0102 & -0.0004 & 0.0133 & -- \\
\hline PRI & -1.8270 & -0.0289 & -0.2509 & 40.3744 & 0.0412 & -2.4596 & 0.0099 & -0.0004 & 0.0188 & -- \\
\hline TREE & -3.6229 & -0.0857 & -1.6642 & 119.3530 & 0.0419 & -6.5647 & 0.0718 & -0.0009 & 0.0537 & -- \\
\hline
\end{tabular}

\begin{tabular}{|c|c|c|c|c|c|c|c|c|c|c|}
\hline \multicolumn{11}{|c|}{ PALISADES None Storm Mode } \\
\hline & $b_{0}$ & $b_{1}$ & $b_{2}$ & $b_{3}$ & $b_{4}$ & $b_{5}$ & $b_{6}$ & $b_{7}$ & $b_{8}$ & $b_{9}$ \\
\hline TRAN & 0.0306 & -0.0049 & 0.1288 & -21.5033 & -0.0081 & 0.5944 & 0.0003 & 0.0004 & 0.0039 & -- \\
\hline POLE & 0.3144 & 0.0132 & -0.0535 & -3.8325 & 0.0052 & 0.4676 & 0.0034 & 0.0001 & -0.0038 & -- \\
\hline svc & -0.3607 & -0.0043 & -0.1887 & 56.3405 & 0.0203 & -2.2083 & 0.0091 & -0.0001 & 0.0039 & -- \\
\hline SEC & -0.0650 & -0.0014 & -0.0337 & 12.5931 & 0.0031 & -0.5552 & 0.0020 & 0.0000 & 0.0008 & -- \\
\hline PRI & -0.1132 & -0.0016 & -0.1779 & 28.6227 & 0.0048 & -1.3893 & 0.0084 & -0.0001 & 0.0016 & -- \\
\hline TREE & -0.5106 & 0.0042 & -0.6058 & 74.7094 & 0.0134 & -3.3416 & 0.0293 & -0.0003 & 0.0027 & -- \\
\hline
\end{tabular}

\begin{tabular}{|c|c|c|c|c|c|c|c|c|c|c|}
\hline \multicolumn{11}{|c|}{ SOUTHERN None Storm Mode } \\
\hline & $\mathrm{b}_{0}$ & $b_{1}$ & $\mathrm{~b}_{2}$ & $b_{3}$ & $b_{4}$ & $b_{5}$ & $b_{6}$ & $b_{7}$ & $b_{8}$ & $b_{9}$ \\
\hline TRAN & -0.2520 & 0.0228 & -0.1356 & -72.7184 & 0.0120 & 4.1214 & 0.0100 & -0.0003 & 0.0002 & -- \\
\hline POLE & 0.6541 & -0.0014 & -0.1012 & -44.0109 & 0.0240 & 2.9115 & 0.0080 & 0.0000 & 0.0006 & -- \\
\hline SVC & -0.4127 & 0.0242 & -0.3208 & -63.4590 & 0.0438 & 4.4951 & 0.0230 & -0.0008 & -0.0010 & -- \\
\hline SEC & -0.0690 & 0.0027 & -0.1250 & -68.4733 & 0.0009 & 3.5668 & 0.0081 & -0.0001 & 0.0003 & -- \\
\hline PRI & -0.0948 & 0.0118 & -0.2553 & -147.2550 & -0.0088 & 7.8961 & 0.0162 & 0.0002 & -0.0024 & -- \\
\hline TREE & 0.0172 & 0.0179 & -0.3751 & -144.7441 & -0.0173 & 7.9592 & 0.0230 & 0.0003 & -0.0022 & -- \\
\hline
\end{tabular}


TABLE 2.3. Backwards Eliminated Model coefficients. Values have been truncated to four decimal places for display purposes.

\begin{tabular}{|c|c|c|c|c|c|c|c|c|c|c|}
\hline \multicolumn{11}{|c|}{ CENTRAL Thunderstorm Storm Mode } \\
\hline & $\mathrm{b}_{0}$ & $b_{1}$ & $b_{2}$ & $\mathrm{~b}_{3}$ & $\mathrm{~b}_{4}$ & $\mathrm{~b}_{5}$ & $b_{6}$ & $b_{7}$ & $b_{8}$ & $b_{9}$ \\
\hline TRAN & 4.8900 & -0.0718 & -- & -1.7918 & -0.3659 & 0.1071 & -0.0160 & 0.0058 & 0.0091 & 2.3927 \\
\hline POLE & -10.1874 & 0.1378 & -- & -4.4476 & 0.7544 & 0.2036 & -- & -0.0090 & -- & 1.7220 \\
\hline Svc & -19.9728 & 0.2501 & -- & -8.5885 & 1.0265 & 0.4068 & -- & -0.0120 & -- & 3.9982 \\
\hline SEC & 5.6927 & -0.0550 & -- & -1.6946 & -0.3955 & 0.1051 & -0.0159 & 0.0062 & -- & 2.3788 \\
\hline PRI & -14.2579 & 0.1926 & -- & -4.7467 & 0.6177 & 0.2641 & -- & -0.0080 & -- & 2.6637 \\
\hline TREE & -17.9514 & 0.2250 & -- & -8.9012 & 0.9001 & 0.4349 & -- & -0.0100 & -- & 4.0509 \\
\hline \multicolumn{11}{|c|}{ METROPOLITAN Thunderstorm Storm Mode } \\
\hline & $\mathrm{b}_{0}$ & $b_{1}$ & $b_{2}$ & $\mathrm{~b}_{3}$ & $\mathrm{~b}_{4}$ & $b_{5}$ & $b_{6}$ & $b_{7}$ & $\mathrm{~b}_{8}$ & $b_{9}$ \\
\hline TRAN & 51.5818 & -0.9140 & -- & 6.4437 & -2.0108 & -0.2200 & -- & 0.0291 & 0.0536 & 2.4381 \\
\hline POLE & 60.1259 & -0.8489 & -- & 4.4710 & -2.1140 & -0.1589 & -- & 0.0299 & -- & 1.9103 \\
\hline SVC & 205.6693 & -2.9438 & -- & 18.8859 & -7.6501 & -0.6218 & -- & 0.1089 & -- & 10.7135 \\
\hline SEC & 90.3195 & -1.2770 & -- & 6.5849 & -3.1912 & -0.2385 & -- & 0.0451 & -- & 2.4577 \\
\hline PRI & 96.8607 & -1.3674 & -- & 8.4476 & -3.4971 & -0.3030 & -- & 0.0491 & -- & 5.9969 \\
\hline TREE & 231.7411 & -3.2633 & -- & 19.3146 & -8.5356 & -0.6825 & -- & 0.1192 & -- & 15.8924 \\
\hline
\end{tabular}

\begin{tabular}{|c|c|c|c|c|c|c|c|c|c|c|}
\hline \multicolumn{11}{|c|}{ PALISADES Thunderstorm Storm Mode } \\
\hline & $b_{0}$ & $b_{1}$ & $\mathrm{~b}_{2}$ & $b_{3}$ & $b_{4}$ & $b_{5}$ & $b_{6}$ & $b_{7}$ & $b_{8}$ & $b_{9}$ \\
\hline TRAN & 51.5663 & -0.8075 & 2.5698 & -- & -2.3680 & 0.0492 & -0.0917 & 0.0369 & -- & 3.2795 \\
\hline POLE & 37.0881 & -0.5448 & 1.7098 & -2.8958 & -1.4011 & 0.1156 & -0.0672 & 0.0209 & -- & 1.6706 \\
\hline SVC & 226.1969 & -3.5905 & 15.0483 & -25.3067 & -8.8957 & 1.0565 & -0.6242 & 0.1422 & -- & 11.2292 \\
\hline SEC & 97.1534 & -1.4559 & 4.1985 & -8.4126 & -3.5581 & 0.2999 & -0.1627 & 0.0539 & -- & 2.4895 \\
\hline PRI & 50.9211 & -0.7904 & 3.6490 & -6.2526 & -2.1328 & 0.2958 & -0.1525 & 0.0329 & -- & 4.1444 \\
\hline TREE & 126.5938 & -1.9231 & 4.9550 & 0.0000 & -5.2179 & -- & -0.1888 & 0.0786 & -- & 4.6866 \\
\hline \multicolumn{11}{|c|}{ SOUTHERN Thunderstorm Storm Mode } \\
\hline & $b_{0}$ & $b_{1}$ & $\mathrm{~b}_{2}$ & $b_{3}$ & $b_{4}$ & $b_{5}$ & $b_{6}$ & $b_{7}$ & $b_{8}$ & $b_{9}$ \\
\hline TRAN & -5.8626 & 0.1999 & 0.1968 & -- & 0.0539 & -- & -- & -- & -0.0507 & 1.3770 \\
\hline POLE & -18.4531 & 0.3859 & -- & -5.8080 & 1.0734 & 0.2300 & -- & -0.0122 & -0.0525 & 1.1398 \\
\hline SVC & -6.5892 & -- & -- & -15.3404 & 0.4725 & 0.5960 & -- & -- & -- & 2.6798 \\
\hline SEC & -10.8217 & 0.1242 & -- & -2.8767 & 0.4909 & 0.1090 & 0.0150 & -0.0055 & -- & 0.5963 \\
\hline PRI & -36.6321 & 0.4239 & -- & -- & 1.6725 & 0.0794 & -- & -0.0186 & -- & 2.8000 \\
\hline TREE & -37.3025 & 0.6805 & -- & -9.3001 & 1.8404 & 0.4242 & -- & -0.0201 & -0.0865 & 2.3396 \\
\hline
\end{tabular}




\begin{tabular}{ccccccccccc}
\hline \multicolumn{10}{c}{ CENTRAL Warm Storm Mode } \\
& $\mathrm{b}_{0}$ & $\mathrm{~b}_{1}$ & $\mathrm{~b}_{2}$ & $\mathrm{~b}_{3}$ & $\mathrm{~b}_{4}$ & $\mathrm{~b}_{5}$ & $\mathrm{~b}_{6}$ & $\mathrm{~b}_{7}$ & $\mathrm{~b}_{8}$ & $\mathrm{~b}_{9}$ \\
\hline TRAN & -2.7719 & 0.0460 & 0.4181 & -- & 0.1415 & 0.0337 & -0.0181 & -0.0012 & -- & -- \\
POLE & 0.5560 & -- & -- & -1.6655 & 0.0487 & 0.0762 & 0.0063 & -- & -- & -- \\
SVC & 1.4761 & -- & -0.8824 & -8.9229 & -- & 0.4376 & 0.0575 & -- & -- & -- \\
SEC & 0.0101 & -0.0068 & 0.1537 & -0.6745 & -- & 0.0363 & -0.0049 & 0.0005 & -- & -- \\
PRI & -0.1787 & -- & -- & -2.0029 & 0.1278 & 0.0006 & 0.0000 & -- & -- & -- \\
TREE & -1.4119 & -0.0771 & -- & -7.2468 & -- & 0.3649 & 0.0192 & 0.0018 & -- & -- \\
\hline
\end{tabular}

\section{METROPOLITAN Warm Storm Mode}

\begin{tabular}{ccccccccccc} 
& $\mathrm{b}_{0}$ & $\mathrm{~b}_{1}$ & $\mathrm{~b}_{2}$ & $\mathrm{~b}_{3}$ & $\mathrm{~b}_{4}$ & $\mathrm{~b}_{5}$ & $\mathrm{~b}_{6}$ & $\mathrm{~b}_{7}$ & $\mathrm{~b}_{8}$ & $\mathrm{~b}_{9}$ \\
\hline TRAN & -1.5937 & 0.0259 & -0.3206 & -2.6612 & 0.0752 & 0.0983 & 0.0140 & -0.0011 & -- & -- \\
POLE & -1.7368 & 0.0217 & -0.2166 & -3.5279 & 0.0931 & 0.1253 & 0.0091 & -0.0010 & -- & -- \\
SVC & -2.9946 & -- & -- & -15.5775 & 0.1580 & 0.5972 & -- & -- & -- & -- \\
SEC & -0.5470 & -- & -0.1977 & -2.7394 & 0.0312 & 0.1010 & 0.0086 & -- & -- & -- \\
PRI & -0.6763 & -- & -0.3694 & -5.7457 & 0.0439 & 0.2109 & 0.0146 & -- & -- & -- \\
TREE & -2.9703 & -- & -- & -11.1794 & 0.1611 & 0.4252 & -- & -- & -- & -- \\
\hline
\end{tabular}

\section{PALISADES Warm Storm Mode}

\begin{tabular}{ccccccccccc} 
& $\mathrm{b}_{0}$ & $\mathrm{~b}_{1}$ & $\mathrm{~b}_{2}$ & $\mathrm{~b}_{3}$ & $\mathrm{~b}_{4}$ & $\mathrm{~b}_{5}$ & $\mathrm{~b}_{6}$ & $\mathrm{~b}_{7}$ & $\mathrm{~b}_{8}$ & $\mathrm{~b}_{9}$ \\
\hline TRAN & 7.0388 & -0.0667 & -0.9421 & -6.0479 & -0.2663 & 0.2681 & 0.0391 & 0.0031 & -- & -- \\
POLE & -- & -- & -9.7127 & -- & 0.3969 & -- & -- & -- & -- & -- \\
SVC & -0.2662 & -- & 0.0000 & -32.5044 & -- & 1.5420 & -- & -- & -- & -- \\
SEC & 8.5512 & -0.0875 & -1.0960 & -11.4824 & -0.3980 & 0.4794 & 0.0529 & 0.0042 & -- & -- \\
PRI & 4.0110 & -- & -1.6087 & -16.5749 & -0.2378 & 0.6976 & 0.0727 & 0.0012 & -- & -- \\
TREE & 14.6179 & -0.1565 & -1.6071 & -20.2991 & -0.6863 & 0.8465 & 0.0771 & 0.0076 & -- & -- \\
\hline
\end{tabular}

SOUTHERN Warm Storm Mode

\begin{tabular}{ccccccccccc} 
& $\mathrm{b}_{0}$ & $\mathrm{~b}_{1}$ & $\mathrm{~b}_{2}$ & $\mathrm{~b}_{3}$ & $\mathrm{~b}_{4}$ & $\mathrm{~b}_{5}$ & $\mathrm{~b}_{6}$ & $\mathrm{~b}_{7}$ & $\mathrm{~b}_{8}$ & $\mathrm{~b}_{9}$ \\
\hline TRAN & -0.2497 & -- & -0.3755 & -2.1991 & -- & 0.1240 & 0.0179 & -0.0003 & 0.0101 & -- \\
POLE & -1.7236 & 0.0321 & -- & -1.1780 & 0.1203 & 0.0809 & -- & -0.0012 & -- & -- \\
SVC & -0.7747 & 0.0622 & -2.0209 & -11.6192 & -- & 0.5119 & 0.1198 & -0.0017 & -- & -- \\
SEC & -0.0066 & 0.0409 & 0.0000 & -3.6899 & -- & 0.1698 & 0.0063 & 0.0000 & -0.0130 & -- \\
PRI & -0.9936 & 0.0357 & -1.0135 & -4.5956 & -- & 0.2470 & 0.0542 & -0.0006 & -- & -- \\
TREE & -4.6971 & 0.0000 & -2.1623 & -7.1037 & 0.1578 & 0.3128 & 0.1173 & -0.0035 & 0.0350 & -- \\
\hline
\end{tabular}




\begin{tabular}{ccccccccccc}
\hline \multicolumn{10}{c}{ CENTRAL Cold Storm Mode } \\
& $\mathrm{b}_{0}$ & $\mathrm{~b}_{1}$ & $\mathrm{~b}_{2}$ & $\mathrm{~b}_{3}$ & $\mathrm{~b}_{4}$ & $\mathrm{~b}_{5}$ & $\mathrm{~b}_{6}$ & $\mathrm{~b}_{7}$ & $\mathrm{~b}_{8}$ & $\mathrm{~b}_{9}$ \\
\hline TRAN & -1.0328 & -- & -0.2662 & -4.1543 & -- & 0.2234 & -- & -0.0010 & 0.0287 & -- \\
POLE & 0.0028 & -- & 0.0000 & 0.0000 & -- & 0.0000 & -- & -- & 0.0138 & -- \\
SVC & 0.8188 & -- & -0.6545 & 2.7171 & -- & -0.2246 & 0.0356 & -- & -- & -- \\
SEC & 0.2248 & 0.0107 & -0.1912 & -- & -- & -- & 0.0075 & -- & -0.0039 & -- \\
PRI & 0.0655 & 0.0124 & -0.2758 & -- & -- & -- & 0.0072 & -- & -- & -- \\
TREE & 40.4453 & -0.7949 & -- & -38.5318 & -1.7107 & 1.9011 & 0.0000 & 0.0334 & -- & -- \\
\hline
\end{tabular}

\begin{tabular}{cccccccccccc}
\hline \multicolumn{10}{c}{ METROPOLITAN Cold Storm Mode } \\
& $\mathrm{b}_{0}$ & $\mathrm{~b}_{1}$ & $\mathrm{~b}_{2}$ & $\mathrm{~b}_{3}$ & $\mathrm{~b}_{4}$ & $\mathrm{~b}_{5}$ & $\mathrm{~b}_{6}$ & $\mathrm{~b}_{7}$ & $\mathrm{~b}_{8}$ & $\mathrm{~b}_{9}$ \\
\hline TRAN & 0.0336 & -- & -- & -0.0069 & -- & -- & -- & 0.0002 & -- & -- \\
POLE & -5.1672 & 0.1264 & 0.1931 & 8.3691 & 0.1655 & -0.2180 & -- & -0.0041 & -- & -- \\
SVC & -45.0084 & 0.7574 & -- & 67.2138 & 1.4591 & -1.7775 & -- & -0.0342 & 0.0951 & -- \\
SEC & -2.7893 & 0.0470 & -- & 4.6629 & 0.0899 & -0.1234 & -- & -0.0021 & 0.0056 & -- \\
PRI & -4.2512 & 0.0730 & -- & 6.1411 & 0.1376 & -0.1579 & -- & -0.0032 & 0.0085 & -- \\
TREE & -19.9717 & 0.4030 & -- & 55.3338 & 0.6498 & -1.4641 & -- & -0.0136 & -- & -- \\
\hline
\end{tabular}

PALISADES Cold Storm Mode

\begin{tabular}{ccccccccccc} 
& $\mathrm{b}_{0}$ & $\mathrm{~b}_{1}$ & $\mathrm{~b}_{2}$ & $\mathrm{~b}_{3}$ & $\mathrm{~b}_{4}$ & $\mathrm{~b}_{5}$ & $\mathrm{~b}_{6}$ & $\mathrm{~b}_{7}$ & $\mathrm{~b}_{8}$ & $\mathrm{~b}_{9}$ \\
\hline TRAN & 0.2514 & -- & -0.9060 & -- & -- & -- & 0.0311 & -0.0011 & 0.0134 & -- \\
POLE & 3.9451 & -0.1381 & 0.0000 & 2.1921 & -0.1611 & -0.0607 & -- & 0.0040 & 0.0222 & -- \\
SVC & 0.5349 & -- & -0.4692 & 0.8184 & 0.0000 & -0.0384 & 0.0234 & -0.0011 & 0.0060 & -- \\
SEC & 0.5683 & -- & -0.5512 & 0.0000 & -0.0307 & -- & 0.0201 & 0.0004 & -- & -- \\
PRI & 0.0341 & -- & -- & 0.3751 & -- & -- & -- & 0.0002 & -- & -- \\
TREE & -0.0663 & -- & -- & -- & -- & -- & -- & -- & 0.0008 & -- \\
\hline
\end{tabular}

\section{SOUTHERN Cold Storm Mode}

\begin{tabular}{ccccccccccc} 
& $\mathrm{b}_{0}$ & $\mathrm{~b}_{1}$ & $\mathrm{~b}_{2}$ & $\mathrm{~b}_{3}$ & $\mathrm{~b}_{4}$ & $\mathrm{~b}_{5}$ & $\mathrm{~b}_{6}$ & $\mathrm{~b}_{7}$ & $\mathrm{~b}_{8}$ & $\mathrm{~b}_{9}$ \\
\hline TRAN & -0.0502 & -- & -- & -- & 0.0441 & -- & -0.0055 & -- & -- & -- \\
POLE & 1.8849 & -- & -1.2966 & 1.8816 & -- & -- & 0.0495 & -- & -- & -- \\
SVC & -7.4519 & -- & 4.7638 & -21.1361 & 0.4232 & 0.8830 & -0.2346 & -- & -- & -- \\
SEC & -2.8073 & -- & -- & -- & 0.1510 & -- & -- & -- & -- & -- \\
PRI & -2.4068 & -- & 1.2017 & -- & 0.1339 & 0.0894 & -0.0569 & -- & -- & -- \\
TREE & -4.3568 & -- & 2.3559 & -- & 0.2321 & 0.0947 & -0.1198 & -- & -- & -- \\
\hline
\end{tabular}




\begin{tabular}{ccccccccccc}
\hline \multicolumn{10}{c}{ CENTRAL Mix Storm Mode } \\
& $\mathrm{b}_{0}$ & $\mathrm{~b}_{1}$ & $\mathrm{~b}_{2}$ & $\mathrm{~b}_{3}$ & $\mathrm{~b}_{4}$ & $\mathrm{~b}_{5}$ & $\mathrm{~b}_{6}$ & $\mathrm{~b}_{7}$ & $\mathrm{~b}_{8}$ & $\mathrm{~b}_{9}$ \\
\hline TRAN & 10.7038 & -0.2303 & -- & -6.1463 & -0.4655 & 0.2951 & -- & 0.0108 & -- & -- \\
POLE & 13.3892 & -0.3281 & 0.3955 & -3.4395 & -0.6627 & 0.1884 & -- & 0.0167 & -- & -- \\
SVC & 5.5355 & -0.3489 & -- & -16.7341 & -0.2069 & 0.8458 & -- & -- & 0.1115 & -- \\
SEC & 0.8216 & -0.0293 & 0.1744 & -- & -- & 0.0162 & -- & 0.0006 & -- & -- \\
PRI & 6.6855 & -0.2242 & -- & -6.6697 & -0.3424 & 0.3659 & -- & 0.0064 & 0.0327 & -- \\
TREE & 35.9538 & -1.0168 & -- & -36.6582 & -1.5258 & 1.7699 & -- & 0.0290 & 0.1074 & -- \\
\hline
\end{tabular}

METROPOLITAN Mix Storm Mode

\begin{tabular}{ccccccccccc} 
& $\mathrm{b}_{0}$ & $\mathrm{~b}_{1}$ & $\mathrm{~b}_{2}$ & $\mathrm{~b}_{3}$ & $\mathrm{~b}_{4}$ & $\mathrm{~b}_{5}$ & $\mathrm{~b}_{6}$ & $\mathrm{~b}_{7}$ & $\mathrm{~b}_{8}$ & $\mathrm{~b}_{9}$ \\
\hline TRAN & 24.8941 & -0.6460 & -2.6138 & 4.6707 & -0.9040 & -0.1435 & 0.0787 & 0.0209 & 0.0204 & -- \\
POLE & 35.4121 & -0.8386 & -3.1490 & 6.2409 & -1.2597 & -0.1867 & 0.0892 & 0.0295 & -- & -- \\
SVC & 207.4523 & -5.3089 & -20.1775 & 38.7585 & -7.5599 & -1.2092 & 0.6003 & 0.1756 & 0.1400 & -- \\
SEC & 39.9132 & -0.9448 & -3.6847 & 7.9916 & -1.4142 & -0.2442 & 0.1072 & 0.0330 & -- & -- \\
PRI & 51.3696 & -1.3424 & -4.7646 & 12.4561 & -1.8611 & -0.4164 & 0.1384 & 0.0441 & 0.0365 & -- \\
TREE & 119.3226 & -3.0187 & -11.6800 & 17.4597 & -4.3754 & -0.5059 & 0.3516 & 0.1005 & 0.0780 & -- \\
\hline
\end{tabular}

\section{PALISADES Mix Storm Mode}

\begin{tabular}{ccccccccccc} 
& $\mathrm{b}_{0}$ & $\mathrm{~b}_{1}$ & $\mathrm{~b}_{2}$ & $\mathrm{~b}_{3}$ & $\mathrm{~b}_{4}$ & $\mathrm{~b}_{5}$ & $\mathrm{~b}_{6}$ & $\mathrm{~b}_{7}$ & $\mathrm{~b}_{8}$ & $\mathrm{~b}_{9}$ \\
\hline TRAN & 3.5403 & -1.3000 & -- & -0.3169 & -0.1013 & - & 0.0517 & 0.0010 & -0.0067 & -- \\
POLE & 1.2515 & -- & -0.2123 & 3.5283 & -- & -0.1118 & -- & 0.0010 & -0.0107 & -- \\
SVC & -0.2806 & -- & -- & -- & 0.0301 & -- & -- & -- & -- & -- \\
SEC & 0.4092 & -0.0057 & -- & -0.1667 & -- & -- & -- & -- & -- & -- \\
PRI & 4.2280 & -0.0480 & -1.2002 & 0.5375 & -0.1474 & -0.0198 & 0.0455 & 0.0024 & -0.0050 & -- \\
TREE & 0.5722 & -- & 0.0401 & -- & -0.0417 & -0.0003 & 0.0024 & 0.0011 & -0.0057 & -- \\
\hline
\end{tabular}

\section{SOUTHERN Mix Storm Mode}

\begin{tabular}{ccccccccccc} 
& $\mathrm{b}_{0}$ & $\mathrm{~b}_{1}$ & $\mathrm{~b}_{2}$ & $\mathrm{~b}_{3}$ & $\mathrm{~b}_{4}$ & $\mathrm{~b}_{5}$ & $\mathrm{~b}_{6}$ & $\mathrm{~b}_{7}$ & $\mathrm{~b}_{8}$ & $\mathrm{~b}_{9}$ \\
\hline TRAN & -2.1430 & -- & 1.5029 & 3.7965 & 0.1198 & -0.1110 & -0.0463 & -- & - & - \\
POLE & -2.4340 & -0.0838 & 1.7033 & 1.5408 & 0.1342 & -- & -0.0641 & -- & 0.0319 & -- \\
SVC & 3.7638 & -- & -- & -10.4041 & -- & 0.5454 & -- & -0.0037 & -- & -- \\
SEC & 0.0251 & -- & -- & 0.0000 & 0.0207 & -- & -- & -- & -- & -- \\
PRI & 1.0101 & -- & -- & -5.2870 & 0.0857 & 0.2380 & -0.0194 & -0.0019 & -- & -- \\
TREE & 0.1270 & -- & -- & -- & -- & 0.0818 & -- & -- & -- & -- \\
\hline
\end{tabular}




\begin{tabular}{|c|c|c|c|c|c|c|c|c|c|c|}
\hline \multicolumn{11}{|c|}{ CENTRAL Heat Storm Mode } \\
\hline & $\mathrm{b}_{0}$ & $b_{1}$ & $\mathrm{~b}_{2}$ & $b_{3}$ & $b_{4}$ & $b_{5}$ & $b_{6}$ & $b_{7}$ & $\mathrm{~b}_{8}$ & $b_{9}$ \\
\hline TRAN & -127.3035 & 1.0530 & 1.9663 & -- & -- & -- & -- & -- & 0.1215 & -- \\
\hline POLE & 0.6480 & -- & 0.7728 & -207.5427 & -- & 15.7278 & -0.0345 & -- & -- & -- \\
\hline Svc & 1.0836 & -- & 0.1352 & -132.8207 & -0.7095 & 10.7542 & 0.0075 & -- & -- & -- \\
\hline SEC & -29.5692 & 0.3234 & -- & 213.2877 & 1.7164 & -10.9215 & -- & -0.0186 & -- & -- \\
\hline PRI & -3.5902 & -- & 0.1265 & -- & -- & -- & -- & -- & 0.0149 & -- \\
\hline TREE & 1.5534 & -- & 1.6271 & -256.6917 & -0.0292 & 15.9423 & -0.0876 & -- & -- & -- \\
\hline \multicolumn{11}{|c|}{ METROPOLITAN Heat Storm Mode } \\
\hline & $b_{0}$ & $b_{1}$ & $\mathrm{~b}_{2}$ & $b_{3}$ & $b_{4}$ & $b_{5}$ & $b_{6}$ & $\mathrm{~b}_{7}$ & $\mathrm{~b}_{8}$ & $b_{9}$ \\
\hline TRAN & 0.3536 & -- & -- & -- & -0.7989 & -- & -- & 0.0086 & -- & -- \\
\hline POLE & -5.0772 & 0.0562 & -- & -- & -- & -- & -- & -- & -- & -- \\
\hline SVC & 0.0763 & -- & -- & -- & -0.8134 & -- & -- & 0.0089 & -- & -- \\
\hline SEC & -2.1421 & 0.0155 & -- & -- & -- & -- & -- & -0.0001 & 0.0033 & -- \\
\hline PRI & -7.1683 & 0.0754 & -- & -- & 0.2291 & -- & -- & -0.0024 & -- & -- \\
\hline TREE & -0.0399 & -- & -- & -- & -0.5440 & -- & -- & 0.0060 & -- & -- \\
\hline
\end{tabular}

PALISADES Heat Storm Mode

\begin{tabular}{ccccccccccc} 
& $\mathrm{b}_{0}$ & $\mathrm{~b}_{1}$ & $\mathrm{~b}_{2}$ & $\mathrm{~b}_{3}$ & $\mathrm{~b}_{4}$ & $\mathrm{~b}_{5}$ & $\mathrm{~b}_{6}$ & $\mathrm{~b}_{7}$ & $\mathrm{~b}_{8}$ & $\mathrm{~b}_{9}$ \\
\hline TRAN & -83.1800 & 0.6241 & -- & -130.6169 & -- & - & -- & - & 0.1061 & -- \\
POLE & 2.3968 & 0.0496 & -- & -- & -- & -- & 0.0043 & -0.0004 & -0.0208 & -- \\
SVC & -18.3540 & 0.0720 & -- & -- & -- & -- & -- & -- & 0.0000 & -- \\
SEC & -3.3203 & 0.0225 & -- & -- & -- & -- & -- & -- & 0.0049 & -- \\
PRI & 0.5996 & -- & -- & -221.1067 & -0.2006 & 8.9441 & 0.0006 & 0.0021 & 0.0000 & -- \\
TREE & -15.3106 & 0.1710 & -- & -276.1301 & 0.6677 & 13.0273 & -- & -0.0074 & 0.0000 & -- \\
\hline
\end{tabular}

SOUTHERN Heat Storm Mode

\begin{tabular}{ccccccccccc} 
& $\mathrm{b}_{0}$ & $\mathrm{~b}_{1}$ & $\mathrm{~b}_{2}$ & $\mathrm{~b}_{3}$ & $\mathrm{~b}_{4}$ & $\mathrm{~b}_{5}$ & $\mathrm{~b}_{6}$ & $\mathrm{~b}_{7}$ & $\mathrm{~b}_{8}$ & $\mathrm{~b}_{9}$ \\
\hline TRAN & -67.7619 & 0.7982 & 0.5062 & -- & -- & -- & -- & -0.0020 & -- & -- \\
POLE & -67.1140 & 0.7513 & 0.1853 & -- & 3.5568 & -- & -- & -0.0393 & -- & -- \\
SVC & 10.8210 & -- & 1.1347 & -6698.3997 & -1.0958 & 410.0621 & -0.0557 & 0.0120 & -0.0379 & -- \\
SEC & 0.2264 & -- & -- & 1677.3585 & -- & -100.0000 & -- & -- & -- & -- \\
PRI & -74.5474 & 0.8165 & -- & 325.2670 & 3.3649 & -- & 0.0056 & -0.0366 & -- & -- \\
TREE & -13.5738 & 0.1601 & -- & 166.4027 & -- & -- & -- & -- & -- & -- \\
\hline
\end{tabular}




\begin{tabular}{ccccccccccc}
\hline \multicolumn{10}{c}{ CENTRAL None Storm Mode } \\
& $\mathrm{b}_{0}$ & $\mathrm{~b}_{1}$ & $\mathrm{~b}_{2}$ & $\mathrm{~b}_{3}$ & $\mathrm{~b}_{4}$ & $\mathrm{~b}_{5}$ & $\mathrm{~b}_{6}$ & $\mathrm{~b}_{7}$ & $\mathrm{~b}_{8}$ & $\mathrm{~b}_{9}$ \\
\hline TRAN & 0.4104 & -- & -0.1248 & -14.2976 & -- & -- & 0.0109 & -0.0003 & 0.0064 & -- \\
POLE & 0.8362 & -- & -- & 33.3998 & -- & -- & 0.0059 & -- & 0.0004 & -- \\
SVC & 0.0521 & 0.0052 & -0.1073 & 58.2516 & 0.0207 & -2.5098 & 0.0106 & -- & -- & -- \\
SEC & -0.0536 & 0.0106 & -0.1802 & 0.0000 & 0.0096 & -- & 0.0111 & -0.0004 & -0.0010 & -- \\
PRI & 0.0078 & -- & -0.1844 & 8.8429 & -0.0043 & -0.1504 & 0.0113 & 0.0001 & 0.0012 & -- \\
TREE & -1.5527 & 0.0117 & -0.5479 & 67.1908 & 0.0474 & -3.4539 & 0.0380 & -0.0009 & 0.0101 & -- \\
\hline
\end{tabular}

METROPOLITAN None Storm Mode

\begin{tabular}{ccccccccccc} 
& $\mathrm{b}_{0}$ & $\mathrm{~b}_{1}$ & $\mathrm{~b}_{2}$ & $\mathrm{~b}_{3}$ & $\mathrm{~b}_{4}$ & $\mathrm{~b}_{5}$ & $\mathrm{~b}_{6}$ & $\mathrm{~b}_{7}$ & $\mathrm{~b}_{8}$ & $\mathrm{~b}_{9}$ \\
\hline TRAN & -1.2490 & 0.0718 & -0.1894 & 0.0000 & 0.0463 & -0.6209 & 0.0061 & -0.0008 & -0.0152 & -- \\
POLE & -0.1533 & -- & -0.0989 & 35.7371 & 0.0076 & -1.5410 & 0.0043 & -- & 0.0006 & -- \\
SVC & -0.0301 & -- & -0.6568 & 96.1204 & 0.0031 & -4.7007 & 0.0329 & -- & -- & -- \\
SEC & -0.4377 & 0.0073 & -0.1795 & 26.2438 & 0.0165 & -1.2186 & 0.0086 & -0.0003 & -- & -- \\
PRI & -0.3075 & 0.0039 & -0.1196 & 25.1651 & 0.0123 & -1.2064 & 0.0056 & -0.0001 & -- & -- \\
TREE & -0.2181 & 0.0200 & -1.3983 & 101.0606 & -- & -4.5333 & 0.0652 & -0.0007 & -- & -- \\
\hline
\end{tabular}

PALISADES None Storm Mode

\begin{tabular}{ccccccccccc} 
& $\mathrm{b}_{0}$ & $\mathrm{~b}_{1}$ & $\mathrm{~b}_{2}$ & $\mathrm{~b}_{3}$ & $\mathrm{~b}_{4}$ & $\mathrm{~b}_{5}$ & $\mathrm{~b}_{6}$ & $\mathrm{~b}_{7}$ & $\mathrm{~b}_{8}$ & $\mathrm{~b}_{9}$ \\
\hline TRAN & -0.1840 & -- & 0.1359 & -- & -- & - & -- & 0.0003 & 0.0032 & -- \\
POLE & 0.1408 & 0.0157 & 0.0119 & -- & -- & 0.3111 & 0.0014 & -- & -0.0041 & -- \\
SVC & -0.5554 & -- & -0.1950 & 57.4766 & 0.0281 & -2.2440 & 0.0094 & -0.0002 & 0.0036 & -- \\
SEC & -0.0834 & -- & -0.0333 & 12.8794 & 0.0037 & -0.5708 & 0.0020 & -- & 0.0004 & -- \\
PRI & -0.1604 & -- & -0.1822 & 28.3142 & 0.0070 & -1.3726 & 0.0086 & -0.0001 & 0.0015 & -- \\
TREE & -0.2102 & -- & -0.5624 & 78.4184 & -- & -3.5310 & 0.0273 & -- & 0.0015 & -- \\
\hline
\end{tabular}

\section{SOUTHERN None Storm Mode}

\begin{tabular}{ccccccccccc} 
& $\mathrm{b}_{0}$ & $\mathrm{~b}_{1}$ & $\mathrm{~b}_{2}$ & $\mathrm{~b}_{3}$ & $\mathrm{~b}_{4}$ & $\mathrm{~b}_{5}$ & $\mathrm{~b}_{6}$ & $\mathrm{~b}_{7}$ & $\mathrm{~b}_{8}$ & $\mathrm{~b}_{9}$ \\
\hline TRAN & -0.0144 & 0.0177 & -- & -80.5308 & -- & 4.5437 & 0.0039 & - & - & - \\
POLE & 0.7047 & -- & -0.1268 & -51.1755 & 0.0200 & 3.2962 & 0.0094 & -- & 0.0003 & -- \\
SVC & -0.0743 & 0.0198 & -0.3799 & -80.4419 & 0.0271 & 5.4126 & 0.0262 & -0.0007 & -- & -- \\
SEC & -0.0533 & 0.0024 & -0.1045 & -66.6010 & -- & 3.4770 & 0.0070 & -- & -- & -- \\
PRI & 0.2870 & -- & -0.2717 & -155.5127 & -0.0279 & 8.3500 & 0.0171 & 0.0004 & -- & -- \\
TREE & 0.4651 & 0.0091 & -0.4506 & -166.1623 & -0.0399 & 9.0994 & 0.0270 & 0.0004 & -- & -- \\
\hline
\end{tabular}


TABLE 2.4. Summary of the CI95 analysis performed for the Overfitted Model. The values represent an average for all territories. The Net CI95 analysis verifies the amount of times that all plant element forecasts fell within the CI95 on a daily basis. The average CI95 analysis is an average of the CI95 for each territory. Bold values indicate the value is closer to 0.95 then those of Table 2.5.

\begin{tabular}{cccccccc}
\hline \multicolumn{7}{c}{ Overfitted Model Confidence Interval Analysis } \\
MODE & TRAN & POLE & SVC & SEC & PRI & TREE & NET \\
\hline THUNDER & $\mathbf{0 . 9 5 8 3}$ & 0.9683 & 0.9791 & 0.9374 & 0.9491 & $\mathbf{0 . 9 3 8 3}$ & $\mathbf{0 . 9 1 7 4}$ \\
WARM & 0.9852 & $\mathbf{0 . 9 5 9 4}$ & 0.9881 & 0.9901 & 0.9856 & 0.9879 & $\mathbf{0 . 9 4 7 5}$ \\
COLD & 0.9639 & $\mathbf{0 . 9 6 3 0}$ & $\mathbf{0 . 9 4 6 3}$ & $\mathbf{0 . 9 6 4 8}$ & $\mathbf{0 . 9 8 1 5}$ & 0.9630 & 0.8380 \\
MIX & 0.9688 & 0.9375 & 0.9688 & 0.9643 & 0.9688 & $\mathbf{0 . 9 0 1 8}$ & $\mathbf{0 . 8 5 2 7}$ \\
HEAT & 1.0000 & $\mathbf{0 . 8 8 7 5}$ & 0.8542 & 0.8333 & 0.7708 & $\mathbf{0 . 9 3 7 5}$ & 0.5958 \\
NONE & 0.9745 & $\mathbf{0 . 9 7 9 5}$ & $\mathbf{0 . 9 8 6 2}$ & 0.9776 & $\mathbf{0 . 9 8 0 8}$ & $\mathbf{0 . 9 8 5 1}$ & 0.9235 \\
Average & 0.9349 & 0.9091 & 0.9143 & 0.9044 & 0.8985 & 0.9121 & 0.8109 \\
\hline
\end{tabular}


TABLE 2.5. Same as Table 2.4 but for the Backwards Eliminated Model. Bold values indicate the value is closer to 0.95 then those of Table 2.4.

\begin{tabular}{cccccccc}
\hline \multicolumn{6}{c}{ Backwards Eliminated Model Confidence Interval Analysis } \\
MODE & TRAN & POLE & SVC & SEC & PRI & TREE & NET \\
\hline THUNDER & 0.9783 & 0.9683 & $\mathbf{0 . 9 6 8 3}$ & $\mathbf{0 . 9 5 9 1}$ & 0.9491 & 0.8906 & 0.8698 \\
WARM & 0.9852 & 0.9780 & $\mathbf{0 . 9 7 5 7}$ & 0.9901 & 0.9834 & 0.9879 & 0.9541 \\
COLD & $\mathbf{0 . 9 4 8 0}$ & 0.9722 & 0.9597 & 0.9861 & 0.9861 & $\mathbf{0 . 9 5 9 7}$ & $\mathbf{0 . 8 6 6 0}$ \\
MIX & 0.9688 & 0.9375 & $\mathbf{0 . 9 3 7 5}$ & 0.9643 & $\mathbf{0 . 9 5 0 9}$ & 0.8482 & 0.7813 \\
HEAT & $\mathbf{0 . 9 1 6 7}$ & 0.7208 & 0.8542 & 0.8333 & $\mathbf{0 . 8 5 4 2}$ & 0.8542 & 0.5958 \\
NONE & $\mathbf{0 . 9 7 6 1}$ & 0.9846 & 0.9887 & 0.9776 & 0.9860 & 0.9863 & $\mathbf{0 . 9 3 1 5}$ \\
Average & 0.9237 & 0.8898 & 0.9094 & 0.9137 & 0.9135 & 0.8843 & 0.7998 \\
\hline
\end{tabular}


TABLE 2.6. Summary of forecast verification scores based on predicting a total of 10 plant damage elements in a day.

\begin{tabular}{ccccc|cccc}
\hline & \multicolumn{3}{c}{ Overfitted Model } & \multicolumn{4}{c}{ Backwards Eliminated Model } \\
SCORE & POD & FAR & CSI & HSS & POD & FAR & CSI & HSS \\
\hline CEN & 0.47 & 0.76 & 0.19 & 0.22 & 0.53 & 0.77 & 0.19 & 0.22 \\
MET & 0.33 & 0.92 & 0.07 & 0.11 & 0.17 & 0.95 & 0.04 & 0.05 \\
PAL & 0.33 & 0.79 & 0.15 & 0.23 & 0.33 & 0.84 & 0.12 & 0.18 \\
SOU & 0.77 & 0.62 & 0.34 & 0.43 & 0.77 & 0.58 & 0.37 & 0.48 \\
\hline TOTAL & 0.56 & 0.73 & 0.22 & 0.31 & 0.57 & 0.73 & 0.22 & 0.31 \\
\hline
\end{tabular}


TABLE 2.7. Same as Table 2.6, except using a threshold of 20 total damaged plant elements.

\begin{tabular}{ccccc|cccc}
\hline & \multicolumn{3}{c}{ Overfitted Model } & \multicolumn{3}{c}{ Backwards Eliminated Model } \\
SCORE & POD & FAR & CSI & HSS & POD & FAR & CSI & HSS \\
\hline CEN & 0.45 & 0.69 & 0.23 & 0.34 & 0.55 & 0.74 & 0.21 & 0.32 \\
MET & 0.33 & 0.80 & 0.14 & 0.23 & 0.17 & 0.86 & 0.08 & 0.14 \\
PAL & 0.67 & 0.83 & 0.15 & 0.26 & 0.67 & 0.83 & 0.15 & 0.26 \\
SOU & 0.80 & 0.73 & 0.25 & 0.37 & 0.80 & 0.72 & 0.26 & 0.38 \\
\hline TOTAL & 0.57 & 0.75 & 0.21 & 0.33 & 0.57 & 0.76 & 0.20 & 0.31 \\
\hline
\end{tabular}


TABLE 2.8. Same as Table 2.6 except using a threshold of 30 total damaged plant elements.

\begin{tabular}{ccccc|cccc}
\hline & \multicolumn{3}{c}{ Overfitted Model } & \multicolumn{3}{c}{ Backwards Eliminated Model } \\
SCORE & POD & FAR & CSI & HSS & POD & FAR & CSI & HSS \\
\hline CEN & 0.44 & 0.56 & 0.29 & 0.43 & 0.44 & 0.60 & 0.27 & 0.40 \\
MET & 0.00 & 1.00 & 0.00 & -0.01 & 0.00 & 1.00 & 0.00 & -0.01 \\
PAL & 0.50 & 0.75 & 0.20 & 0.32 & 0.78 & 0.50 & 0.44 & 0.60 \\
SOU & 0.50 & 0.64 & 0.26 & 0.40 & 0.55 & 0.60 & 0.30 & 0.44 \\
\hline TOTAL & 0.39 & 0.69 & 0.21 & 0.33 & 0.50 & 0.60 & 0.28 & 0.43 \\
\hline
\end{tabular}


TABLE 2.9. Complete data for the 26 July 2009 Case Study. Model = Modeled data (according to Thunderstorm storm type); Obs = Observed data. The bold-faced values indicate where the model error is two or less (where observed damage is $>0$ ).

\begin{tabular}{ccc|cc|cc|cc}
\hline & \multicolumn{2}{c}{ CEN } & \multicolumn{2}{c}{ MET } & \multicolumn{2}{c}{ PAL^ } & \multicolumn{2}{c}{ SOU } \\
& Obs & Model & Obs & Model & Obs & Model & Obs & Model \\
\hline TRAN & 9 & 24 & 0 & 4 & $\mathbf{8}$ & $\mathbf{7}$ & 12 & 3 \\
POLE & 6 & 20 & 0 & 5 & 6 & 2 & 12 & 5 \\
SVC & 0 & 44 & 0 & 30 & 2 & 11 & 13 & 20 \\
SEC & 0 & 24 & 0 & 5 & 0 & 1 & 8 & 3 \\
PRI & 3 & 28 & 0 & 11 & 5 & 5 & 43 & 7 \\
TREE & 14 & 49 & 0 & 35 & 7 & 5 & 60 & 11 \\
\hline
\end{tabular}

$\wedge$ The maximum wind gust was corrected for a suspect observation at TEB. The maximum measured wind gust from TEB not associated with the passage of thunderstorms is substituted and the Thunderstorm storm mode as applied. 
TABLE 2.10. Same as Table 2.9, but for the 28 January 2009 Mix storm mode case study.

\begin{tabular}{ccc|cc|cc|cc}
\hline & \multicolumn{2}{c}{ CEN } & \multicolumn{2}{c}{ MET } & \multicolumn{2}{c}{ PAL } & \multicolumn{2}{c}{ SOU } \\
& Obs & Model & Obs & Model & Obs & Model & Obs & Model \\
\hline TRAN & 0 & 4 & 1 & 0 & 1 & 0 & 2 & 2 \\
POLE & 10 & 3 & 1 & 0 & 0 & 1 & 4 & 3 \\
SVC & 0 & 6 & $\mathbf{0}$ & $\mathbf{0}$ & 0 & 1 & 1 & 6 \\
SEC & $\mathbf{1}$ & $\mathbf{1}$ & $\mathbf{0}$ & $\mathbf{0}$ & $\mathbf{0}$ & $\mathbf{0}$ & 0 & 1 \\
PRI & $\mathbf{4}$ & $\mathbf{3}$ & $\mathbf{0}$ & $\mathbf{0}$ & 0 & 1 & 1 & 4 \\
TREE & 0 & 14 & $\mathbf{0}$ & $\mathbf{0}$ & $\mathbf{0}$ & $\mathbf{0}$ & 0 & 2 \\
\hline
\end{tabular}


TABLE 2.11. Same as Table 2.9, but for the 12 February 2009 None storm mode case study.

\begin{tabular}{ccc|cc|cc|cc}
\hline & \multicolumn{2}{c}{ CEN } & \multicolumn{2}{c}{ MET $^{\text {w }}$} & \multicolumn{2}{c}{ PAL^ $^{\wedge}$} & \multicolumn{2}{c}{ SOU } \\
& Obs & Model & Obs & Model & Obs & Model & Obs & Model \\
\hline TRAN & 30 & 1 & 10 & 1 & 6 & 0 & 12 & 3 \\
POLE & 32 & 1 & 9 & 2 & 12 & 21 & 43 & 3 \\
SVC & 69 & 1 & 25 & 8 & 73 & 4 & 22 & 3 \\
SEC & 6 & 0 & 10 & 2 & 10 & 0 & 6 & 1 \\
PRI & 20 & 0 & 13 & 3 & 12 & 0 & 14 & 3 \\
TREE & 22 & 0 & 102 & 8 & 3 & 0 & 36 & 3 \\
\hline
\end{tabular}

w This day was diagnosed as a Warm storm mode day, so the Warm storm mode equations are used for the damage forecast presented.

$\wedge$ This day was originally diagnosed as Questionable due to TTN reporting 0.08 " of precipitation without reporting the occurrence of precipitation. See text for more details. 
TABLE 2.12. Same as Table 2.9, but for the 4 April 2009 None storm mode case study.

\begin{tabular}{ccc|cc|cc|cc}
\hline & \multicolumn{2}{c}{ CEN } & \multicolumn{2}{c}{ MET } & \multicolumn{2}{c}{ PAL $^{\text {w }}$} & \multicolumn{2}{c}{ SOU } \\
& Obs & Model & Obs & Model & Obs & Model & Obs & Model \\
\hline TRAN & $\mathbf{1}$ & $\mathbf{1}$ & $\mathbf{0}$ & $\mathbf{0}$ & $\mathbf{3}$ & $\mathbf{1}$ & $\mathbf{2}$ & $\mathbf{1}$ \\
POLE & 9 & 2 & $\mathbf{0}$ & $\mathbf{0}$ & 2 & 0 & 2 & 2 \\
SVC & $\mathbf{1}$ & $\mathbf{1}$ & $\mathbf{0}$ & $\mathbf{0}$ & 1 & 0 & 0 & 2 \\
SEC & 3 & 0 & $\mathbf{0}$ & $\mathbf{0}$ & $\mathbf{0}$ & $\mathbf{0}$ & 1 & 0 \\
PRI & 0 & 1 & $\mathbf{0}$ & $\mathbf{0}$ & 1 & 0 & 0 & 1 \\
TREE & $\mathbf{4}$ & $\mathbf{2}$ & 0 & 1 & 1 & 0 & $\mathbf{0}$ & $\mathbf{0}$ \\
\hline
\end{tabular}

w This day was diagnosed as a Warm storm mode day, so the Warm storm mode equations are used for the damage forecast presented. 
TABLE 2.13. Same as Table 2.9, but for the 17 July 2009 event. Multiple storm modes were diagnosed across the PSE\&G service territories and were applied to produce the damage forecast.

\begin{tabular}{|c|c|c|c|c|c|c|c|c|}
\hline \multicolumn{9}{|c|}{ CASE STUDY: 16 July 2009 (Various Storm Modes) } \\
\hline & \multicolumn{2}{|c|}{ CEN $^{N}$} & \multicolumn{2}{|c|}{$\mathrm{MET}^{\mathrm{H}}$} & \multicolumn{2}{|c|}{ PAL $^{w}$} & \multicolumn{2}{|c|}{ SOU $^{\mathrm{TH}}$} \\
\hline & Obs & Model & Obs & Model & Obs & Model & Obs & Model \\
\hline TRAN & 1 & 2 & 0 & 0 & 1 & 1 & 2 & 5 \\
\hline POLE & 0 & 1 & 0 & 0 & 0 & 0 & 3 & 5 \\
\hline Svc & 0 & 1 & 0 & 0 & 0 & 0 & 10 & 15 \\
\hline SEC & 0 & 0 & 0 & 0 & 0 & 0 & 2 & 2 \\
\hline PRI & 0 & 0 & 0 & 0 & 0 & 1 & 13 & 10 \\
\hline TREE & 2 & 2 & 1 & 0 & 0 & 0 & 29 & 10 \\
\hline
\end{tabular}

${ }^{\mathbf{N}}$ Denotes the None storm mode was used to calculate the plant damage forecast.

${ }^{\mathrm{H}}$ Denotes the Heat storm mode was used to calculate the plant damage forecast.

${ }^{\mathrm{w}}$ Denotes the Warm storm mode was used to calculate the plant damage forecast.

${ }^{\mathrm{TH}}$ Denotes the thunderstorm storm mode was used to calculate the plant damage forecast. 
TABLE 2.14. Other possible model forecasts for Central using the Heat, Warm, and Thunderstorm storm modes for 17 July 2009.

\begin{tabular}{cccc}
\hline & \multicolumn{2}{c}{ CENTRAL } \\
& HEAT & WARM & THUNDER \\
\hline TRAN & $\mathbf{0}$ & $\mathbf{2}$ & $\mathbf{3}$ \\
POLE & 1 & 1 & 1 \\
SVC & $\mathbf{0}$ & 1 & 1 \\
SEC & $\mathbf{0}$ & $\mathbf{0}$ & 3 \\
PRI & $\mathbf{0}$ & 2 & 1 \\
TREE & $\mathbf{1}$ & $\mathbf{2}$ & $\mathbf{2}$ \\
\hline
\end{tabular}


TABLE 2.15. Other possible model forecasts for Metropolitan using the None, Warm, and Thunderstorm storm modes for 17 July 2009.

\begin{tabular}{cccc}
\hline \multicolumn{4}{c}{ METROPOLITAN } \\
& NONE & WARM & THUNDER \\
\hline TRAN & 1 & 0 & 0 \\
POLE & 0 & 0 & 1 \\
SVC & 0 & 1 & 9 \\
SEC & 0 & 0 & 0 \\
PRI & 0 & 0 & 0 \\
TREE & 0 & 1 & 4 \\
\hline
\end{tabular}


TABLE 2.16. Other possible model forecasts for Palisades using the Heat, None, and Thunderstorm storm modes for 17 July 2009.

\begin{tabular}{cccc}
\hline & \multicolumn{3}{c}{ PALISADES } \\
& HEAT & NONE & THUNDER \\
\hline TRAN & 0 & 1 & 0 \\
POLE & 1 & 1 & 0 \\
SVC & 0 & 1 & 0 \\
SEC & 0 & 0 & 0 \\
PRI & 0 & 0 & 0 \\
TREE & 0 & 1 & 0 \\
\hline
\end{tabular}


TABLE 2.17. Other possible model forecasts for Southern using the Heat, None, and Warm storm modes for 17 July 2009.

\begin{tabular}{cccc}
\hline & \multicolumn{2}{c}{ SOUTHERN } & \\
& HEAT & NONE & WARM \\
\hline TRAN & $\mathbf{0}$ & $\mathbf{2}$ & $\mathbf{2}$ \\
POLE & $\mathbf{2}$ & $\mathbf{2}$ & $\mathbf{2}$ \\
SVC & 0 & 2 & 1 \\
SEC & $\mathbf{0}$ & $\mathbf{1}$ & $\mathbf{0}$ \\
PRI & 1 & 2 & 1 \\
TREE & 1 & 1 & 1 \\
\hline
\end{tabular}


TABLE 2.18. Model plant damage forecast using station observations (Obs) and forecasts from the Rutgers-PSE\&G Undergraduate Forecast Program (Forecast) as predictors for 12-15 March 2010. The Warm mode was applied to all days. Plant elements are abbreviated same as before, but transformer and primary wire damage counts were unavailable when the data was requested.

\begin{tabular}{|c|c|c|c|}
\hline Element & Obs & Forecast & $\begin{array}{c}\text { Observed } \\
\text { Damage }\end{array}$ \\
\hline SEC & 62 & 86 & 448 \\
\hline SVC & 286 & 345 & 1600 \\
\hline POLE & 85 & 82 & 1011 \\
\hline TREE & 178 & 200 & 1368 \\
\hline Total & 611 & 713 & 4427 \\
\hline
\end{tabular}


TABLE 2.19. Same as Table 2.18, except corrected to properly diagnose 14 March as a Warm storm mode day.

\begin{tabular}{cccc}
\hline & Obs & Forecast & Observed \\
Element & & & Damage \\
& & & 448 \\
\hline SEC & 60 & 90 & 1600 \\
SVC & 288 & 412 & 1011 \\
POLE & 80 & 89 & 1368 \\
& & & \\
TREE & 175 & 253 & 4427 \\
\hline Total & 603 & 843 & \\
\hline
\end{tabular}


TABLE 2.20. Same as Table 2.18 except the restrictor coefficients are removed in the model equations for all territories. The warm storm mode was used to calculate damage on all days to provide the maximum possible forecast.

\begin{tabular}{cccc}
\hline Element & Obs & Forecast & $\begin{array}{c}\text { Observed } \\
\text { Damage }\end{array}$ \\
\hline SEC & 214 & 274 & 448 \\
SVC & 583 & 800 & 1600 \\
POLE & 165 & 179 & 1011 \\
TREE & 570 & 705 & 1368 \\
\hline Total & 1532 & 1960 & 4427 \\
\hline
\end{tabular}


TABLE 2.21. Maximum observations for wind gust and precipitation within the PSE\&G service territories. All values were obtained from the appropriate local NWS office (Upton, NY for Metropolitan and Palisades and Mount Holly, NJ for Central and Southern).

\begin{tabular}{|c|c|c|}
\hline Territory & $\begin{array}{c}V_{\max } \\
m p h \\
{\left[\mathrm{~m} \mathrm{~s}^{-1}\right]}\end{array}$ & $\begin{array}{c}\text { LWE }_{\max } \\
\text { in. } \\
\text { [mm] }\end{array}$ \\
\hline CEN & $\begin{array}{c}62 \\
{[22.7]}\end{array}$ & $\begin{array}{c}6.08 \\
{[154.4]}\end{array}$ \\
\hline MET & $\begin{array}{c}55 \\
{[24.6]}\end{array}$ & $\begin{array}{c}5.17 \\
{[131.3]}\end{array}$ \\
\hline PAL & $\begin{array}{c}78 \\
{[34.9]}\end{array}$ & $\begin{array}{c}4.64 \\
{[117.9]}\end{array}$ \\
\hline SOU & $\begin{array}{c}63 \\
{[28.1]}\end{array}$ & $\begin{array}{c}3.78 \\
{[96.0]}\end{array}$ \\
\hline
\end{tabular}


TABLE 2.22. Model plant damage forecast using the values from Table 20 in place of forecasted or station observed values. The model equations were applied with all coefficients and restrictor coefficients removed for analysis.

\begin{tabular}{|c|c|c|c|c|c|}
\hline \multirow[b]{2}{*}{ Element } & \multicolumn{2}{|c|}{ Restrictors } & \multicolumn{2}{|c|}{ No Restrictors } & \multirow{2}{*}{$\begin{array}{l}\text { TOTAL } \\
\text { DAMAGE }\end{array}$} \\
\hline & $V_{\text {max }}$ & $S F_{1 \max }$ & $V_{\max }$ & $S F_{1 \max }$ & \\
\hline SEC & 149 & 175 & 345 & 385 & 448 \\
\hline SVC & 626 & 762 & 1012 & 1222 & 1600 \\
\hline POLE & 108 & 123 & 199 & 225 & 1011 \\
\hline TREE & 371 & 463 & 821 & 966 & 1368 \\
\hline Total & 1254 & 1523 & 2376 & 2798 & 4427 \\
\hline
\end{tabular}


TABLE 2.23. A summary of the observed total plant element damage from each territory for 1-5 September 2009. The total damage is calculated as the sum of the damage from each territory. Light indicate wind gusts were not reported.

\begin{tabular}{|c|c|c|c|c|c|c|c|}
\hline \multicolumn{8}{|c|}{ Evidence of Lagged Damage Reporting } \\
\hline \multirow[b]{3}{*}{2006} & \multirow{3}{*}{$\begin{array}{c}\mathrm{V}_{\max } \text { Range } \\
\text { MPH } \\
{[\mathrm{m} \mathrm{s}-1]}\end{array}$} & \multirow{3}{*}{$\begin{array}{c}\text { LWEd Range } \\
\qquad \begin{array}{c}\text { In. } \\
{[\mathrm{mm}]}\end{array}\end{array}$} & \multirow{3}{*}{ CEN } & \multirow{3}{*}{ MET } & \multirow{3}{*}{ PAL } & \multirow{3}{*}{ SOU } & \multirow{3}{*}{ Total } \\
\hline & & & & & & & \\
\hline & & & & & & & \\
\hline \multirow[t]{2}{*}{ 1-Sep } & $23-40$ & $0.08-0.33$ & 14 & 10 & 4 & 21 & 49 \\
\hline & [10.3-17.9] & [2-8.4] & & & & & \\
\hline \multirow[t]{2}{*}{ 2-Sep } & $35-41$ & $1.09-2.15$ & 306 & 164 & 567 & 211 & $1248^{\star *}$ \\
\hline & [15.6-18.3] & {$[22.7-54.6]$} & & & & & \\
\hline \multirow[t]{2}{*}{ 3-Sep } & $16-25$ & trace & 70 & 11 & 365 & 11 & $457^{*}$ \\
\hline & {$[7.1-11.2]$} & {$[0.25]$} & & & & & \\
\hline \multirow[t]{2}{*}{ 4-Sep } & Light & 0.00 & 11 & 1 & 100 & 6 & 118 \\
\hline & Light & {$[0.0]$} & & & & & \\
\hline \multirow[t]{2}{*}{ 5-Sep } & $<19$ & $0.28-0.56$ & 31 & 0 & 46 & 13 & 90 \\
\hline & $<8.5$ & [7.1-14.2] & & & & & \\
\hline
\end{tabular}

** Represents the $3^{\text {rd }}$ highest daily cumulative plant damage total in the Training dataset.

* Represents the $7^{\text {th }}$ highest daily cumulative plant damage total in the Training dataset. 


\section{FIGURES}

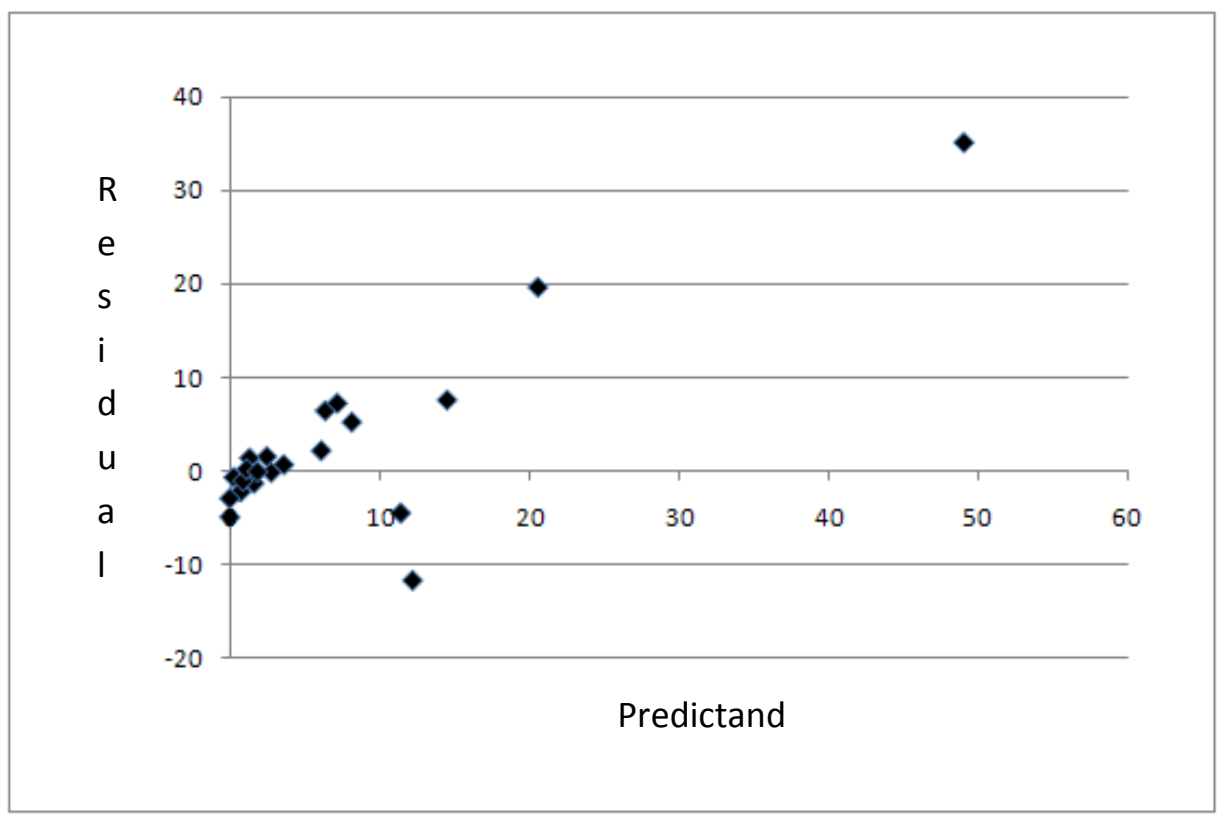

FIG 2.1. Plot of model error (residual) and predicted damage (predictand) for Tree related damage in Central for the Thunderstorm storm mode. 

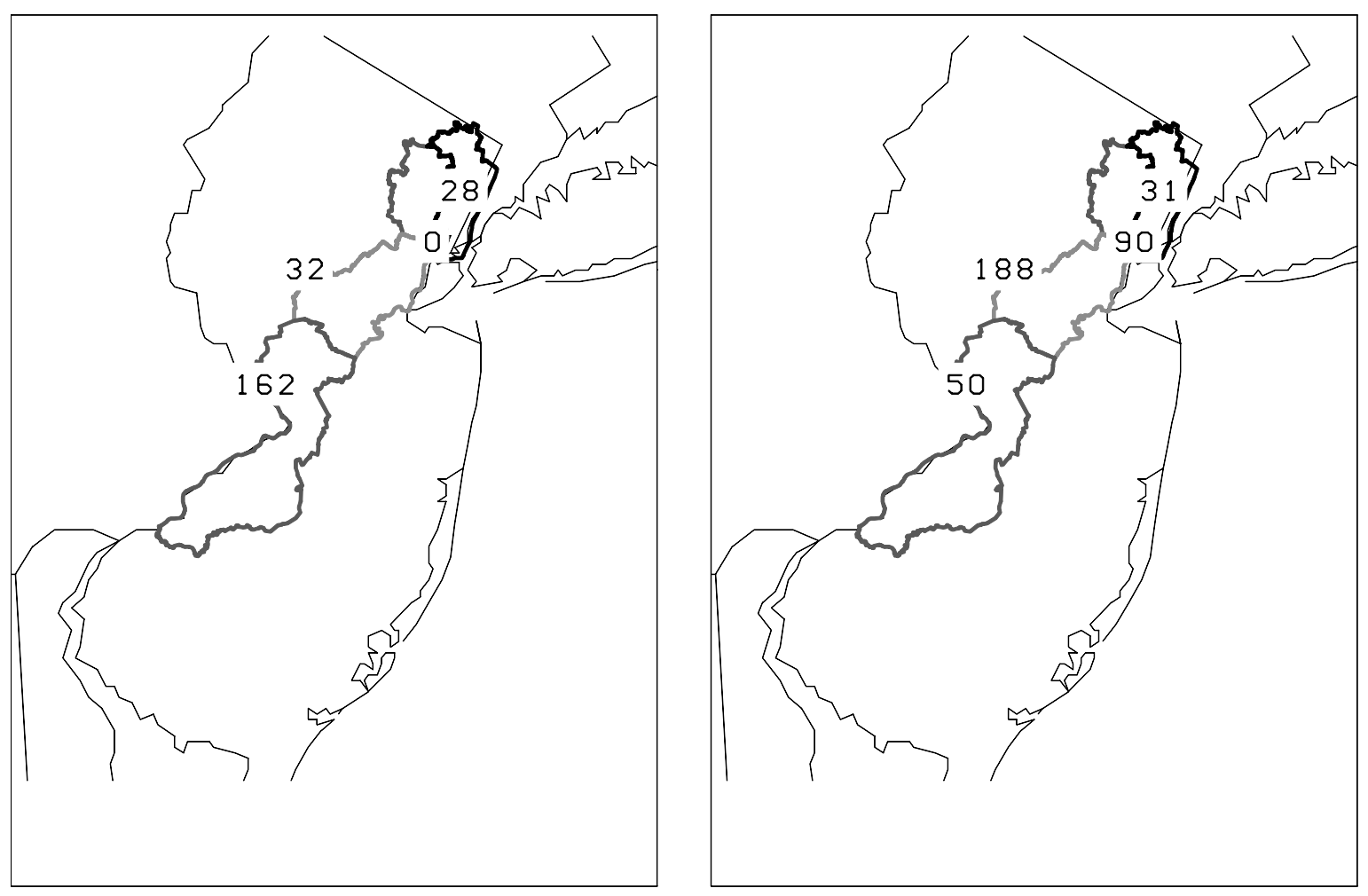

FIG 2.2. PSE\&G plant damage observations (left) and Thunderstorm storm mode model prediction (right) for 26 July 2009. 

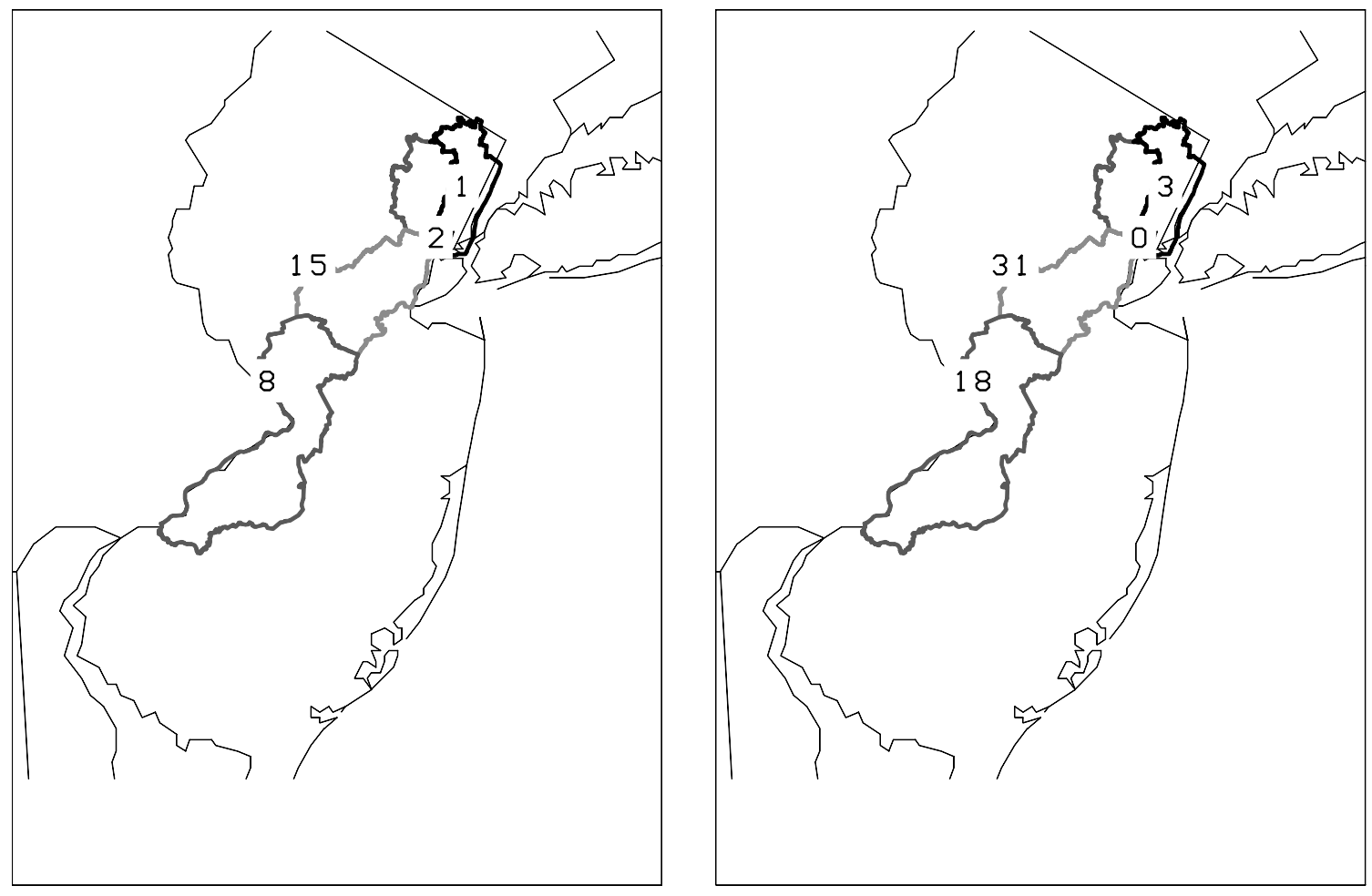

FIG 2.3. Same as Fig. 2.2 but for 28 January 2009. 

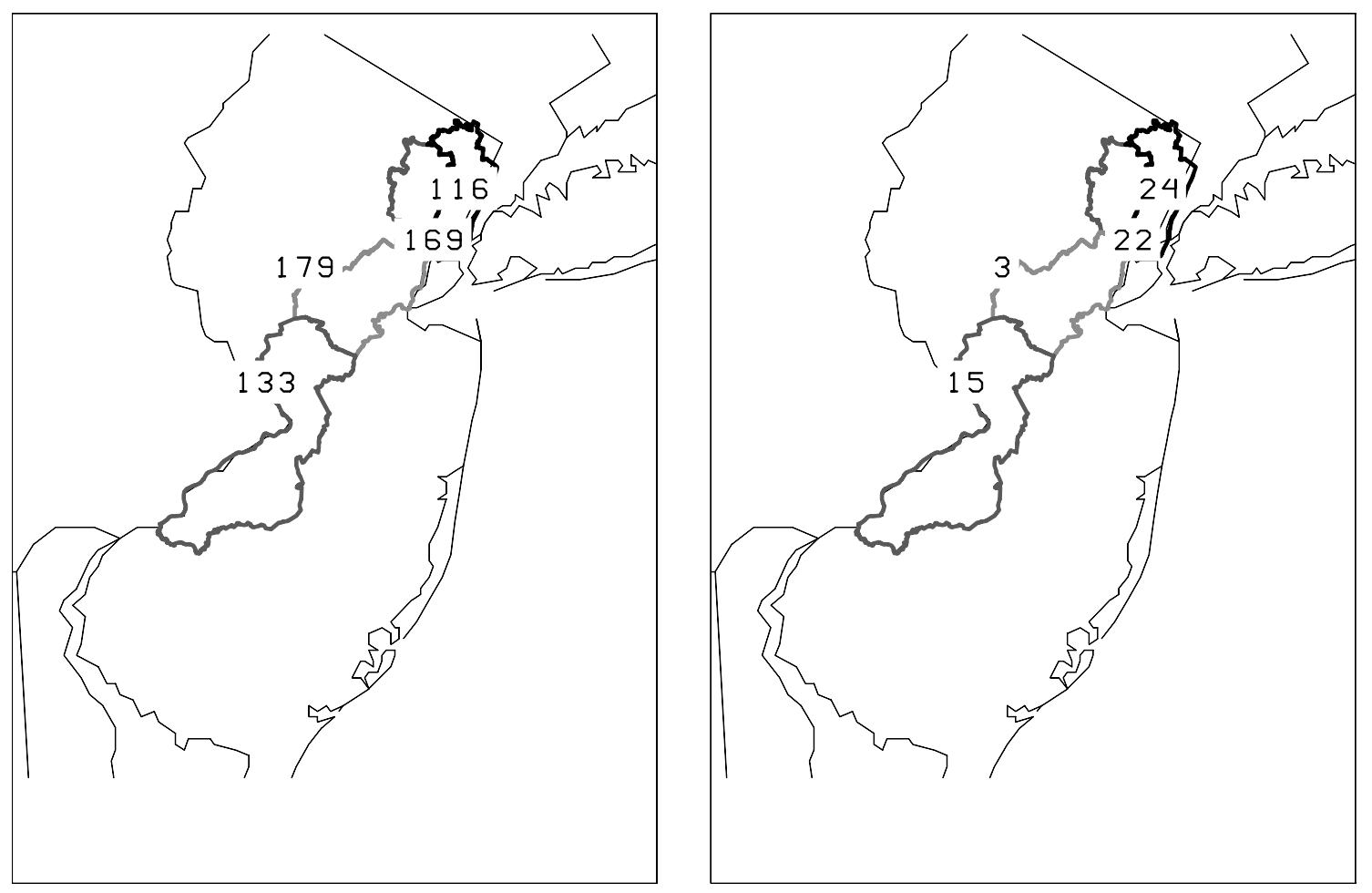

FIG 2.4. Same as Fig. 2.2 but for 12 February 2009. 

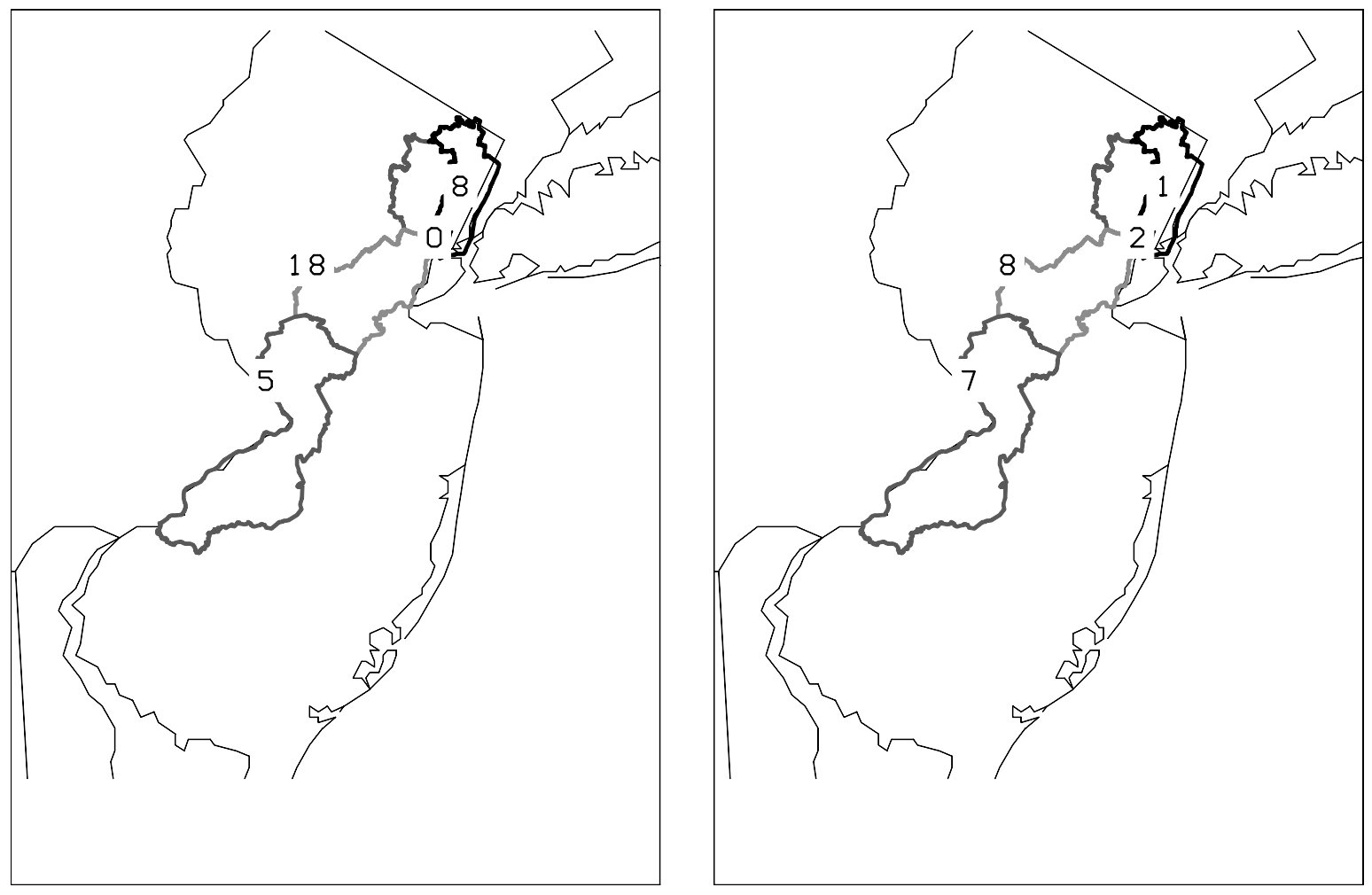

FIG 2.5. Same as Fig. 2.2 but for 4 April 2009. 

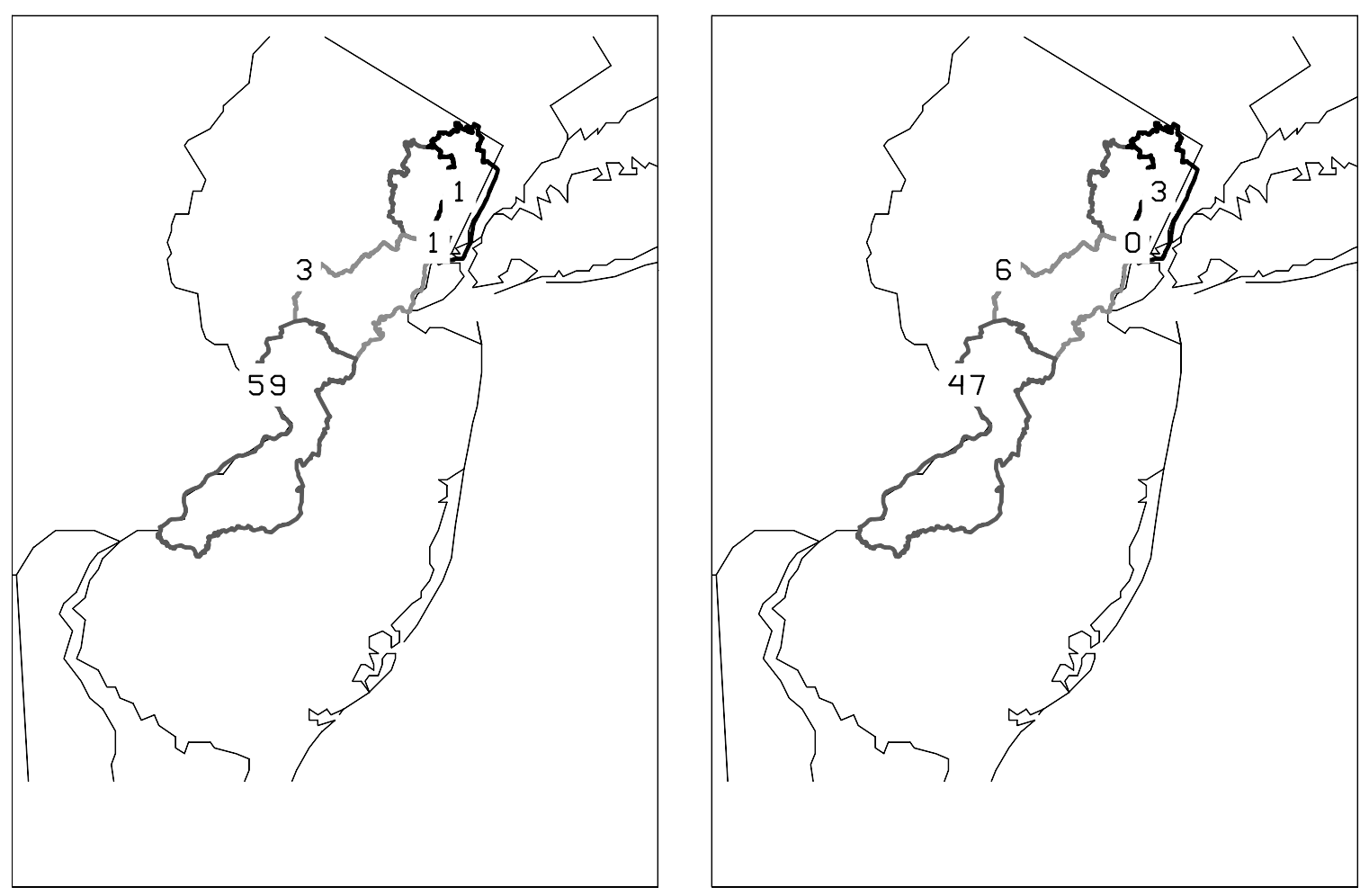

FIG 2.6. Same as Fig. 2.2 but for 16 July 2009. 

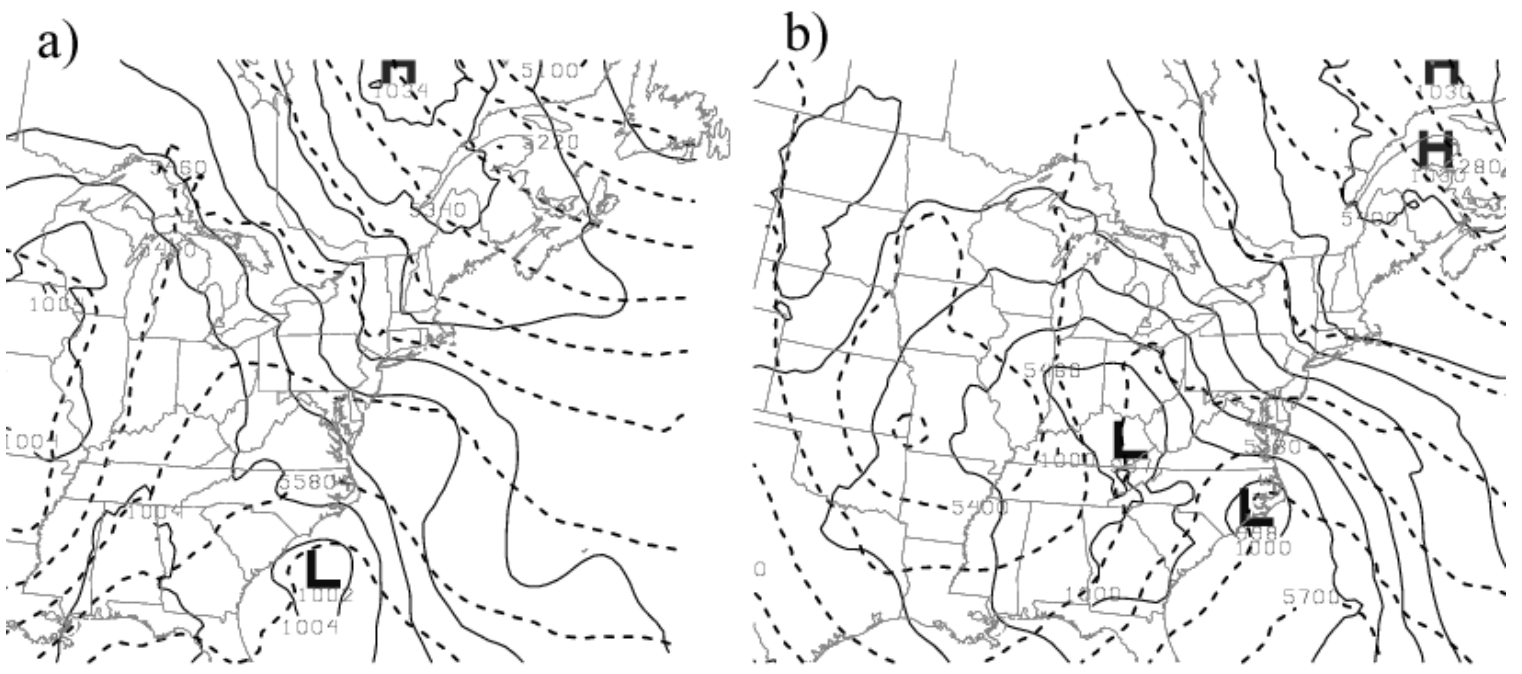

c)

d)
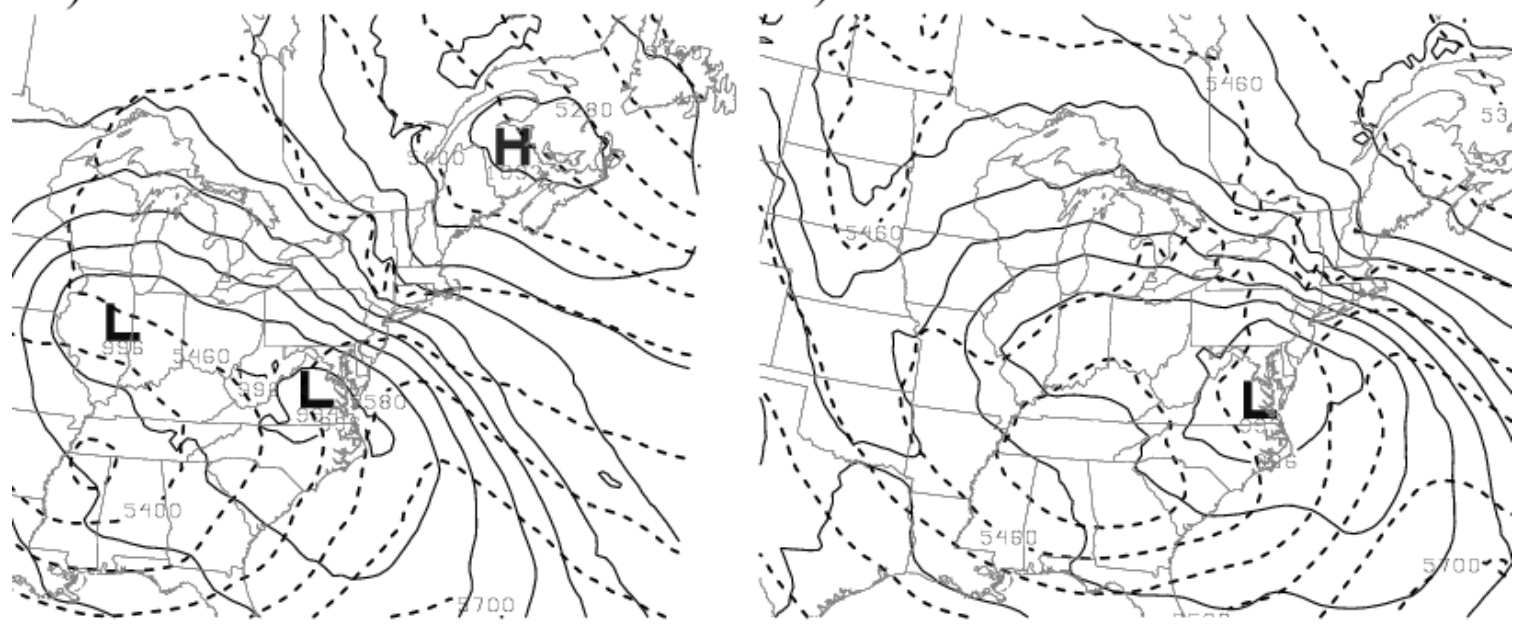

Fig 2.7. Map of Sea Level Pressure in millibars (dark solid lines) and 1000-500 mb thickness (dark dashed lines) for a) 12 UTC 12 March 2010, b) 00 UTC 13 March 2010, c) 12 UTC March 13 2010, and d) 00 UTC 14 March. 


\section{REFERENCES}

Balijepalli, N., S. S. Venkata, C. W. Richter Jr., R. D. Christie, and V. J. Longo, 2005: Distribution system reliability assessment due to lightning storms. IEEE Trans. Power Delivery., 20, 12532159.

Bothwell, P. D., 2002: Prediction of cloud-to-ground lightning in the western United States. Ph. D. thesis, University of Oklahoma, 178 pp.

Brown, R. E., S. Gupta, R. D. Christie, S. S. Venkata, R. Fletcher, 1997: Distribution systems reliability assessment: Momentary interruptions and storms. IEEE Trans.Power Delivery, 14, 1569-1575.

Cerruti, B. J., S. G. Decker, L. A. Bowers, W. K. Wittman, and J. Carlson, 2009: Undergraduate forecasting and nowcasting for a major urban public utility. Preprints, 8th Symp. on the Urban Environment, Phoenix, AZ, Amer. Meteor. Soc., J22.6.

Changnon S. A. and Karl T. R. 2003: Temporal and spatial variations of freezing rain in the contiguous United States: 1948-2000. J. Appl. Meteor., 42, 1302-1315.

Changnon, S. A., 2007: Catastrophic winter storms: An escalating problem. Climatic Change, 84, 131-139.

DeGaetano, A. T., B. N. Belcher, and P. L. Spier, 2008: Short-term ice accretion forecasts for electric utilities using the Weather Research and Forecasting Model and a modified precipitationtype algorithm. Wea. Forecasting, 23, 838-853.

Draper, N.R. and Smith, H.,1998: Applied Regression Analysis. Wiley-Interscience 736 pp.

Fan, S., K. Methaprayoon, and W. J. Lee, 2009a: Multiregion load forecasting for system with large geographical area. IEEE Trans. Ind. Appl., 45, 1452-1459.

Fan, S., L. Chen, and W. J. Lee, 2009b: Short-term load forecasting using comprehensive combination based on multimeteorological information. IEEE Trans. Ind. Appl., 45, 1460-1466.

Glahn, H. R., and D. A. Lowry, 1972: The use of model output statistics in objective weather forecasting. J. Appl. Meteor., 11, 1203-1211.

Glahn, H.R., 1985: Statistical weather forecasting. In: Probability, Statistics and Decision Making in the Atmospheric Sciences, Murphy, A. H. and R. W. Katz (eds). Westview Press: Boulder, CO; 289-335.

Gronas, S.,1995: The seclusion and intensification of the New-Years-Day Storm 1992. Tellus, 47A, 733-746.

Han, S., S. D. Guikema, S. M. Quiring, K. Lee, D. Rosowsky, and R. A. Davidson, 2009:

Estimating the spatial distribution of power outages during hurricanes in the Gulf coast region.

Reliab. Eng.Sys.Saf., 94, 199-210

Harnack, R., K. Apffel, and M. Georgescu, 2001: The determination of observed atmospheric differences between heavy and light precipitation events in New Jersey, USA. Intl. J. of Clim., 21, 1529-1560. 
Hippert, H. S., C. E. Pedreira, and R. C. Souza, 2001: Neural networks for short-term load forecasting: A review and evaluation. IEEE Trans. Power Syst., 16, 44-55.

James, R. P., J. M. Fritsch, and P. M. Markowski, 2005: Environmental distinctions between cellular and slabular convective lines. Mon. Wea. Rev., 133, 2669-2691.

Li, H., and L. A. Treinish, 2010: Statistical solution to forecasting electric power outages caused by severe storms. Preprints, First Conference on Weather, Climate, and the New Energy Economy, Atlanta, GA, Amer. Meteor. Soc., J11.3.

Liu, H., R. A. Robinson, and T. V. Apanasovich, 2008: Spatial generalized linear mixed models of electric power outages due to hurricanes and ice storms. Reliab. Eng.Sys. Saf., 93, 897--912.

National Weather Service, cited 2010: Winter Storm Summary for March 12, 210 to March 15, 2010 Event. [Available online at http://www.erh.noaa.gov/phi/show_wss.php.]

Rakov, V. A. and F. Rachidi, 2009: Overview of recent progress of lightning research and lightning protection. IEEE Trans. Electromagn. Compat., 51, 428-442.

Roebber, P.J., 2009: Visualizing multiple measures of forecast quality. Wea. Forecasting. 24, 601-608.

Ružić, S., Vŭcković, A., and Nikolic, N., 2003: Weather sensitive method for short term load forecasting in Electric Power Utility of Serbia. IEEE Trans. Power Delivery, 18, 1581-1586.

Saini, L.M., 2007: Peak load forecasting using bayesian regularization, resilient and adaptive backpropagation learning based artificial neural networks. Electr. Power Syst. Res., 78, 13021310.

SPC, cited 2009: U.S. Local Storm Database. [Available online at http://www.spc.noaa.gov.]

Takata, H., T. Hachino, and K. Komatsu, 2005: Prediction of electric power damage by typhoons in Japan via a two-stages predictor. Dynamics of Continuous Discrete and Impulsive SystemsSeries B-Applications and Algorithms. 1, 84-89.

Treinish, L. A.,A. P. Praino, H. Li, E. Novakovskaia, J. M. Drexel, R. Derech, and B. Hertell, 2010: Operational evaluation of a meso-scale weather and outage prediction service for electric utility operations. Poster, First Conference on Weather, Climate, and the New Energy Economy, Atlanta, GA, Amer. Meteor. Soc., 506.

Wilks, D. S., 2006: Statistical Methods in the Atmospheric Sciences. 2nd ed. Academic Press, $648 \mathrm{pp}$.

Wittman, W., L. A. Bowers, J. Carlson, R. Dunk, and S. Glenn, 2006: Weather forecast benchmarking and plant damage modeling for public utilities. Proc. 3rd Annual Meeting, Baltimore, MD, MACOORA.

Vannitsem, S. and C. Nicolis, 2007: Dynamical properties of Model Output Statistics forecasts. Mon. Wea. Rev., 136, 405-419. 
Yang, D., B. E. Goodison, J. R. Metcalfe, V. S. Golubev, R. Bates, T. Pangburn, and C. L., Hanson, 1998: Accuracy of NWS 8-inch standard non-recording precipitation gauge: Results of WMO intercomparison. J. Atmos. Oceanic Technol., 15, 54-68. 